\title{
IUCN
}

\section{Best Practice Guidelines for Health Monitoring and Disease Control in Great Ape Populations}

Kirsten V. Gilardi, Thomas R. Gillespie, Fabian H. Leendertz, Elizabeth J. Macfie, Dominic A. Travis, Christopher A. Whittier \& Elizabeth A. Williamson

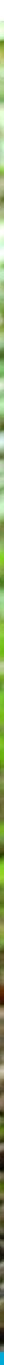

Occasional Paper of the IUCN Species Survival Commission No. 56 


\section{About IUCN}

IUCN, International Union for Conservation of Nature, helps the world find pragmatic solutions to our most pressing environment and development challenges.

IUCN's work focuses on valuing and conserving nature, ensuring effective and equitable governance of its use, and deploying naturebased solutions to global challenges in climate, food and development. IUCN supports scientific research, manages field projects all over the world, and brings governments, NGOs, the UN and companies together to develop policy, laws and best practice.

IUCN is the world's oldest and largest global environmental organization, with more than 1,200 government and NGO Members and almost 11,000 volunteer experts in some 160 countries. IUCN's work is supported by over 1,000 staff in 45 offices and hundreds of partners in public, NGO and private sectors around the world.

Web: www.iucn.org

\section{IUCN Species Survival Commission}

The Species Survival Commission (SSC) is the largest of IUCN's six volunteer commissions with a global membership of 8,000 experts. SSC advises IUCN and its members on the wide range of technical and scientific aspects of species conservation and is dedicated to securing a future for biodiversity. SSC has significant input into the international agreements dealing with biodiversity conservation. Web: www.iucn.org/what/work_by_topic

\section{IUCN Species Programme}

The IUCN Species Programme supports the activities of the IUCN Species Survival Commission and individual Specialist Groups, as well as implementing global species conservation initiatives. It is an integral part of the IUCN Secretariat and is managed from IUCN's international headquarters in Gland, Switzerland. The Species Programme includes a number of technical units covering Wildlife Trade, the Red List, Freshwater Biodiversity Assessments (all located in Cambridge, UK), and the Global Biodiversity Assessment Initiative (located in Washington DC, USA).

\section{IUCN SSC Primate Specialist Group}

The Primate Specialist Group (PSG) is concerned with the conservation of more than 700 species and subspecies of prosimians, monkeys, and apes. Its particular tasks include carrying out conservation status assessments, the compilation of action plans, making recommendations on taxonomic issues, and publishing information on primates to inform IUCN policy as a whole. The PSG facilitates the exchange of critical information among primatologists and the professional conservation community. The PSG Chairman is Dr. Russell A. Mittermeier and the Deputy Chair is Dr. Anthony B. Rylands.

Web: www.primate-sg.org 


\section{Best Practice Guidelines for Health Monitoring and Disease Control in Great Ape Populations}

Kirsten V. Gilardi, Thomas R. Gillespie, Fabian H. Leendertz, Elizabeth J. Macfie, Dominic A. Travis, Christopher A. Whittier \& Elizabeth A. Williamson

Contributors: Kenneth Cameron, Michael Cranfield, Lynne Gaffikin, Gladys Kalema-Zikusoka, Sophie Köndgen, Siv Leendertz, Elizabeth Lonsdorf, Michael Muehlenbein, Lawrence Mugisha, John Bosco Nizeyi, Felicia Nutter, Klára Petrželková, Patricia Reed, Innocent Rwego, Benard Ssebide \& Steve Unwin
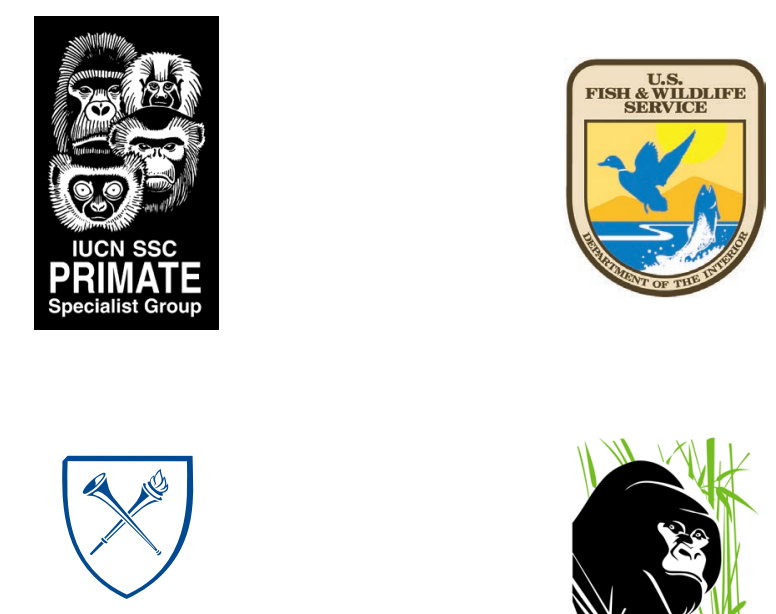

EMORY

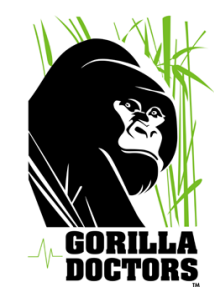

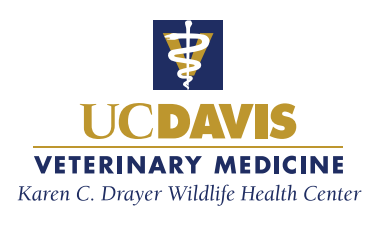

UCDAVIS

VETERINARY MEDICINE Karen C. Drayer Wildlife Health Center

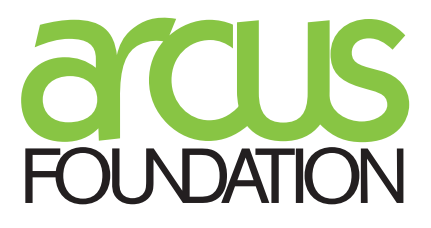

ROBERT KOCH INSTITUT

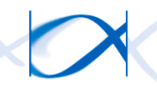

Tufts

Cummings School

of Veterinary Medicine 
The designation of geographical entities in this book, and the presentation of the material, do not imply the expression of any opinion whatsoever on the part of IUCN or other participating organizations concerning the legal status of any country, territory, or area, or of its authorities, or concerning the delimitation of its frontiers or boundaries. The views expressed in this publication do not necessarily reflect those of IUCN or other participating organizations.

Published by: $\quad$ IUCN, Gland, Switzerland

Copyright: $\quad$ C 2015 International Union for Conservation of Nature and Natural Resources

Reproduction of this publication for educational or other non-commercial uses is authorized without prior written permission from the copyright holder(s) provided the source is fully acknowledged.

Reproduction of this publication for resale or other commercial purposes is prohibited without prior written permission of the copyright holder(s).

Citation: $\quad$ Gilardi, K.V., Gillespie, T.R., Leendertz, F.H., Macfie, E.J., Travis, D.A., Whittier, C.A. \& Williamson, E.A. (2015). Best Practice Guidelines for Health Monitoring and Disease Control in Great Ape Populations. Gland, Switzerland: IUCN SSC Primate Specialist Group. 56pp.

ISBN:

978-2-8317-1274-1

IUCN library record: https://portals.iucn.org/library/node/45793

DOI:

http://dx.doi.org/10.2305/IUCN.CH.2015.SSC-OP.56.en

Available from:

http://www.primate-sg.org

https://portals.iucn.org/library/sites/library/files/documents/SSC-OP-056.pdf

Cover photos: [front cover] A visitor to the chimpanzees of Mahale National Park, Tanzania, wears a facemask @ [back cover] A veterinarian visually evaluates the health of a gorilla in Volcanoes National Park, Rwanda @ Chris Whittier

Layout by: Kim Meek, [e-mail] k.meek@mac.com

French translation: Christelle Colin

Bahasa translation: Fransiska Sulistyo

Contributors: $\quad$ K.N. Cameron, M.R. Cranfield, L. Gaffikin, G. Kalema-Zikusoka, S. Köndgen, S.A.J. Leendertz, E.V. Lonsdorf, M.P. Muehlenbein, L. Mugisha, J.B. Nizeyi, F.B. Nutter, K. Petrželková, P.E. Reed, I. Rwego, B. Ssebide \& S. Unwin

Funded by: Arcus Foundation \& United States Fish and Wildlife Service 


\section{Table of Contents}

Section 1. Executive Summary, Guiding Principles \& Summaries of Best Practice............. 1

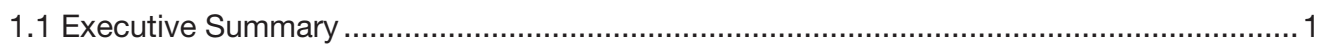

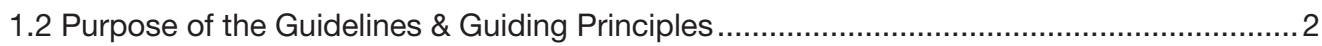

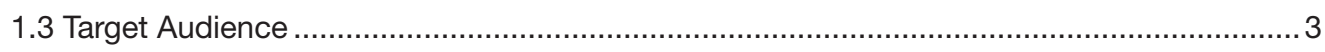

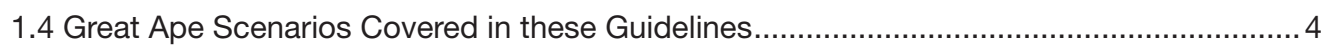

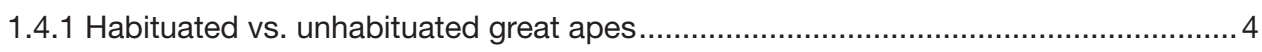

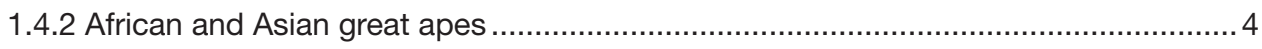

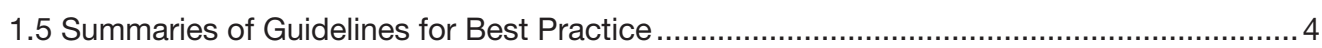

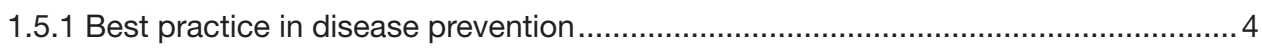

1.5.2 Best practice in health monitoring and disease surveillance................................ 6

1.5.3 Best practice in clinical interventions...............................................................

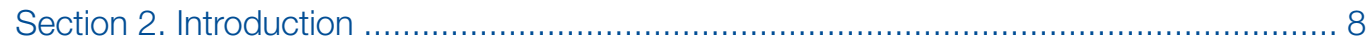

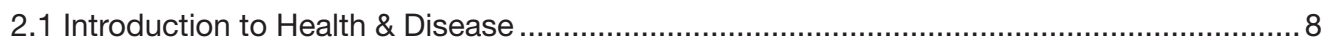

2.2 ‘One Health’ Approach to Great Ape Conservation..........................................................

Section 3. Best Practice in Disease Prevention ……................................................. 11

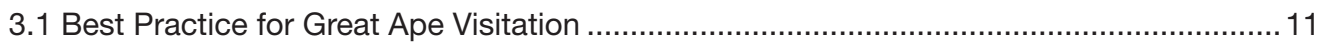

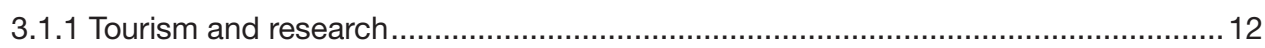

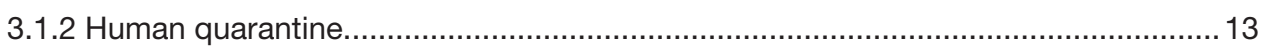

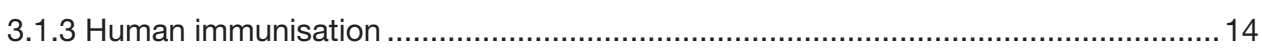

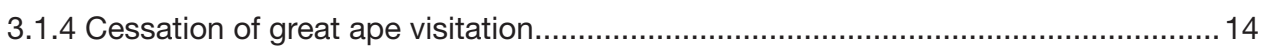

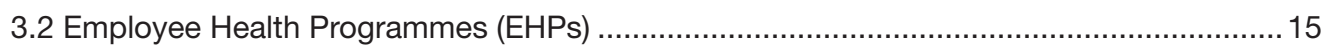

Section 4. Best Practice in Health Monitoring \& Disease Surveillance............................. 16

4.1 Health Monitoring \& Disease Surveillance .................................................................. 16

4.1.1 Health monitoring and disease surveillance data ................................................... 16

4.1.2 Monitoring the health of unhabituated great apes............................................. 18

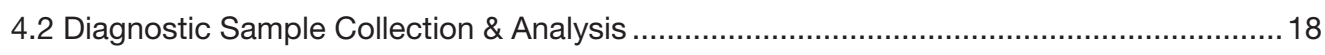

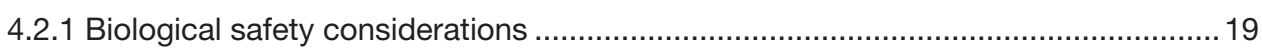

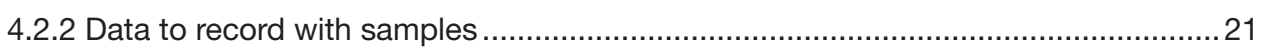

4.2.3 Non-invasive collection and handling of biological samples .................................21

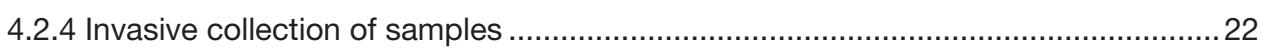

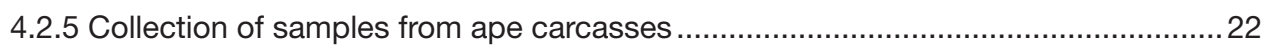

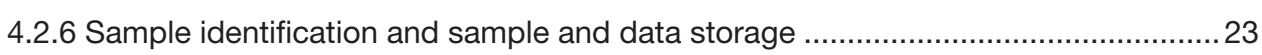

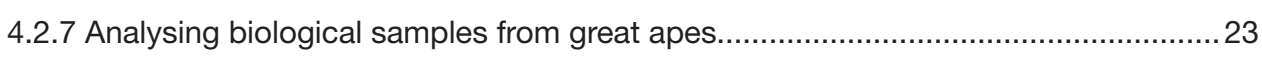

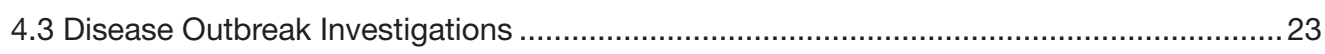

Section 5. Best Practice in Health Interventions ......................................................... 24

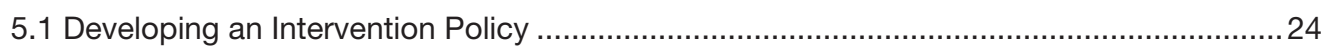

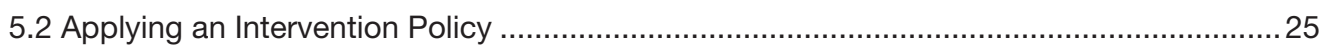

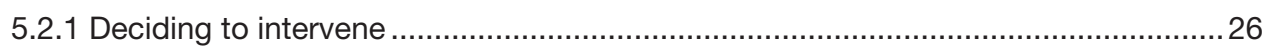

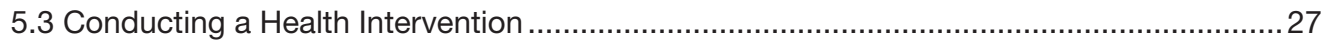

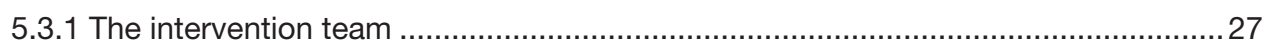

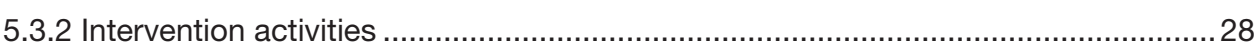

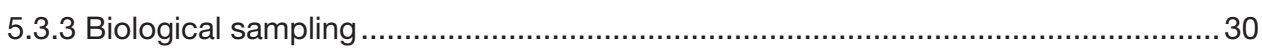

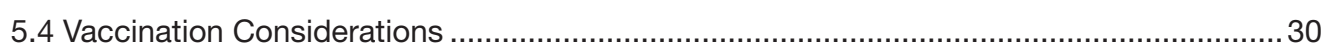

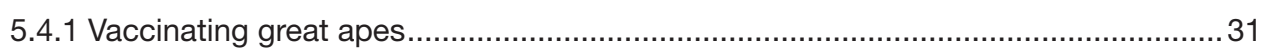

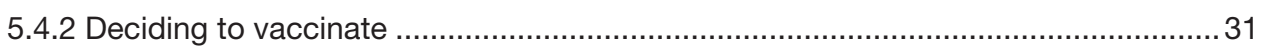

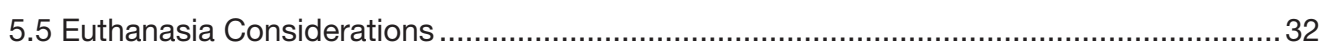


Section 6. Health Issues of Concern in Great Ape Populations ................................. 32

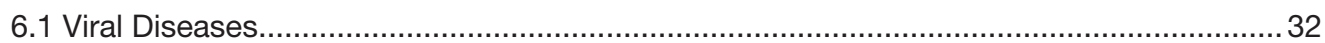

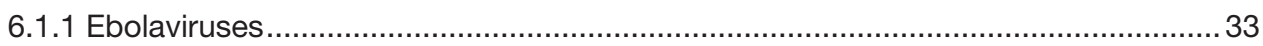

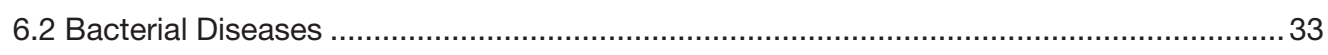

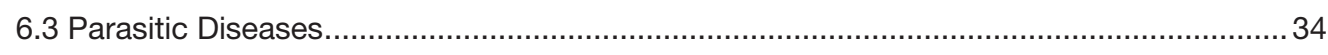

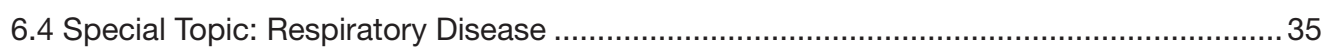

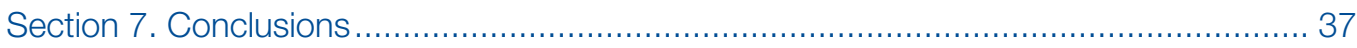

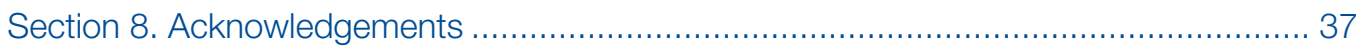

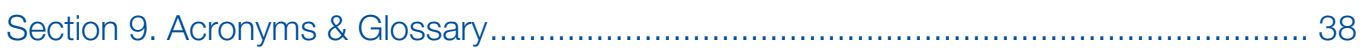

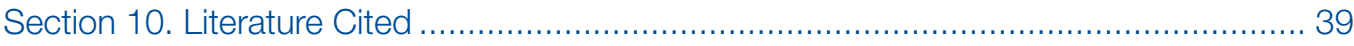

Section 11. Contacts \& Resources for Further Information ................................. 44

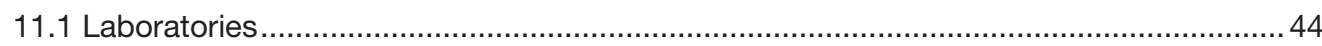

11.2 Global Health Information \& Reporting Websites ................................................... 44

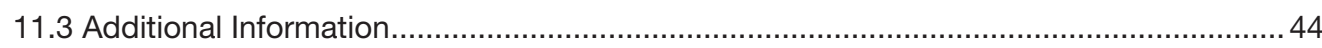

Appendix I. An Example of Quarantine \& Hygiene Procedures .............................. 45

Appendix II. Examples of Data Sheets and Forms ....................................... 51

Appendix Ila. Health-monitoring checksheet used at Gombe Stream Research Centre,

Tanzania, as part of daily focal data collection ................................................................ 51

Appendix Ilb. Health-monitoring checksheet used by WCS Congo in Nouabalé-Ndoki National Park, Republic of Congo .............................................................................. 52

Appendix Ilc. Daily health observation sheet used by the Gorilla Doctors to monitor the health of habituated mountain gorillas.......................................................................... 54

Appendix Ild. Example of a Disease Outbreak Situation Report ..........................................55

Appendix III. Flow Chart of the Clinical Response Decision Tree for Mountain Gorillas ..... 56 


\section{Section 1. Executive Summary, Guiding Principles \& Summaries of Best Practice}

\subsection{Executive Summary}

Due to their phylogenetic relatedness, great apes and humans share susceptibility to many infectious diseases, and the potential for new diseases to be transmitted to wild great apes is of particular concern (Calvignac-Spencer et al. 2012). As great ape tourism becomes more popular, great ape research more imperative, and landscape conversion more rampant, the risk that human pathogens will be introduced to immunologically naïve wild populations becomes greater, and this could result in catastrophic losses of great apes. Therefore, it is critical that tourism and research projects involving close proximity ${ }^{1}$ between great apes and people assess the risks entailed, and establish and implement disease prevention and control measures. Disease prevention should be regarded as a top priority, recognising that it is easier and more economical to prevent the introduction of an infectious agent into a great ape population, than to attempt to treat, control or eradicate a health problem once introduced. Disease prevention programmes should be centred on monitoring health parameters, and modifying human activities accordingly, in order to reduce the risk of disease transmission to great apes. By design, such programmes will also minimise the risk of disease transfer from great apes to humans, and even from humans to other humans. Continual monitoring of the health of great apes forms the basis for establishing what is normal and abnormal and thus improves our understanding of great ape population health, allows us to determine the effectiveness of disease prevention and health management strategies, and provides a basis for conducting responsible and reasonable health interventions when needed.

The aim of these guidelines is to provide governments, policy makers, conservation practitioners, researchers, great ape tourism professionals and funding agencies with recommendations of best practices for great ape health monitoring and disease prevention. These recommendations revisit and update, as appropriate, the previous health protection standards recommended by Homsy (1999). Acknowledging that there is no such thing as zero risk of disease, taking measures to prevent or control disease spread will never eliminate the disease risks, therefore the recommendations herein are primarily aimed at minimising, rather than trying to eliminate, the threat of disease transmission from humans to great apes. Implementing the best practices presented here should substantially reduce the risks that human activities pose to great ape health and, in so doing, signal a clear commitment to great ape conservation.

Great apes are curious and often very interested in novel objects that may carry infectious agents. A hairband, unintentionally dropped by a visitor to Virunga NP, DRC, was picked up and investigated by these mountain gorillas (c) LuAnne Cadd. Park staff, tourists and researchers must be vigilant to prevent such risky situations arising

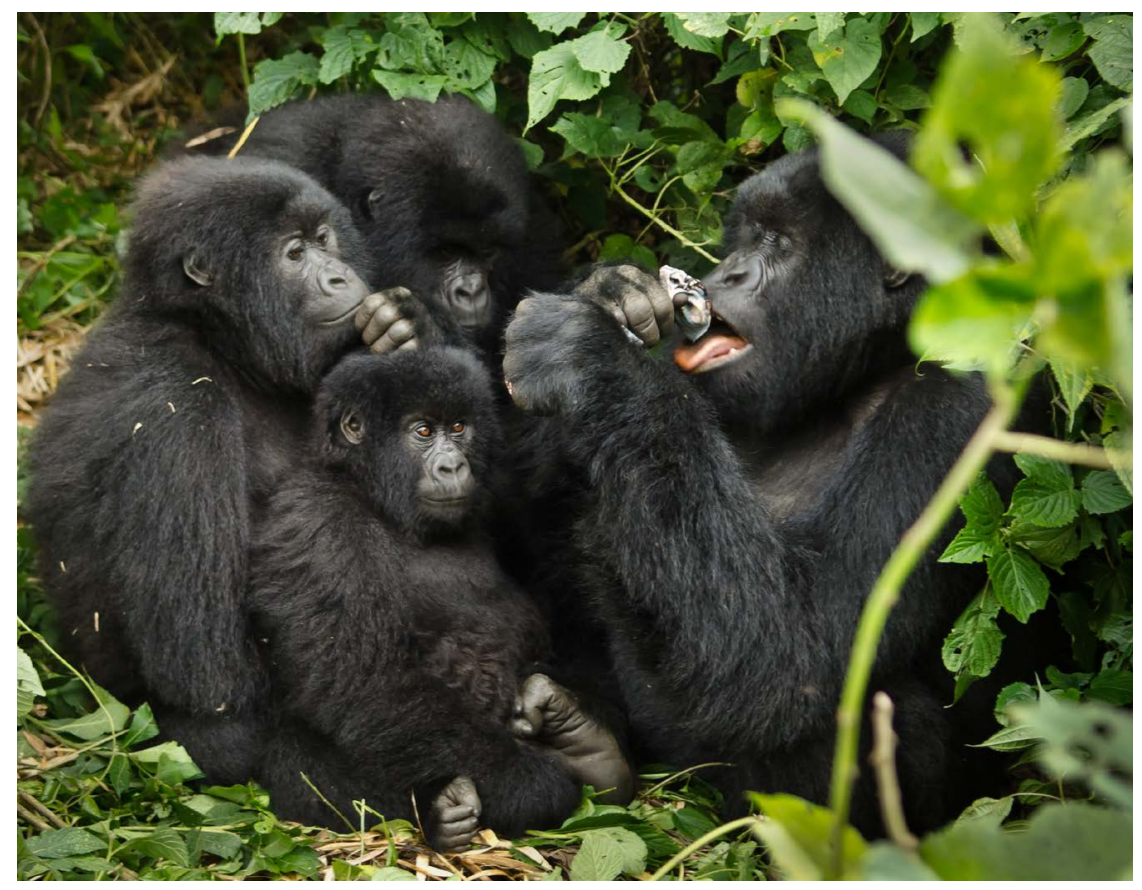

1 Within 10 metres, but no closer than 7 metres 


\section{Primate Specialist Group \& the Section on Great Apes}

The Section on Great Apes (SGA) of the IUCN Species Survival Commission (SSC) Primate Specialist Group (PSG) is an international group of experts involved in great ape conservation and research. The role of the SGA is to promote conservation action on behalf of great apes, based on the best scientific information available. To do this, members of the SGA develop guidelines for best practice in great ape conservation and research, formulate action plans that clarify conservation priorities, and advise on the effective protection of great apes and their habitats.

\section{Links to other Best Practice guidelines for great ape conservation}

A series of IUCN best practice guidelines for great ape conservation is freely available for download (www. primate-sg.org/best_practices). Disease risks have shaped the formulation of guidelines in each of the areas of intervention highlighted below and we recommend that readers of the health and disease guidelines also refer to these other publications.

Great ape tourism (Macfie \& Williamson 2010) - The tourism guidelines include information on the 'rules' that are designed to control opportunities for the transmission of disease to great apes visited by tourists, on hygiene issues in and around tourism infrastructure, and are a key reference for the health and disease guidelines. www.primate-sg.org/best_practice_tourism

Prevention and mitigation of conflict between humans and great apes (Hockings \& Humle 2009) - Great apes that compete with humans for access to critical resources, such as food and habitat, are in increasingly close proximity to areas of human activity. This document provides a framework for mitigating conflict and for the avoidance of practices that exacerbate the risks of disease transmission. www.primate-sg.org/ best_practice_conflict

Reducing the impact of commercial logging (Morgan \& Sanz 2007) \& Implementing 'ape friendly' practices in Central Africa's logging concessions (Morgan et al. 2013) - Severe alteration of great ape habitat exacerbates their exposure to disease; therefore, timber companies are advised to enforce sanitation measures in forest camps and to implement education and health programmes for staff who operate in great ape habitat. It is also recommended that logging companies develop protocols for detecting and reporting signs of emerging diseases, such as Ebolavirus. www.primate-sg.org/best_practice_logging

Re-introduction of great apes (Beck et al. 2007)_- The goal of many ape sanctuaries is to re-introduce rehabilitated individuals to their natural habitat. The risks of novel diseases being transmitted to other wildlife by animals that have been kept in captivity are considerable, so this publication includes information on disease risk assessment and preparing great apes for release. www.primate-sg.org/best_practice_reintroduction

\subsection{Purpose of the Guidelines \& Guiding Principles}

Habitat loss and poaching are recognised threats to the survival of great apes (IUCN 2015); however, it has become increasingly clear that infectious diseases are also of major concern for great ape conservation. For example, Zaire ebolavirus is thought to have killed thousands of central chimpanzees (Pan troglodytes troglodytes) and western lowland gorillas (Gorilla gorilla gorilla) (e.g., Walsh et al. 2003). As a result, the western lowland gorilla was upgraded to Critically Endangered on the IUCN Red List of Threatened Species (Walsh et al. 2008), and infectious disease is now listed among the top three threats to some great ape taxa.

While many viruses, bacteria and parasites circulate among great ape populations with little to no consequence for their health and survival, some are known to cause disease (Leendertz et al. 2006; Gillespie et al. 2008; Section 6). The threat of human pathogens infecting great apes has sparked considerable discussion about the relative costs and benefits of tourism, scientific research and management paradigms that bring humans into close proximity with apes (Wallis \& Lee 1999; Woodford et al. 2002; Köndgen et al. 2008). While tourism and research have unquestionably contributed positively to great ape conservation, enhancing their scientific and economic value, such activities may have unintended consequences for great ape health and survival (Macfie \& Williamson 2010). It should also be noted that while the transmission of human pathogens to great apes is a conservation concern, the opposite transmission path is a human health concern: humans are susceptible to great ape pathogens. For example, the form of human immunodeficiency virus-1, the virus that caused the AIDS pandemic, arose from the spillover and adaptation of a chimpanzee immunodeficiency virus to humans (Gao et al. 1999). 
The purpose of these guidelines is to summarise our current understanding of great ape health challenges and to make recommendations for best practice in great ape health monitoring and disease prevention. Several guiding principles have informed the development of these best practice recommendations:

$\diamond$ Applying best practice to avoid transmission of human pathogens to great apes is an ethical obligation at all tourism and research sites.

$\diamond$ It is generally easier and more economical to prevent the transmission of a human pathogen to a great ape (individual or population) than to attempt to treat, control or eradicate a disease problem once introduced. Therefore, it is best practice for all Protected Area Authorities, and great ape tourism and research projects to give the highest priority to the implementation of disease prevention programmes.

$\diamond$ It is not possible to achieve zero risk; however, the cumulative effect of making concerted efforts to comply with recommendations for disease prevention will substantially reduce the risk that human pathogens pose to great apes.

$\diamond$ Applying the precautionary principle to recommended best practices for great ape health is warranted: in other words, in the absence of scientific evidence that a disease agent or human action or policy is or is not a risk or harmful to great apes, it is safest to assume that such agents or actions do pose a health risk to great apes until scientifically proven otherwise.

$\diamond$ Assessing and improving the health of the people who work in great ape habitat, especially those who are frequently in close proximity to wild great apes, is imperative.

\subsection{Target Audience}

The primary target audience for these guidelines is Protected Area Authorities (PAAs) in the great ape range states, as well as other natural resource managers with jurisdiction over great apes or their habitats, besides policy makers based in wildlife management ministries, agencies and institutions. Protected Area (PA) and wildlife managers include national and international non-governmental organisations (NGOs) managing conservation sites or projects or otherwise engaged in field activities. Hereafter, we refer to this group as PA+ managers, personnel or sites. The decision-makers whose policies we hope will be informed by this document include all of those responsible for approving access to and the use of areas where great apes occur, whether for tourism, research or resource extraction. These users will benefit from considering the guidelines when implementing management and protection plans, and in supporting tourism and research activities in aid of great ape conservation.

These guidelines will also assist great ape tourism professionals with better conducting their operations and informing their clients. Conservation professionals, scientific researchers, extractive industry personnel and projects that involve activities in great ape habitat should also implement the relevant disease prevention recommendations contained in these guidelines. The guidelines will also be useful to donors who fund great ape conservation projects, and to international development and humanitarian organisations working with communities in or adjacent to great ape habitat.

Hundreds of thousands of tourists visit habituated great apes every year. Most tourism sites now issue disposable facemasks to all visitors (c) Martha Robbins

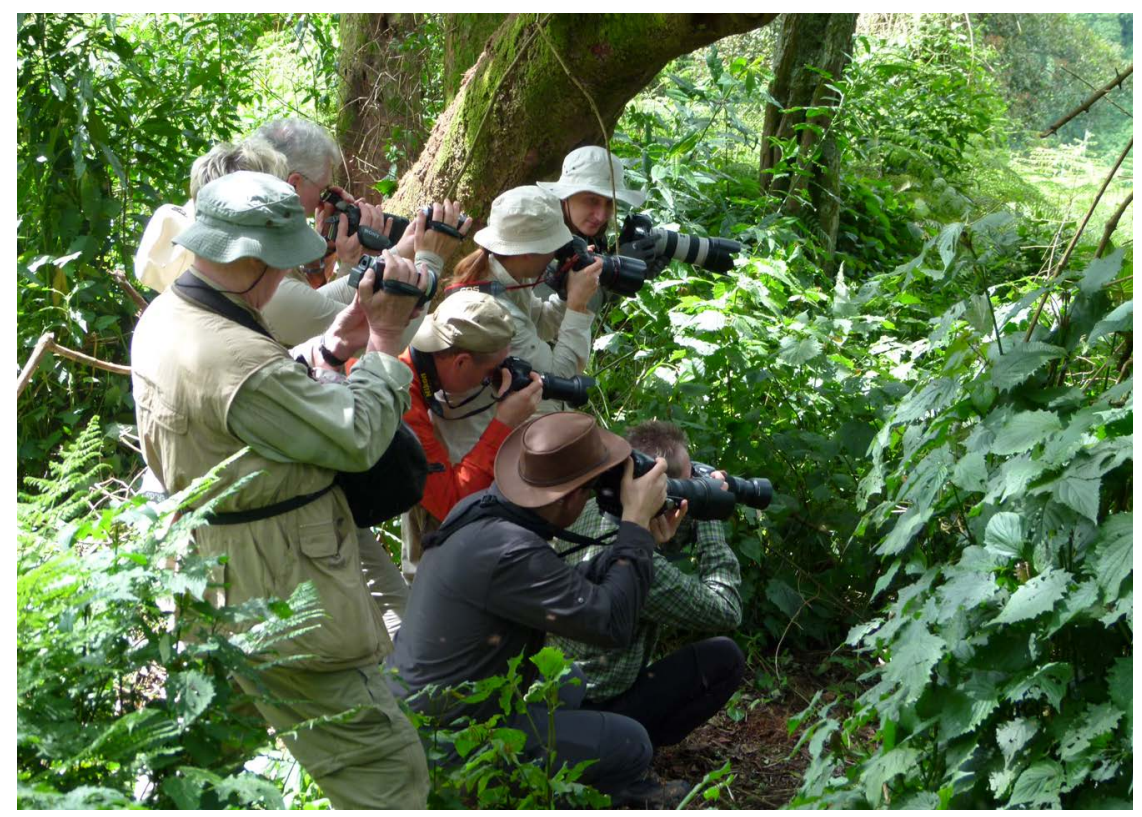




\subsection{Great Ape Scenarios Covered in these Guidelines}

\subsubsection{Habituated vs. unhabituated great apes}

'Habituation' is the term used to describe the acceptance by animals of a human observer as a neutral element in their environment (Williamson \& Feistner 2011). This document is intended for use where people come into close proximity or have indirect contact with wild great apes, both human-habituated (or undergoing habituation) and unhabituated to human presence ${ }^{2}$. It is not intended to address situations where apes are in captivity. In places where great apes are habituated, the opportunities for transmission of disease to and from great apes are multiplied. At the same time, so are the opportunities for mitigating those risks through compliance with tourism best practices for the prevention of pathogen transmission, health monitoring, veterinary interventions (e.g., immobilisation and treatment or vaccination) and health research. At most sites where great apes are habituated, interventions are rare and great ape health is assessed through observations of behaviour and outward signs of illness or injury, combined with analyses of non-invasively collected biological samples (e.g., faeces, urine, saliva). Non-invasive sampling techniques may be the only tools available for monitoring unhabituated great apes and may be more realistically applied at a population level, as such animals are rarely seen, although their faeces, urine and saliva may be recoverable.

\subsubsection{African and Asian great apes}

These guidelines are broadly applicable to all species of great ape. That said, it should be recognised that social systems and population structures vary among great ape taxa and these differences influence the occurrence and patterns of disease. For example, highly social great apes are at higher risk of communicable infections than solitary animals (Rushmore et al. 2013; Carne et al. 2014). Differences in population density, seasonality of dietary stress or habitat use can also influence the occurrence and spread of disease (e.g., Masi et al. 2012). PA+ managers should apply these guidelines as appropriate to the great ape species with which they work.

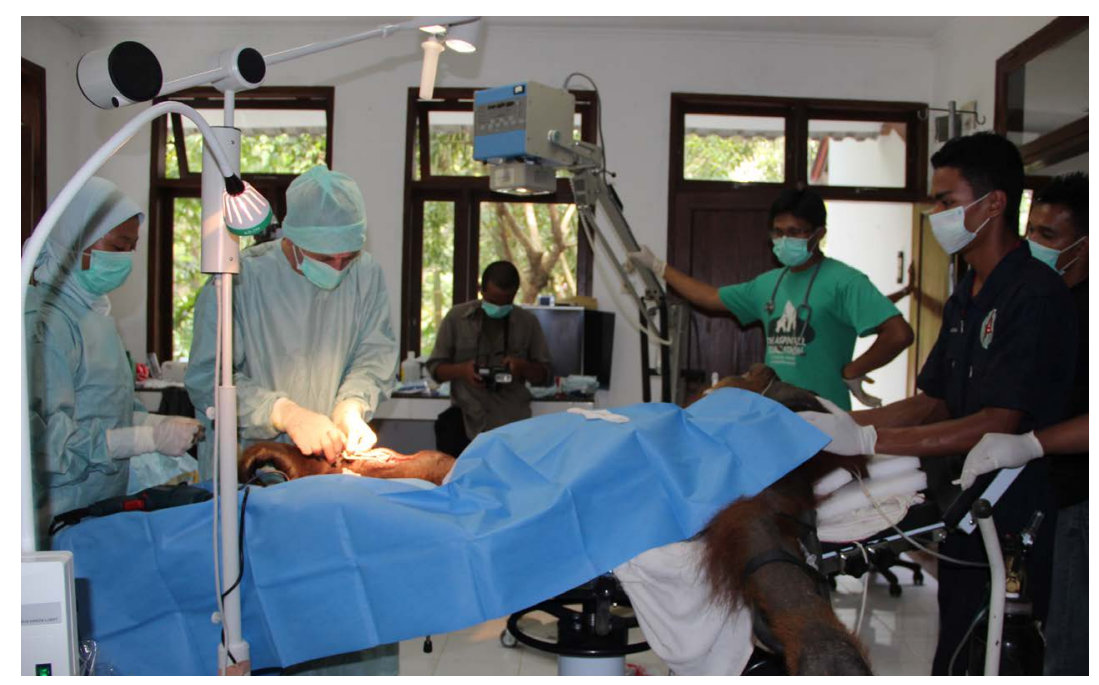

A veterinary team performing surgery on a wild adult male orangutan who sustained a broken leg during capture in an isolated forest patch being converted to an oil palm plantation. It would be too socially disruptive to bring a group-living great ape into a clinic for surgery; however, male orangutans lead more solitary lives, so social reintegration after an intervention is less of a challenge. This orangutan was released at the edge of the Bukit Tigapulih NP in Sumatra (C) lan Singleton/SOCP

\subsection{Summaries of Guidelines for Best Practice}

Summaries of best practice for great ape health are presented here; more detail and science-based justifications for these recommendations, where available, are presented in Sections 3, 4 and 5. PA+ managers in the great ape range countries, including NGOs managing projects engaged in field activities where great apes exist, are encouraged to apply these best practices to the challenges presented by their particular context (e.g., large groups of habituated terrestrial gorillas vs. often solitary, arboreal orangutans).

\subsubsection{Best practice in disease prevention}

\section{Pre-visit recommendations}

$\diamond$ The minimum age of all people visiting great apes should be 15 years.

$\diamond$ If a person is ill, he/she should not visit great apes. 
$\diamond$ If a person is ill, he/she should remain quarantined from close proximity to great apes until 7 days after cessation of clinical signs of illness.

$\diamond$ All people who will be in regular and frequent close proximity with great apes (e.g., PAA personnel, veterinarians, researchers, film-makers) should be immunised according to the local government's recommendations for childhood vaccination and should be tuberculosis (TB) tested once annually.

$\diamond$ All people arriving from outside the country who will come into more frequent and longer-term close proximity with great apes than tourists (including veterinarians, researchers, film-makers) should undergo a minimum 7-day quarantine prior to setting foot in great ape habitat.

Within-visit considerations

$\diamond$ Minimise time/contact: Visitors coming into close proximity with great apes should minimise their time doing so; the standard for tourists is no more than 1 hour per visit.

$\diamond$ Start clean for each visit - clothing: Everyone visiting great apes should wear clean clothing that is washed or changed between visits to different groups ${ }^{3}$ of great apes or sites.

$\diamond$ Start clean for each visit - footwear: Everyone visiting great apes should wear footwear that is washed before and after visiting a great ape group, including between visits to different groups.

$\diamond$ Start clean for each visit - hands: Everyone visiting great apes should sanitise their hands (by washing with soap and water or using an alcohol-based gel on hands free of food, dirt or other substances) before and after entering great ape habitat.

$\diamond$ Stay away: To decrease the risk of airborne pathogen transmission, every person visiting great apes should maintain a minimum distance of at least 7 metres (23 feet) from the animals.

The minimum 7-metre distance allowed between tourists and great apes is demonstrated by a scaled model in Bwindi Impenetrable NP, Uganda @ Luke Berman

3 We use 'group' as shorthand for any social unit of great apes. Bonobos and chimpanzees live in communities, and are often found in parties. Orangutans are more solitary than other apes, apart from mother-infant units. 
$\diamond$ Wear a facemask: As an additional preventive measure, everyone coming within 10 metres of a great ape (but still no closer than 7 metres) should wear a surgical mask; masks should be replaced if they become wet or torn during the visit, and carried out of the forest and properly disposed of after use.

$\diamond$ Sneeze right: If a person needs to sneeze or cough while visiting great apes, they should keep their mask on, turn away from the animals, and cover the mouth and nose with the crook of the elbow rather than the hand, or sneeze inside their clothing.

$\diamond$ Proper toilet hygiene: If a person needs to urinate while in great ape habitat, they should move $100 \mathrm{~m}$ in the opposite direction, out of sight of the apes and, if possible, dig a hole at least $30 \mathrm{~cm}$ deep. Waste (such as toilet tissue) should be transported out of the forest.

$\diamond$ 'Go' before you visit: Defaecation should not be allowed in great ape habitat; if a person needs to defaecate while in the forest, all faeces and solid waste (such as toilet tissue) should be bagged and transported out of the habitat.

Other risk management considerations

$\diamond$ In the event that a significant portion of a great ape group or community is ill, PA+ managers should temporarily halt visitation (except by those who are monitoring the outbreak) until the disease event is over.

$\diamond$ All great ape tourism and research projects should implement an employee health programme.

$\diamond \mathrm{PA}+$ managers should support and help implement low-cost community health interventions, such as provision of potable water sources, latrines and hand-washing stations, and health and hygiene education to communities living near protected areas.

\subsubsection{Best practice in health monitoring and disease surveillance}

$\diamond$ PAAs or their conservation partners should implement a great ape health monitoring and disease surveillance programme.

$\diamond$ A minimum set of health-related data should be collected for each habituated great ape (individual identification, sex, age class, normal vs. abnormal clinical signs pertaining to body condition, activity level, respiration, injuries, discharge and faeces) every day, if possible, including not seen or absent.

$\diamond$ PAAs and other wildlife managers should share information on disease occurrence/outbreaks in a transparent and timely fashion.

$\diamond$ Collection of biological specimens from great apes, whether invasively or non-invasively (without touching or otherwise coming into direct contact with the animal), should be done with the highest level of attention to biological safety for the person conducting the sampling.

$\diamond$ Personal protective equipment (PPE) should be worn by all people who have direct contact with great apes or biological specimens.

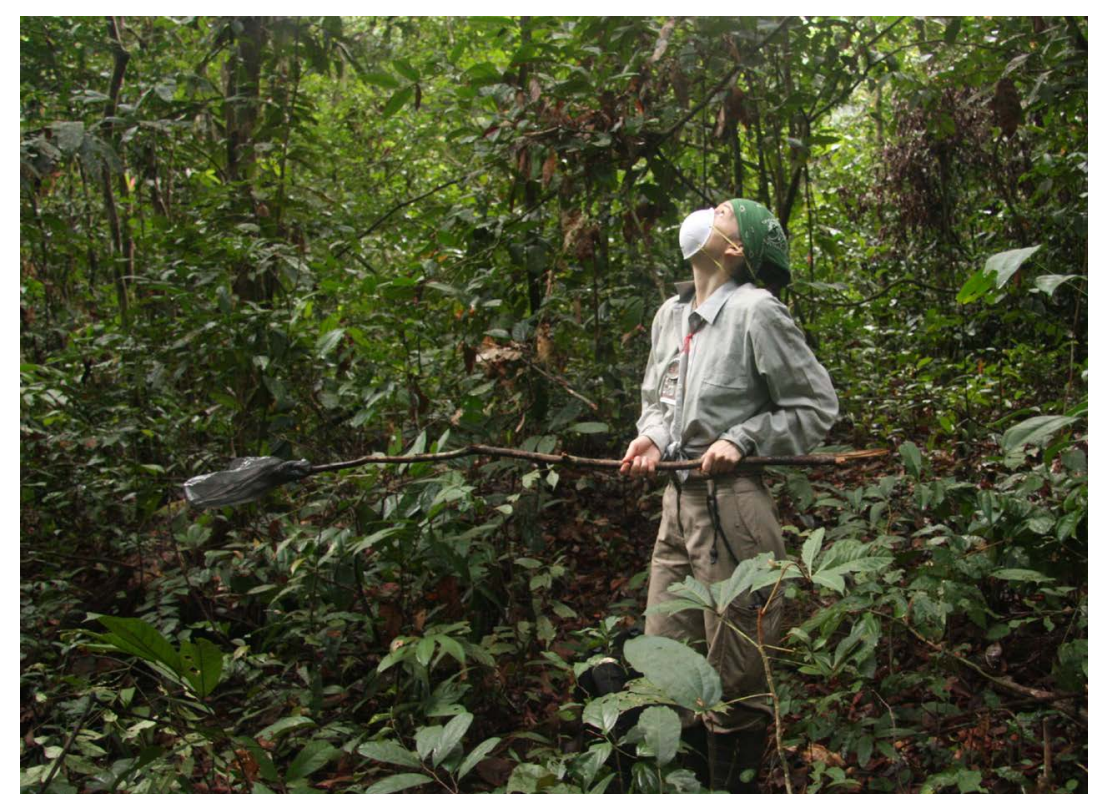

Non-invasive collection of urine under a chimpanzee nest using a simple device made of a plastic bag attached to the forked end of a twig (C) Sonja Metzger/TCP. It is strongly advised that anyone handling biological samples wears disposable gloves while doing so 
$\diamond$ Invasive collection of samples that require direct handling of the living animal (e.g., blood, mucosal swabs) should be performed only by veterinarians or veterinary technicians, or by other highly-trained people.

$\diamond$ All tubes, containers or bags containing biological samples collected from great apes should be clearly labelled with a unique animal identifier, specimen identifier and date.

$\diamond$ All samples collected from great apes not immediately needed for analyses should be stored long term ('bio-banked') in biological resource centres for future studies that may aid in the conservation and health of great apes.

$\diamond$ If a dead ape is found, the PAA should be notified and the carcass examined by health professionals or trained project personnel regardless of whether the cause of death is known or suspected.

$\diamond$ Anyone collecting biological samples should practice good hygiene and wash their hands before and after all procedures.

\subsubsection{Best practice in clinical interventions}

$\diamond \mathrm{PA}+$ managers should establish a policy regarding great ape health interventions before they are faced with the need to make urgent decisions regarding ill or injured great apes.

$\diamond$ A health intervention should be considered if a group or community of great apes is experiencing a disease outbreak.

$\diamond$ A health intervention should be considered if an illness or injury is human-induced.

$\diamond$ A health intervention could be considered if the death of an individual is expected to have populationlevel consequences (e.g., disrupt the social structure or significantly reduce the growth of a population).

$\diamond$ A health intervention may not be warranted if a great ape is experiencing a naturally-acquired illness or injury (e.g., a wound sustained in a fight with another great ape) or is showing only mild clinical signs of illness or injury.

$\diamond$ All members of an intervention team should be trained, experienced and equipped with proper PPE.

$\diamond$ During a clinical intervention, all team members should know their roles and understand that a trained animal health professional (who is at least under the supervision of a veterinarian) should serve as the lead for all clinical decision-making regarding the ill/injured great ape, including halting the intervention should it be deemed unsafe for the animal, the group and/or the intervention team to proceed.

$\diamond$ Individual great apes treated or immobilised for any reason should be properly monitored post-procedure.

$\diamond$ Vaccinating wild great apes should be considered if safe and effective vaccines for the specific pathogen are available and if other disease prevention and control methods have failed to reduce or eliminate the threat of a particular disease to the apes.

$\diamond$ If euthanasia is deemed necessary, it should be performed only with PAA knowledge and approval, and by a veterinary team with the expertise, knowledge, equipment and supplies necessary for the procedure.

Human-induced injuries: this adult male chimpanzee was speared by poachers in Kibale NP, Uganda; a veterinary team immobilised him to clean the wound and administer antibiotics $($ ) Paco Bertolani

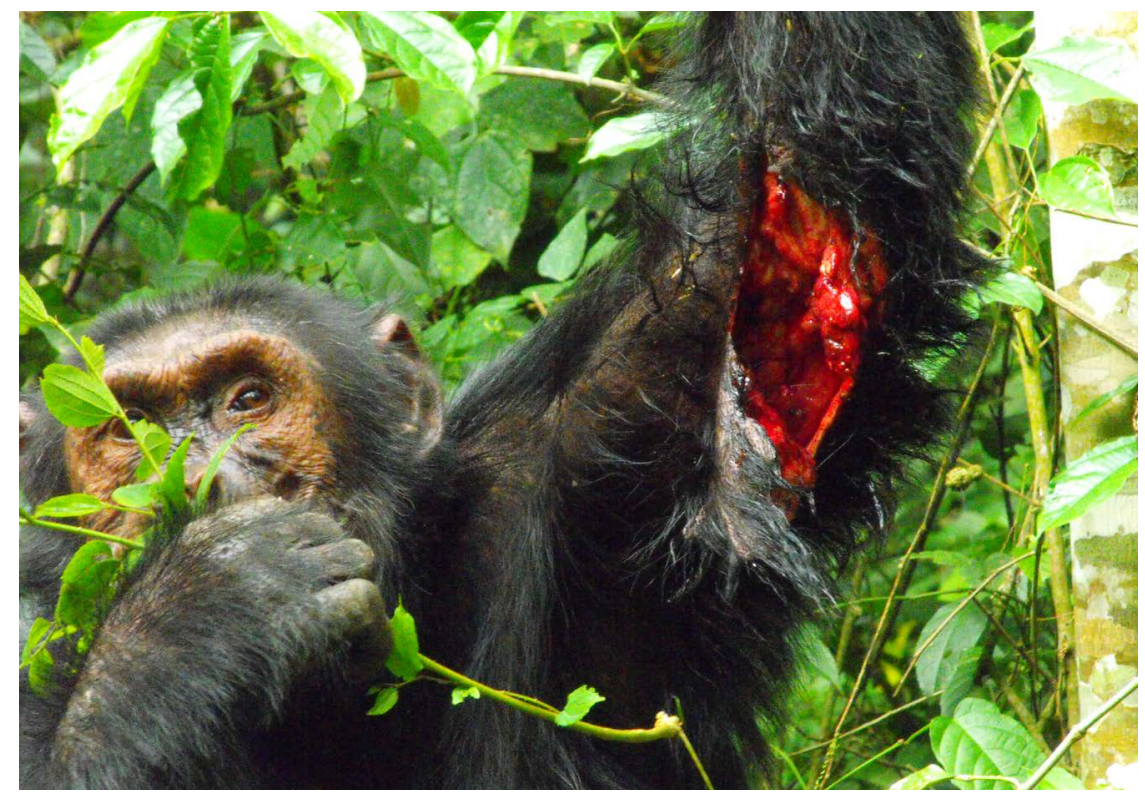




\section{Section 2. Introduction}

\subsection{Introduction to Health \& Disease}

To effectively communicate health risks and implement disease prevention, all involved must have a working knowledge of the basics of disease transmission and basic health terminology. For the purpose of these guidelines, we shall define health as a state of sound physical well-being, generally characterised by an absence of disease (illness or injury). A disease is an abnormal condition of a body part or whole animal resulting and characterised by an identifiable set of clinical signs. An infection is the entry of an infectious agent into the body that may be inapparent (causing no clinical signs) or manifest (causing clinical disease). An infectious agent is an organism (e.g., a virus, bacterium, parasite) that is capable of invading and multiplying itself in another organism. Not all infectious agents are pathogens (cause pathology or disease), and there are agents which cause disease in some species but not in others. Terms applied to infectious disease transmission include a reservoir (a species in which an infectious agent resides without causing illness in that species, but from which the agent can be spread to other species); and a pathogen that is shared among humans and animals is termed zoonotic and the resulting disease is called a zoonosis. For more definitions of terms, see the glossary in Section 9.

It is necessary to have some knowledge of the routes by which those agents are shared in order to understand and evaluate the risks of disease transmission. Transmission can occur through direct or indirect contact. Typically, direct transmission routes include contact by touching, biting or ingesting, as well as direct projection of droplets (blood, respiratory secretions, saliva) containing the infectious agent, transmitted by sneezing, coughing, spitting or talking/vocalising. Indirect transmission routes involve pathogens present on fomites (objects such as equipment), or in vectors (e.g., insects) in which the infectious agent spends part of its lifecycle.

An understanding of disease timelines and states is also important. Upon being infected, an animal or human undergoes an incubation period during which the infectious agent is present, but not yet causing clinical signs. In most infections, there is a window of time called an infectious period during which an infected individual is able to pass the agent on to others. Incubation periods and infectious periods may overlap in time. This is important because during these periods, infections can be transmitted between individuals before becoming clinically apparent.

Some infected animals or humans may become permanent or long-term carriers of infectious agents and serve as reservoirs capable of maintaining the pathogen and remaining infectious to other individuals for long periods or intermittently. Endemic diseases are those that are constantly present in a given population, while outbreaks or epidemics are occurrences of an illness that exceed the normal or expected levels of that disease in the population. Thus, disease surveillance and monitoring are vital to any disease risk management plan. The terms monitoring and surveillance are often used synonymously, but they have small but important differences in meaning: monitoring is designed to detect and regularly report on any change in the normal health status of a population, whereas surveillance is aimed more at identifying the first cases of a disease in a population (in order to minimise impact).

Great apes and humans are genetically closely related, which creates a high potential for infectious pathogen exchange. Examples of cases of likely or proven human-to-great ape disease transmission include respiratory disease (Kaur et al. 2008; Köndgen et al. 2008; Palacios et al. 2011; Yoshida et al. submitted), human herpes simplex virus (Gilardi et al. 2014), polio-like disease (Goodall 1986; Kortlandt 1996), a measles-like disease (Hastings et al. 1991), scabies (Kalema-Zikusoka et al. 2002), and enteric helminths and protozoa (Hasegawa et al. 2014; Parsons et al. 2015). Close proximity between great apes and people is known to promote transmission of bacteria such as Escherichia coli, Salmonella and Shigella, and gorillas and chimpanzees living close to humans have been shown to harbour gastrointestinal $E$. coli that are resistant to multiple antibiotics used by people (Goldberg et al. 2007; Rwego et al. 2008; Janatova et al. 2014). Simply put, many human pathogens can infect great apes and many have the capacity to cause individual death or threaten whole communities or populations.

Section 6 summarises what we know about major groups of pathogens that adversely affect great apes and highlights diseases that may have emerged as a result of human-great ape contact. However, a comprehensive review of great ape pathogens and health conditions is beyond the scope of these guidelines. Illness and death due to noninfectious diseases such as cancer, congenital deformities or dental disease occur but are unlikely to be mitigated in 
wild animals (see Section 5.1) and are therefore not covered herein. Other categories of infectious diseases do not seem to pose a significant risk to great apes at the population level (e.g., fungal diseases ${ }^{4}$ ).

\section{2 ‘One Health’ Approach to Great Ape Conservation}

'One Health' is a perspective and strategy that recognises that the health of humans, other animals and the environment are inextricably linked (Karesh \& Cook 2005). Policy makers at national and international levels recognise that infectious diseases hinder a nation's economic development and advancement. To this end the Millennium Development Goals (UN 2009) and now the Sustainable Development Goals ${ }^{5}$ not only promote sustaining biodiversity, but also address a number of health targets that could directly benefit great apes, including reducing child mortality through actions such as vaccinating children against measles, a known threat to great apes, and promoting access to improved water sources, sanitation and pharmaceuticals, all of which can directly help reduce infectious diseases in humans and therefore reduce risk to great apes.

Most great ape range nations fall in the bottom $20 \%$ of countries worldwide on the Human Development Index (UNDP 2014), and the majority of their citizens are engaged in subsistence living, therefore dependent on dwindling natural resources. Poor situations are compounded by large-scale displacements from conflict areas. Crowded and unsanitary IDP (internally displaced persons) camps are often plagued by infectious diseases that can have devastating effects not only on people, but also on great apes in the camps' immediate vicinity.

Practicing 'One Health' requires a holistic approach involving PA and wildlife managers, veterinarians, ecologists, human health practitioners, public health workers, communities, enforcement officers and policy makers. 'One Health' is a highly relevant and useful framework for great ape conservation, because it recognises that, in addition to the risks posed by people entering the habitat to approach the apes themselves, great apes are coming into ever-increasing contact with humans, often in degraded tracts of habitat used and surrounded by both humans and domestic animals. Examples of such occurrences:

- Crop-raiding or foraging by great apes venturing outside park boundaries

- Local people harvesting natural resources (firewood and other NTFPs) in great ape habitat, whether legally or illegally

- Extraction of natural resources (mining, oil and gas) and forest conversion (agriculture, logging) occurring within great ape ranges

- Great apes and people sharing water sources

- Local people using paths through great ape habitat (sometimes illegally)

When great apes leave the relative safety of national parks, there is increased likelihood of contact with local people and livestock, and exposure to their pathogens (see Rwego et al. 2008) () Chris Whittier

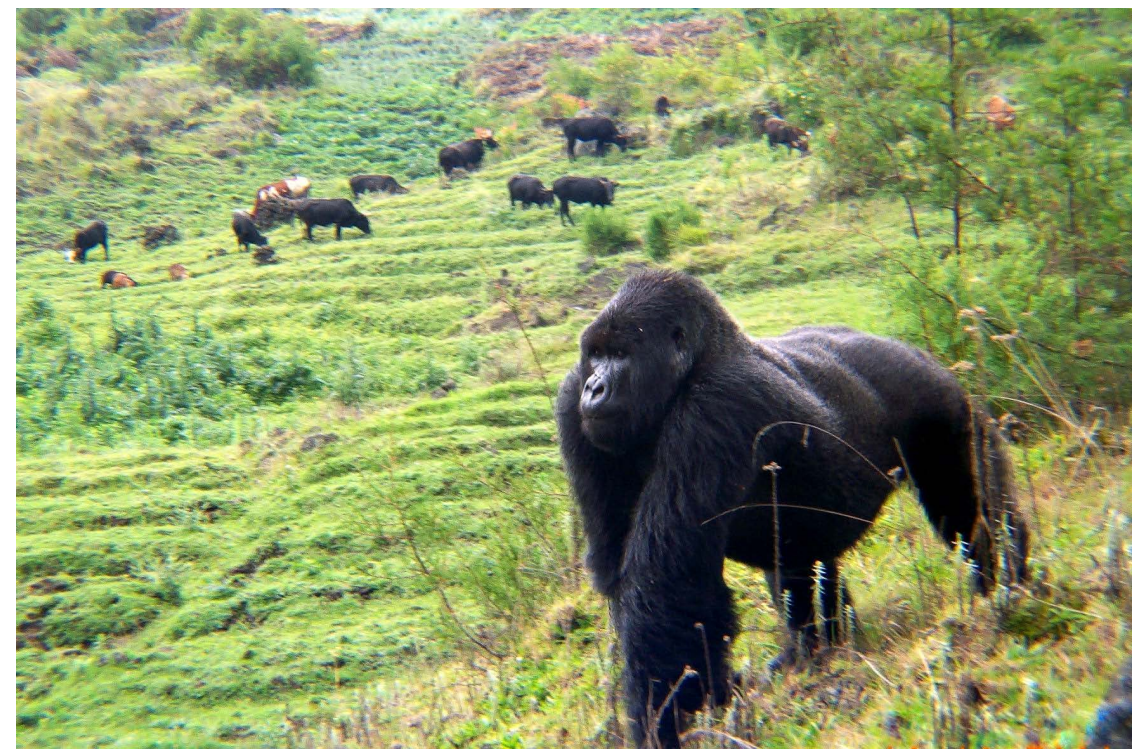

4 While no significant fungal diseases have been reported in great apes, it is important to note that in other wildlife species, fungal pathogens have emerged to devastate populations. For example, chytridiomycosis in amphibians has caused the near or total extinction of frogs locally and regionally across the globe (Skerratt et al. 2007), and Pseudogymnoascus destructans, the etiologic agent of white-nose syndrome in bats, is causing widespread losses of bats in North America (Foley et al. 2011).

5 https://sustainabledevelopment.un.org/sdgs 
- Local people employed by conservation, research or tourism projects operating in great ape habitat

- Incursion of fighting factions and military personnel into great ape habitat in conflict zones.

With the conversion of natural forest to agricultural land or logging concessions comes a higher likelihood of interface between great apes and humans and/or their livestock and, therefore, a higher risk of zoonotic disease transmission (Hockings \& Humle 2009). Also, where human population density is high, as occurs around some great ape habitats (e.g., those of mountain gorillas, Gorilla beringei beringei), there is higher risk of infectious diseases spread among community members.

Great apes live in ever-shrinking tracts of habitat under constant encroachment by humans; therefore, the health of people living, working or touring near to or in great ape habitat is also paramount. The trackers, guides, guards, researchers, veterinarians and others required to support great ape tourism and research play a significant role in potential transmission of diseases to great apes, in part because they often live in settlements bordering great ape habitat with substandard hygiene and a relative lack of access to health care, and because they often spend long periods of time in close proximity to great apes as part of their work. Tourists are also a great concern because they come from many parts of the world, potentially carrying 'exotic' pathogens to which apes may be immunologically naïve, and are often in close proximity to great apes within days, if not hours, of leaving their homes.

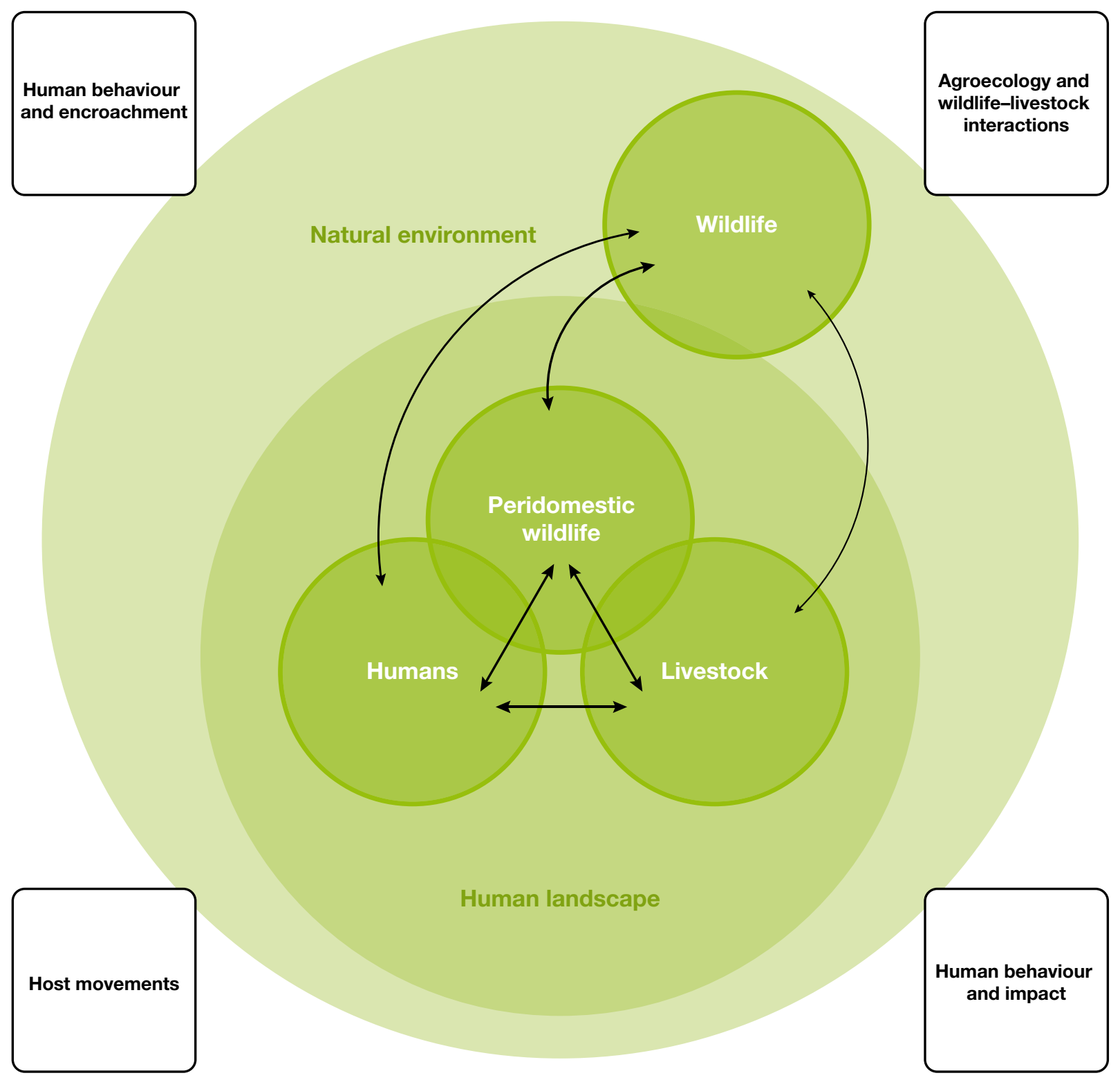

Figure 1. Pathogen flow and drivers at the human-livestock-wildlife interface. Arrows indicate direct, indirect or vector-borne pathogen flow; each box represents a driver. Reproduced from IUCN \& OIE (2014) with permission 
Numerous public health interventions have been designed and implemented to successfully prevent or minimise infectious diseases around the globe. Many simple, low-cost community health interventions, such as potable water sources and latrines, can be supported by conservation programmes aiming to reduce threats to great apes. Support for such interventions can be in the form of advocacy, logistical assistance, communications and/or hands-on implementation of integrated projects.

\section{Section 3. Best Practice in Disease Prevention}

Disease prevention is a set of activities intended to ensure that disease does not affect a population. Disease control is a set of activities aimed at minimising the impact of a disease once it has entered a population. The following best practices focus on the prevention and control of disease transmission from humans to great apes. Implementation of these guidelines will not eliminate the risk of human diseases being passed on to great apes, but will substantially reduce the risk of their occurrence.

Establishing and implementing disease prevention and control measures must be given the highest priority, taking precedence even over great ape health monitoring or intervention programmes. Disease prevention and control is centred on human activities that reduce the risk of transmitting disease to great apes, but by design, will also reduce the potential for disease transmission from great apes to people. Because great apes are most frequently visited by park personnel, tourists, researchers, veterinarians, film crews and journalists - hereafter referred to as visitors - the following recommendations focus on these groups of people.

It should be kept in mind that any combination of rules will only reduce the risk of disease transmission. It will not be possible to totally exclude any transmission risk, not only because of the inability to completely control both human and ape behaviour in a natural environment, but also because the applied measures themselves have limitations (e.g., the fit of masks to different face shapes). However, applying best practice to avoid transmission of human pathogens to great apes is an ethical obligation at all tourism and research sites.

\subsection{Best Practice for Great Ape Visitation}

Great ape tourism and research sites, where people spend considerable time in close proximity to wild animals, create opportunities for human-to-great ape disease transmission. Visitors travel from all areas of the world. They will have spent hours in enclosed spaces (aeroplanes) and in transit (airports), and will have been exposed to thousands of other travellers and their pathogens. Upon arrival in great ape range countries, visitors may be further exposed to additional pathogens through interaction with local people and animals. Their own susceptibility to becoming ill may be enhanced by the fatigue and stress of travel, changes in diet or climate, and the novelty of pathogens to which they are exposed. These individuals often have their first ape encounter within 72 hours of leaving their homes. Furthermore, in some regions, it is not uncommon for tourists to visit great apes at several sites in succession, or to visit a bat cave, a school, an orphanage, or a community with livestock or other animals that are a

Silverback mountain gorilla stops to look at visitors in Virunga NP, DRC @) LuAnne Cadd. The rangers and tourists wear facemasks to reduce the chances that respiratory pathogens will be passed to the gorillas

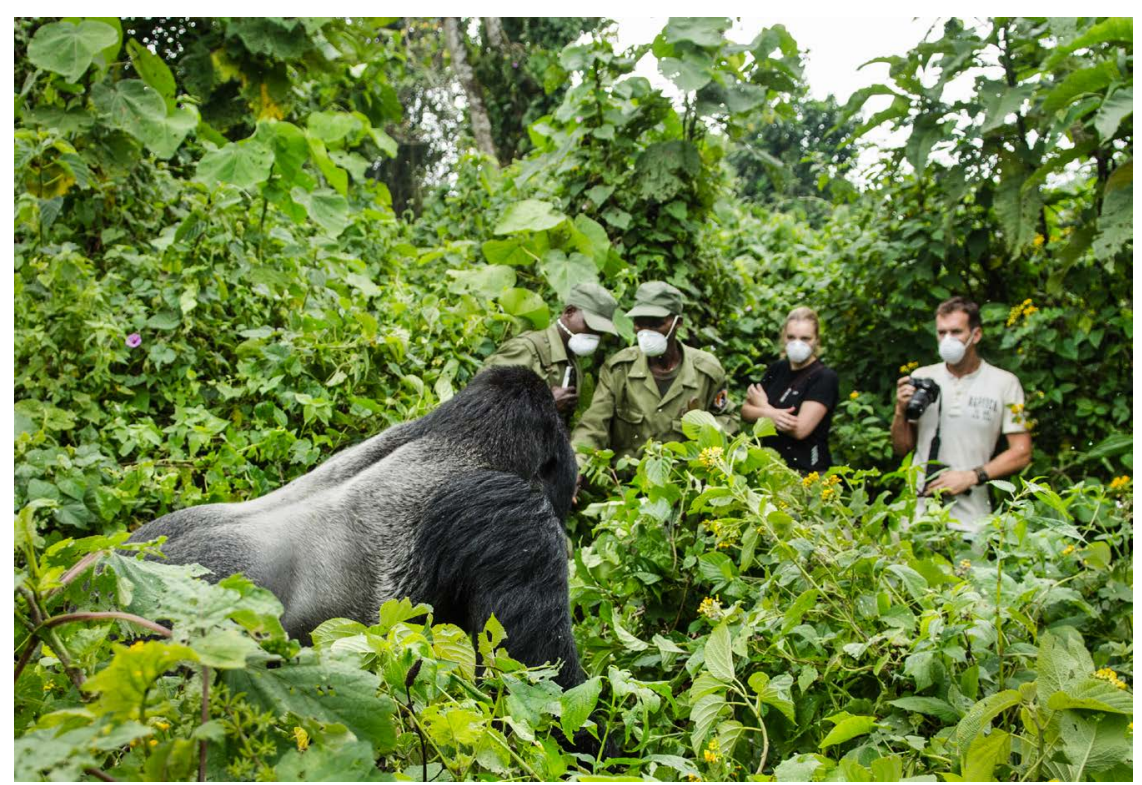


potential source of disease. Thus, tourists may inadvertently transport pathogens into great ape habitat, or from one ape group to another.

Given the worrying conservation status of great apes worldwide and the fact that disease outbreaks in small populations can be catastrophic, applying the precautionary principle to recommended best practice for great ape health is warranted. Thus, in the absence of scientific evidence that a disease agent or human action or policy is or is not harmful to great apes, it is safest to assume that such agents or actions do pose a health risk until scientifically proven otherwise. The following best practices, designed to minimise the risk of human-to-great ape disease transmission, should be applied and adhered to at all great ape sites where people (PAA personnel and visitors) are coming into close proximity to great apes.

\subsubsection{Tourism and research}

As detailed in Best Practice Guidelines for Great Ape Tourism (Macfie \& Williamson 2010), PA personnel and visitors should strive to adhere to the following guidelines to minimise the inherent risks of introducing disease when viewing great apes. PA personnel should also try to ensure that their colleagues do the same. The following recommendations are based on the IUCN tourism guidelines (ibid.) and corroborated by evidence where noted. Exceeding the following recommendations will further reduce the likelihood of infectious agents being transferred to great apes ${ }^{6}$. Where science-based data to justify recommendations are lacking, the precautionary principle (i.e. caution practiced in the context of uncertainty) applies.

- If a person is feeling unwell or exhibiting signs of illness, they should not visit great apes because clinically ill people are shedding pathogens that could infect great apes.

- If a person has been ill, they should undergo quarantine away until 7 days after the cessation of clinical signs of illness (see Section 3.1.2).

- The minimum age of all people visiting great apes should be 15 years, because children are more susceptible to a greater variety of communicable disease agents and are therefore more likely to be shedding infectious agents (Monto 2002), and because children are less likely to understand and be able to comply with visitation rules.

- Every person visiting great apes should maintain a minimum distance of at least 7 metres (23 feet) from the animals; 7 metres is the minimum distance that exceeds how far a sneezed droplet can travel in an indoor environment (Xie et al. 2007), and droplets can carry infectious particles (Jones \& Brosseau 2015).

- Any individual great ape or great ape group ${ }^{7}$ should be visited by only one tourist group per day, not exceeding the maximum number of tourists deemed appropriate for the species $^{8}$, and for no more than 1 hour per visit. This is to minimise stress for the great apes (Muehlenbein et al. 2012; Shutt et al. 2014) and to reduce the disease risks. PAA staff and researchers who spend longer periods of time close to great apes should comply fully with all other disease prevention best practices.

- Everyone likely to come within 10 metres of a great ape should wear a surgical mask to reduce airborne transmission of infectious particles from their nose or mouth to the great apes (Johnson et al. 2009); masks should be provided by park personnel, put on before approaching great apes, replaced if they become wet or torn during the visit, then carried out of the forest and properly disposed of by park personnel after use.

- Everyone visiting great apes should sanitise their hands (by washing with soap and water or using an alcohol-based gel) before and after entering great ape habitat.

- Everyone visiting great apes should wear clean clothing that is washed or changed between visits to different animals or groups, to minimise the potential for transferring a disease agent that may be adherent to clothing.

- Everyone visiting great apes should wear footwear that is clean before, and washed after, a visit, including between visits to different groups, and if possible disinfected after washing, to minimise the potential for transferring a disease agent that may be adherent to footwear.

6 For example, keeping at greater distances, monitoring visitors for signs of fever, requiring visitors to show proof of immunisation.

7 'Group' is used for any social unit of great apes: a community, a party or a mother-infant pair.

8 For discussion and species-specific tourist group size recommendations see Macfie \& Williamson (2010). 
Research assistants in Taï NP, Ivory Coast, wear single-use facemasks and dedicated forest clothes to minimise the risks of sharing pathogens with the habituated chimpanzees they are following @ Sonja Metzger/TCP

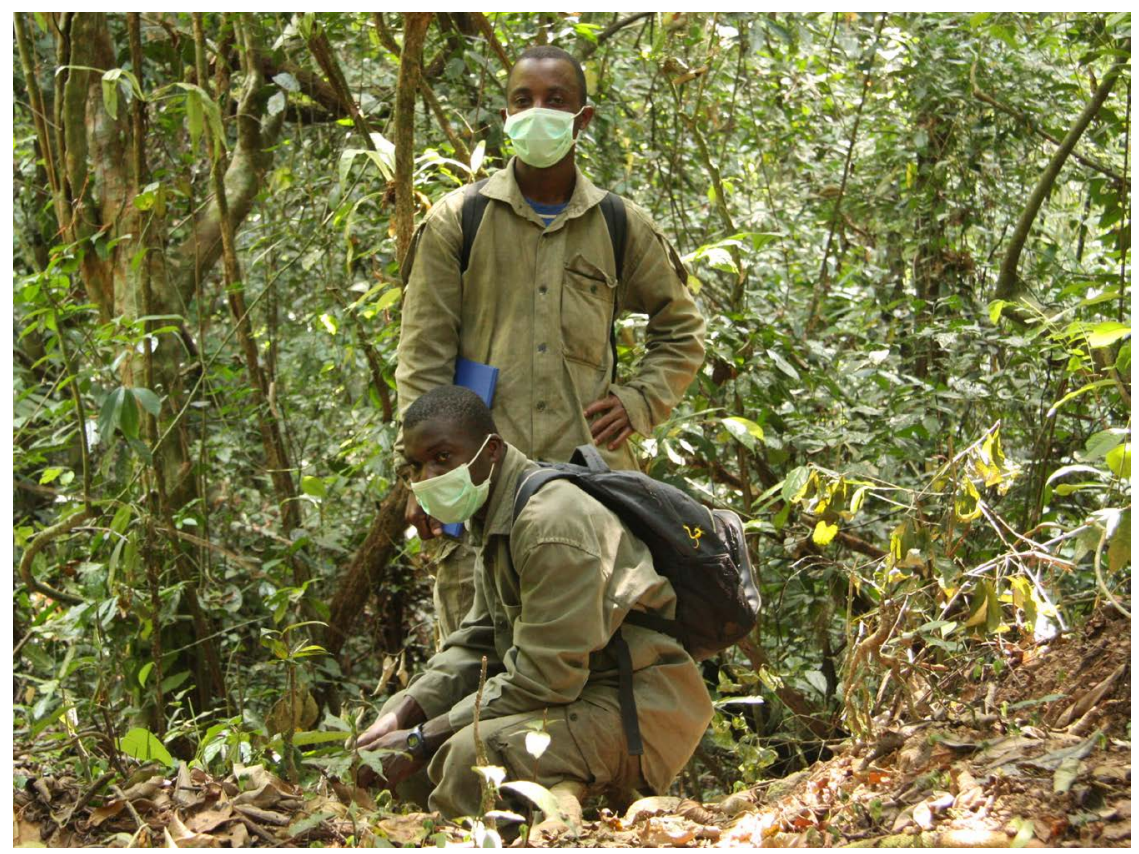

- If a person needs to sneeze or cough while visiting great apes, they should keep the mask on, turn away from the animals and cover the mouth and nose with the crook of the elbow or inside of clothing, rather than the hand, to minimise the contamination of the immediate environment with infectious particles.

- If a person needs to urinate while in great ape habitat, they should move in the opposite direction, out of sight of the apes, and dig a hole at least $30 \mathrm{~cm}$ deep, to minimise the potential for great apes to come into direct contact with the urine. Solid waste (such as toilet tissue) should be transported out of the forest.

- Defaecation should not be allowed in great ape habitat; if a person needs to defaecate while in the forest, all faeces and solid waste (such as toilet tissue) should be bagged, transported out and disposed of appropriately, to minimise the potential for great apes to come into direct contact with human faeces that may contain disease agents.

- Cigarette smoking should be prohibited and cigarette butts must not be disposed of in great ape habitat.

- Infrastructure at research and tourism sites should be designed and managed to minimise disease risks through appropriate siting to avoid areas used by great apes and protocols for food and waste management.

\subsubsection{Human quarantine}

Without exception, anyone who has been ill should not come into close proximity of great apes until 7 days after cessation of clinical signs. This includes park personnel, researchers, film-makers and tourists.

In addition, people who travel internationally to work with great apes for research, veterinary or other (e.g., filming) purposes, may have been exposed to a wide variety of infectious diseases at home or en route that could be spread in the course of conducting their work. Although the potential transmission of a novel pathogen also applies to tourists, the nature of the work of veterinarians, researchers and film-makers requires them to spend extended periods of time in close proximity to great apes (longer than the 1-hour maximum permitted for tourist visits). Therefore, to minimise the chances that a long-term visitor will shed infectious agents acquired prior to or during international travel, all long-term visitors arriving from outside the country should undergo a 7-day quarantine prior to entering ape habitat or otherwise coming into close proximity with a great ape. Seven days is the maximum incubation period for most human upper respiratory viruses, some of which are known to infect great apes (Lessler et al. 2009; see also Fig. 2). Appendix I is a human quarantine protocol in place at a great ape research site.

Furthermore, if an individual becomes ill during the quarantine period, they should begin an additional 7-day quarantine period on the first day that they are no longer showing clinical signs. Once the quarantine period has concluded and an individual is cleared to start conducting their work with great apes, all current rules for minimising the risk of disease transmission (Section 3.1.1 above) should be adhered to.

It is also important for park personnel, researchers, veterinarians and others who routinely come into close proximity with great apes, to recognise that using some modes of public transport, such as buses, and frequenting crowded public places, such as schools and markets, creates greater opportunities to contract infectious diseases. When 
and where possible, people working with great apes should be mindful of, and minimise, these risks, especially during quarantine periods.

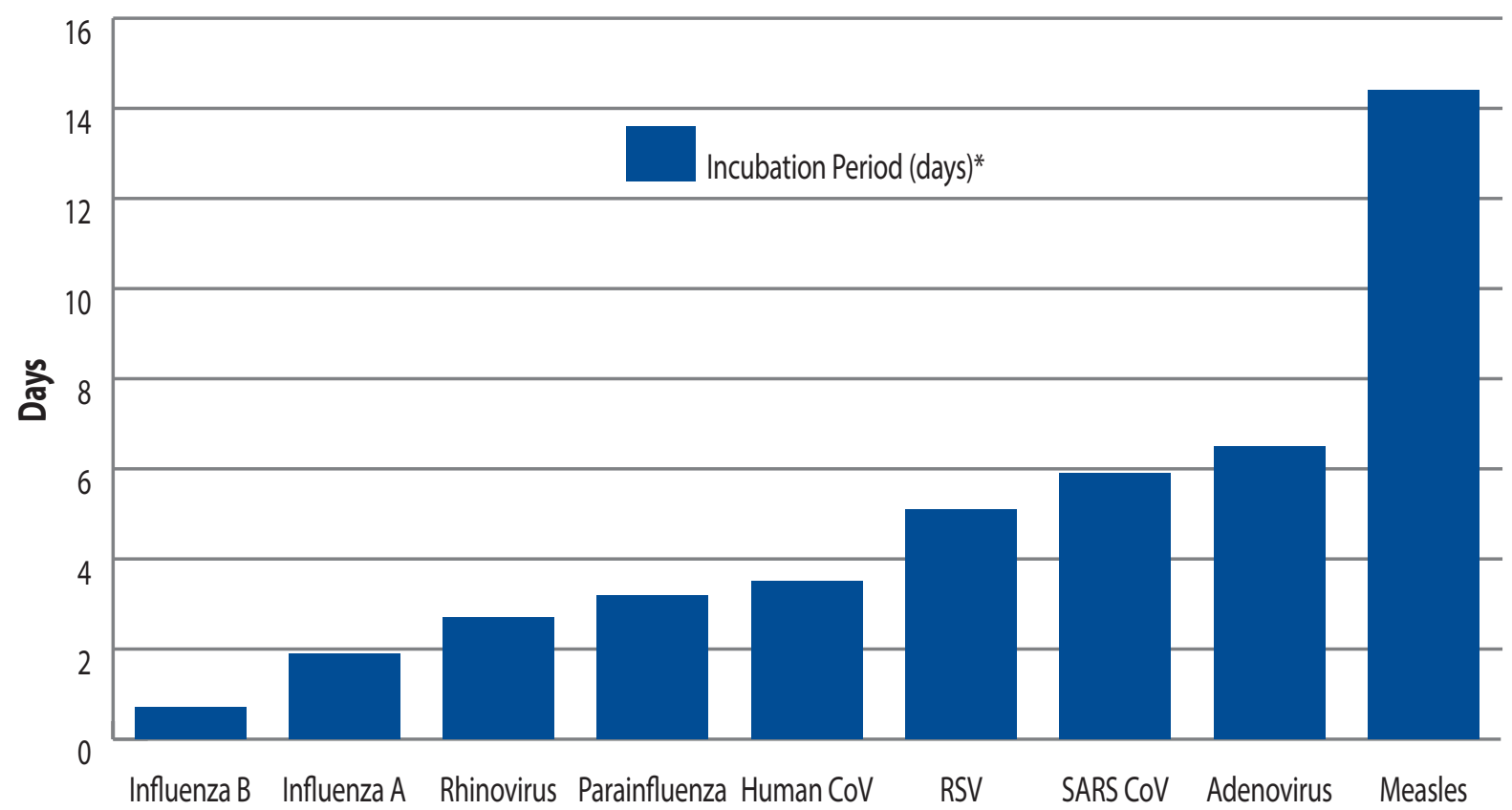

Figure 2. Incubation periods for select human respiratory viruses. Estimated time (in days) to onset of clinical signs in 75 out of 100 infected individuals (from Lessler et al. 2009). Coronavirus (CoV); Respiratory Syncitial Virus (RSV); Severe Acute Respiratory Syndrome (SARS)

\subsubsection{Human immunisation}

Ideally, all individuals who will likely come into more frequent and/or close proximity to great apes (PAA personnel and longer-term visitors) should be immunised according to local government recommendations for childhood vaccination (see also Section 3.2), although it is recognised that some childhood vaccines are not safe or effective in adults. Acknowledging that government recommendations may not be complied with in developing countries, at a minimum, PA staff and visitors should be immunised against the measles virus, because it is highly infectious to primates. Whilst polio has been eradicated from most of the world, it remains endemic in Africa and Asia and, because poliovirus is infectious for great apes, anyone from these regions who is likely to be in close proximity to apes should be vaccinated against polio. Vaccines should be administered by human health providers sufficiently in advance of great ape visitation to allow the vaccine to become effective.

PA staff and longer-term visitors should be tested for tuberculosis (TB) once annually, with negative results documented before ape visits commence. TB testing is typically done by intradermal tuberculin skin test, but increasingly also or instead by a blood test (measuring gamma interferon). People who have been previously vaccinated for TB with BCG (Bacillus Calmette-Guerin) should be tested with gamma interferon assays and ideally chest radiography or sputum culture. Because great apes are highly susceptible to TB, any person actively infected with TB must not work anywhere near great apes.

\subsubsection{Cessation of great ape visitation}

In the event that a portion of a great ape group is ill, PAAs should seek expert opinion from a veterinarian and give serious consideration to temporarily halting visitation (except by those who are monitoring the outbreak) until the disease event is over. This should be done for several reasons:

- Illness in several individual great apes may portend a disease outbreak, in which case measures to limit the spread of the disease including accidental transmission to human visitors should be implemented, as should increased monitoring of the affected population. 
- Illness and injury are physiologically taxing processes for a great ape's immune system; human visitation of ill great apes may cause additional stress (Muehlenbein et al. 2012; Shutt et al. 2014), which, even if minimal, may slow the recovery process.

- In some situations, the immunity of a sick individual, group or community of great apes may be overwhelmed in fighting an infectious disease, in which case they may be less able to effectively mount an immune response to a newly-introduced pathogen from a human visitor.

- The pathogen(s) infecting the great apes may also pose a risk for people who come into close proximity.

\subsection{Employee Health Programmes (EHPs)}

It is crucial to assess and improve the health of the people who work in great ape habitat, especially those who are frequently in close proximity to the apes themselves. PAA personnel and tourism support workers (rangers, guides, porters, trail cutters) may spend many hours in the forest, not only tracking habituated great apes, but also in indirect contact with unhabituated apes simply by virtue of their shared use of habitat. Researchers and veterinarians, while fewer in number and perhaps spending less time in the forest, do close follows of focal animals and groups while collecting data or treating ill and injured animals.

A formalised approach to mitigating this threat through risk-reduction is an occupational or employee health programme (Ali et al. 2004; MGVP 2002 Employee Health Group 2004; Travis et al. 2006). EHPs are designed to ensure the health and safety of those who work in close proximity to great apes, with the added benefit of reducing the likelihood of diseases being transmitted to great apes in their natural environment. In addition to reducing the risk of pathogen transfer from PA+ personnel to great apes, EHPs also provide benefits in the form of greater operational efficiency for the PAA or project (fewer sick days taken by employees) and greater morale among the work force.

Elements of a standard EHP, as resources allow, are:

- A periodic, at least annual, physical examination administered by a physician.

- Basic health tests (e.g., body temperature, complete blood count, urinalysis, faecal parasitology) to reveal underlying or chronic conditions that could affect quality of life or life expectancy.

- Diagnostic testing (including imaging tests, like chest radiographs) for select infectious diseases, such as malaria, TB, hepatitis and HIV and others of particular concern in the region.

- Verification and/or boosting of immunisations for select communicable diseases of concern for great apes (see Section 3.1.3).

- De-worming medications administered to personnel and to their immediate families on a quarterly basis, alternating the medication quarterly to reduce the potential for anthelmintic resistance.

- Referral of employees found to have emergency, complicated or chronic conditions to a health care facility or programme for treatment (e.g., employees who are found to be infected with HIV should be referred to a government-approved clinic able to provide adequate and sustained HIV care, treatment and support); the minimum EHP responsibility should be to ensure that referrals occur and are effective.

- Health and hygiene education relevant to the location and situation.

While an EHP should offer all personnel a physical examination by designated clinicians at least once a year, the frequency of examinations will be determined by resource availability and in situations where risk assessment suggests that shorter clinical examination intervals would substantially reduce the risk of disease transfer. Ideally, employees should be examined before or at the time of hire, to establish baseline levels and determine eligibility for specific job responsibilities, such as fieldwork. While this is the ideal model from an occupational health perspective, from a patient privacy/confidentiality and ethical standpoint, permission should be obtained from the employee for such procedures, to prevent employment discrimination against sick individuals (e.g., a positive HIV test is not an indication that an employee cannot work or be hired, but rather that the employee needs appropriate care, treatment and support to adhere to her/his treatment in order to minimise the risk for HIV-associated infectious diseases such as TB, which are of concern for great apes and for work colleagues).

EHPs should also focus on the prevention of childhood infectious diseases through available and state recommended vaccines in order to reduce the incidence of diseases that pose risks for great apes. Whenever possible, diagnostic tests should be performed to assess levels of immunity (i.e. antibodies) to communicable pathogens; laboratory tests to distinguish 'active' from past or chronic infections are indicated.

Faecal testing for gastrointestinal parasites and immediate, if needed, treatment of employees is essential for many reasons: employee infection rates are typically high; employees are the most likely people to defaecate in great ape 
habitat because they are often in the forest all day; treatment regimens are standard; drugs are inexpensive and widely available; and gastrointestinal pathogens shared among people and great apes have been well documented (see Section 6). In fact, the risk of transmission is sufficiently high that, ideally, prophylactic treatment for some parasites should be provided on a quarterly basis to all employees and their families. Quarterly de-worming treatment contributes positively to employee well-being and also provides an opportunity for health and hygiene education.

EHPs should direct employees to appropriate hospitals and clinics for treatment of any medical conditions or infections detected through the EHP. Confirmed chronic disease cases should be referred to national health programmes or to other local institutions for more complex or emergency care. Finally, although extending EHP services to family members helps achieve overall objectives, it is recognised that such programmes can only be offered where resources permit (financial, human and otherwise).

\section{Section 4. Best Practice in Health Monitoring \& Disease Surveillance}

The study of the causes, distribution and control of diseases in populations is called epidemiology and it forms the foundation of the great ape health monitoring practices described herein. An epidemiologic approach improves our understanding of the health of a population, helps identify abnormalities in health patterns and allows us to determine whether steps being taken to reduce disease risks are effective. Population health monitoring also allows for the recognition of incidents of illness or injury in great apes, which may or may not be addressed clinically (see Sections 5 and 6).

\subsection{Health Monitoring \& Disease Surveillance}

Monitoring is the ongoing and systematic collection, analysis, interpretation and dissemination of information with the intention of detecting deviations from normal. Surveillance is the ongoing and systematic collection, analysis, interpretation and dissemination of information with the intention of such information leading to action (i.e. a management response or immobilisation). With regard to great ape health, types of monitoring and surveillance information include presence or absence of animals, observable clinical signs and symptoms, laboratory test results and environmental and/or behavioural factors that may indicate disease. Such information is used to detect outbreaks of disease, describe patterns of disease transmission, evaluate prevention and control measures, and prioritise future veterinary care needs.

The combining of surveillance and monitoring results in an integrated system capable of addressing both known/ expected and new/emerging diseases. The key to an effective surveillance and monitoring system is to adopt systematic and standardised methods for collecting data. Standardised methods are critical, because they allow $\mathrm{PA}+$ managers to compare information from populations in different contexts, and systematic sampling is essential because it allows comparisons over time and thereby identification of deviations from 'normal'.

At most project sites with habituated great apes, observational health assessments can be conducted alongside routine behavioural data collection. In this way, health information becomes part of the profile of an individual for whom you may have a host of other demographic and life-history measures available. Even at sites with unhabituated great apes, standardised health measures may still be collected alongside other observational systems that are in place, such as viewing platforms or camera traps. The important point is to collect as much relevant information as possible, in a standardised way, on as many individuals as possible (both healthy and sick).

\subsubsection{Health monitoring and disease surveillance data}

To investigate disease impacts, data should be collected at the population level to estimate normal or expected rates of disease. For example, an observation of five animals with signs of illness (such as coughing) and 45 animals without signs (10\% prevalence) may suggest a very different management action than observing 20 sick and five healthy individuals (80\% prevalence).

Monitoring and surveillance of habituated great apes is substantially more achievable and yields more data of higher quality for informing contingency and management plans than health monitoring of unhabituated great apes. The difference, of course, is that habituated great apes are observable, perhaps even daily and for lengthy periods of time. Furthermore, habituated great apes should be individually identifiable and are more easily chemically immobilised, if necessary, for complete clinical examinations and thorough diagnostic sampling (covered in Section 5.3). PA+ personnel who are in a position to observe great apes daily and look for health abnormalities form the foundation of a 
A young female bonobo at Wamba, DRC, was caught in a snare set to catch terrestrial mammals such as duikers. Researchers helped to release her by cutting the stick to which the snare was attached, but the wire remained, binding her fingers. Here an elderly female is seen trying to remove the wire, while others look on (C) Takeshi Furuichi

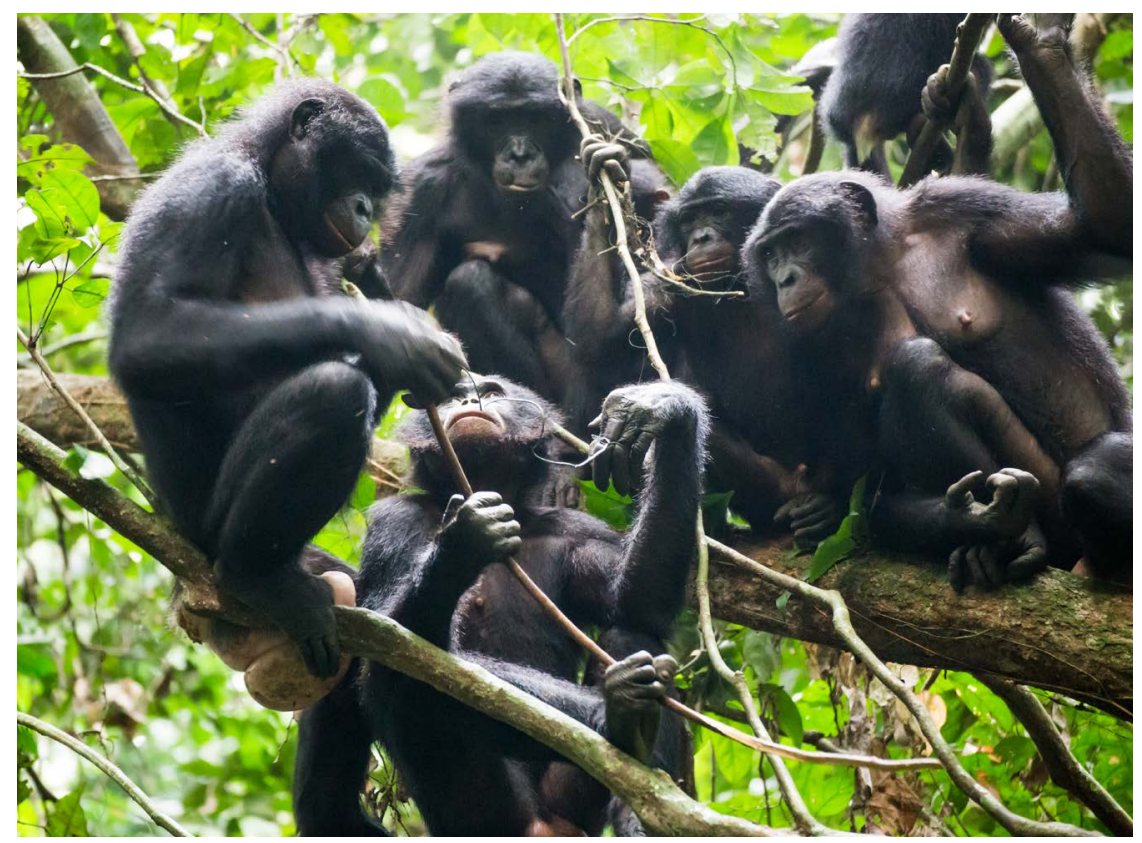

health monitoring and surveillance programme. Observers can be trained to note key health indicators in each individual great ape and determine whether they are healthy or not.

The following recommendations are based on lessons learned from the long-term monitoring of habituated great apes at research and tourism sites in the Democratic Republic of Congo, Rwanda, Tanzania and Uganda (Lonsdorf et al. 2006; Cranfield \& Minnis 2007; Hanamura et al. 2008).

People observing great apes for signs of disease should maintain a distance of at least 7 metres from all animals and should wear a surgical mask to reduce the risk of transmission of an infectious pathogen to the apes.

For each habituated individual observed, whether it appears to be healthy, sick or injured, the following data should be collected daily or as often as resources will allow.

\begin{tabular}{|l|l|}
\hline Data & Description \\
\hline Identification & Individual name or number \\
\hline Sex & Male, female or unknown \\
\hline Age & Class (e.g., adult, juvenile or infant) \\
\hline Observed signs: & Normal vs. abnormal \\
\hline 1) Body condition & e.g., good, poor, thin, emaciated \\
\hline 2) Activity level & e.g., active, quiet, unwilling to move \\
\hline 3) Respiration & Breaths/min; coughing or sneezing \\
\hline 4) Skin/hair & Intact or with wounds or hair loss \\
\hline 5) Discharge from the head & From eyes, ears, nose, mouth \\
\hline 6) Discharge from body & e.g., from reproductive tract, from wounds \\
\hline 7) Faeces & Consistency, frequency, appearance \\
\hline
\end{tabular}

The following covariates should also be recorded:

\begin{tabular}{|l|l|}
\hline Data & Description \\
\hline Date & Self-explanatory \\
\hline Time & Self-explanatory \\
\hline Location & GPS coordinates; and/or name \\
\hline Altitude & Self-explanatory \\
\hline Observers & Number and types of people present \\
\hline Animal group & Presence or absence of known individuals \\
\hline
\end{tabular}

Examples of observation checksheets, which can be tailored to each site as appropriate and practical for a particular species, can be found in Appendix II. 
The proportion of a group seen may be influenced by group size, vegetation and observer experience. Thus, a longer time period will be required for veterinarians, trackers or guides to make adequate observations of the entirety of a large group. Ideally, every habituated individual should be observed daily or, if not possible, at least weekly. The aim is to ensure that an animal requiring veterinary observation or intervention may be seen within 24-48 hours, the actionable window of time. Weekly or more frequent observations will also enable the detection of an individual that has not been seen for a significant period of time, prompting a search (if necessary) for animals that might be ill, injured or deceased.

Initial and refresher training on the identification, classification and recording of clinical signs should be conducted with park personnel and any other individuals who will be observing great apes for signs of disease, to ensure that observational data are collected consistently and reliably; such training is best delivered by experienced field veterinarians and researchers. Standardised training materials should be developed for use in all training sessions.

When abnormalities are seen, veterinarians should be notified so that they may plan for follow-up observations and clinical care as indicated. Due to their area of expertise, veterinarians and veterinary technicians are best positioned to further describe observations using standardised language (terms) for clinical signs. Data collected by both veterinarians and non-veterinarians can then be used to make decisions according to a pre-established set of steps (contingency plan) to systematically minimise the spread of potentially dangerous pathogens, as well as to maintain transparency regarding decision-making and case management for governmental and non-governmental partners (see Section 5).

\subsubsection{Monitoring the health of unhabituated great apes}

It is very challenging to monitor the health of a population that is not habituated to the presence of humans. Unhabituated great apes actively avoid people, so sightings are rare. Nevertheless, the health of unhabituated apes can and should be monitored using surveys of foraging and/or sleeping/resting sites, and collecting faeces or hair from their nests (see Section 4.2.3). In the last 20 years, huge strides have been made in the development of noninvasive sampling techniques and state-of-the-art diagnostics, making investigations of stress, reproduction, diet and nutritional status of unhabituated great apes feasible (e.g., Murray et al. 2013). Pathogens as well as antibodies formed against them can be detected in faecal samples (e.g., Gillespie et al. 2008; Kaiser et al. 2010; Köndgen et al. 2010; Prugnolle et al. 2010; Reed et al. 2014). Saliva remaining on discarded, partially eaten food may also provide pathogen-specific information (Schaumburg et al. 2013; Smiley Evans et al. 2015). Blood found on leaves or other substrates after violent encounters or injury, even in small amounts, is an extremely valuable material, which can be used for antibody and pathogen detection (Leendertz et al. 2006). Recent successes in non-invasive diagnostic development for great apes include the use of commercially available urinary dipstick tests (e.g., Knott 1998; Sleeman \& Mudakikwa 1998; Leendertz et al. 2010), which measure pH, reproductive hormones (to detect pregnancy) and the presence of leucocytes, protein, blood, haemoglobin, glucose, nitrite, ketones, bilirubin and urobilinogen. Drops of fresh urine collected from vegetation are put on each of the pads on the test strip shortly after collection and the result is read against a reference colour chart. The parameters can indicate certain diseases and provide data on normal great ape biology. In another recent innovation, a method of measuring rectal body temperature through temperature decline in faeces has been developed (Jensen et al. 2009).

Genetic material from faeces can be used to distinguish between individual animals in the test results, and even forms the basis of population-wide surveys (Guschanski et al. 2009). Not all the demographic variables specified in Section 4.1 .1 can be recorded with such samples, but attempts should be made to collect as much of this information as possible, so that any data from diagnostic tests conducted on samples collected from unknown individuals can be attributed at least to the species.

\subsection{Diagnostic Sample Collection \& Analysis}

Great ape health data are critical for understanding the factors that cause disease and for developing appropriate protocols for prevention or treatment strategies. Our understanding of great ape health starts in the field with the collection of observational data (see Section 4.1), followed by systematic biological sample collection from healthy, sick, injured or dead animals. Samples can be collected non-invasively (without touching or otherwise coming into direct contact with the animal) or invasively (via hands-on techniques, during chemical immobilisation, for example), and can be collected from both habituated and unhabituated great apes. PAAs should strive to facilitate government approval (e.g., permits for park access, sample collection and for sample shipment, including CITES permits) for sample collection and analyses. 
Gorilla faeces next to a Grauer's gorilla nest in Kahuzi-Biega NP, DRC. Faeces can be collected for genetic analysis of both the apes and their parasites and gut flora $(\subset$ Damien Caillaud

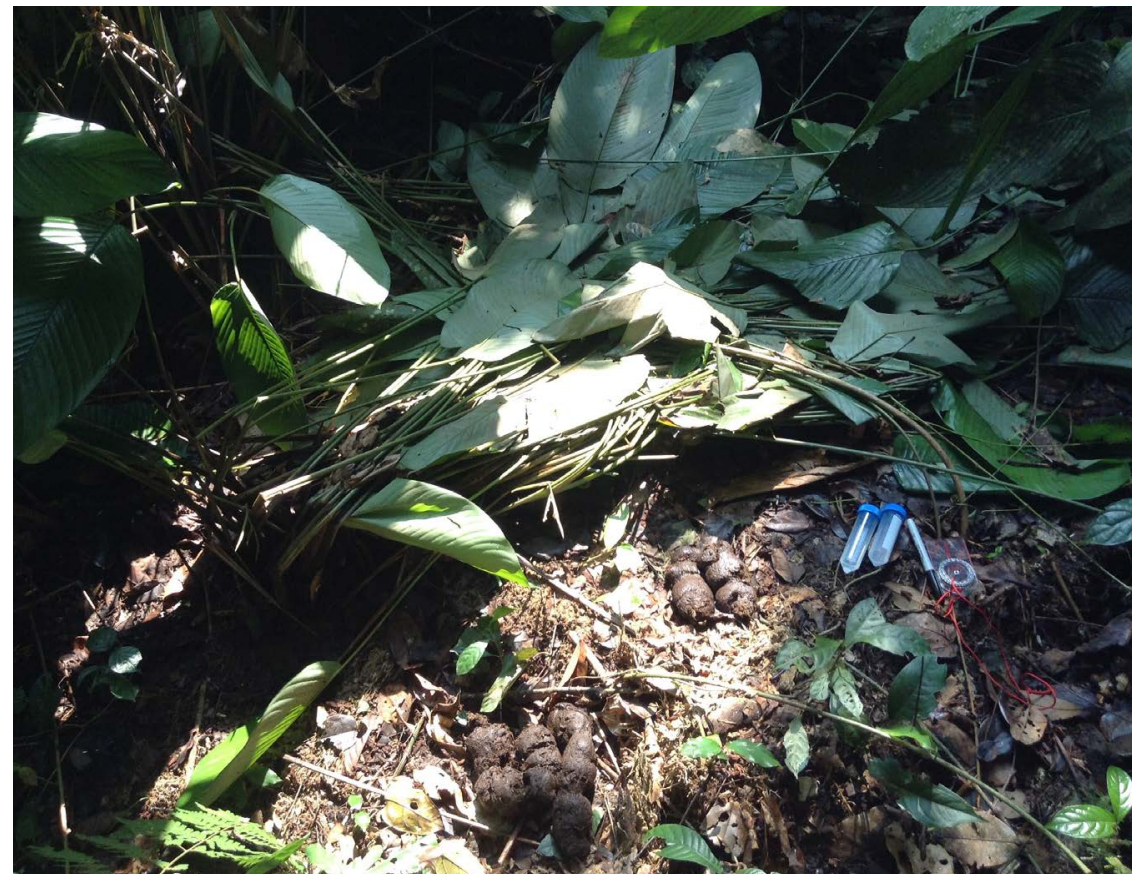

The collection of biological specimens from great apes, whether invasively or non-invasively, should be done with the highest level of attention to biosafety for the person conducting the sampling. The following recommendations apply to any person obtaining samples from a great ape, whether invasively or non-invasively.

\subsubsection{Biological safety considerations}

Biological safety (or 'biosafety') refers to actions that minimise the risk of exposure of a person to an infectious disease threat. First and foremost, in addition to the use of personal protective equipment (PPE - see below) anyone collecting samples from great apes should wash their hands frequently and practice good hygiene. The importance of hand washing to prevent infection and the spread of infectious pathogens cannot be over-emphasised. Anyone intending to collect samples from primates should make provisions for washing in the field. People handling biological samples should wash their hands thoroughly after removing their disposable gloves and other PPE articles; thus, essential supplies (e.g., water, soap, a bucket, clean paper or cloth towels and/or sanitising gels or wipes) should be available, at least upon exiting the field situation and before entering vehicles or buildings. Proper hand washing requires the use of liquid, bar or powder soap and lathering for at least 15 seconds over hands, wrists and forearms, then rinsing and drying with a fresh paper or clean cloth towel. If soap and water are not available, the proper use of sanitising alcohol-based gels is a reasonable option. People handling great ape samples should always avoid touching their face or head with their hands while working.

Personal protective equipment (PPE) helps protect people who are handling great apes or great ape samples from contamination by infectious pathogens of great ape origin. It is critical that proper training in the putting on, taking off and disposing of PPE is given to all staff involved in biological sample collection and refreshed regularly. The minimum PPE to be worn by any person non-invasively collecting great ape samples (i.e. not directly touching the animal in order to do so) differs when great apes are or are not in the immediate vicinity of the person.

When great apes are not in the immediate vicinity $(>10 \mathrm{~m})$, the minimum PPE to be worn by any person non-invasively collecting samples includes:

- Disposable gloves

- Dedicated boots that can be disinfected.

When non-invasively collecting samples in close proximity to great apes (within $10 \mathrm{~m}$; for example, collecting freshly deposited faecal samples from great apes that are being closely followed so that samples can be linked to individuals), the minimum PPE to be worn includes the above, plus:

- A disposable surgical mask to protect apes against exhaled infectious particles. If samples are being collected from great apes suffering from illness, for example during a disease outbreak, it is highly recommended that a person collecting samples non-invasively from great apes at close proximity should wear an N95 mask to minimise the inhalation of infectious particles in collected samples. 


\section{Facemasks}

The differences between an N95 respirator mask and a standard surgical mask are important. In addition to decreasing aerosolised spread of potential pathogens from the wearer, the N95 mask protects the wearer from inhaling a droplet or aerosolised pathogens into the nose and lungs. In contrast, surgical masks primarily decrease the aerosolised diffusion of potential pathogens from the wearer (in other words it protects other people and animals from any infectious droplets that may be exhaled by the wearer, during a sneeze for example), but only protects the wearer from direct contact with droplet-sized particles (Johnson et al. 2009). To learn about properly fitting an N95 mask, view this video: Mask Fitting - 3M ${ }^{\mathrm{TM}}$ Particulate Respirator Fit Test Video http://bit.ly/maskfitting

The minimum PPE to be worn by any person who will have direct contact with an immobilised great ape (i.e. touching the animal in order to collect the sample) includes all of the above, plus:

- Safety glasses/goggles or a face shield, to protect eyes

- Long-sleeved coveralls or shirt and trousers to cover arms and legs.

Personnel using N95 masks should be fit-tested to make sure they wear a mask with a proper seal (if not properly fit-tested, an N95 mask is no more protective than a surgical mask).

People wearing PPE may experience heat stress and general discomfort in hot or humid environments. It is important for people wearing PPE to remain hydrated by drinking adequate water before and after wearing PPE.

Most PPE and sanitising items (e.g., paper towels) are disposable and designed to be used only once. Items should be properly disposed of as 'medical waste' after each use. Disposable items should be removed carefully and placed in a bag for proper disposal. The outside of the disposal bag should be sprayed with a disinfectant once the bag is closed and tied. Medical waste bags should be sealed and disposed of properly. While disposal methods will differ by situation or location, a disposal site should be identified prior to PPE use, and should entail burning or deep burial at a site distant from the field site, not disposal in an open pit or rubbish heap. Local officials or those supervising the work should be involved in deciding how best to dispose of used PPE and other disposable items that are likely to be contaminated.

Reusable items, such as clothing and plastic goggles, should be placed in a separate bag for disinfection. People handling biological samples should wash their hands thoroughly after removing their disposable gloves and other PPE articles. Field clothing and footwear should be changed before getting into vehicles and/or entering clean facilities.

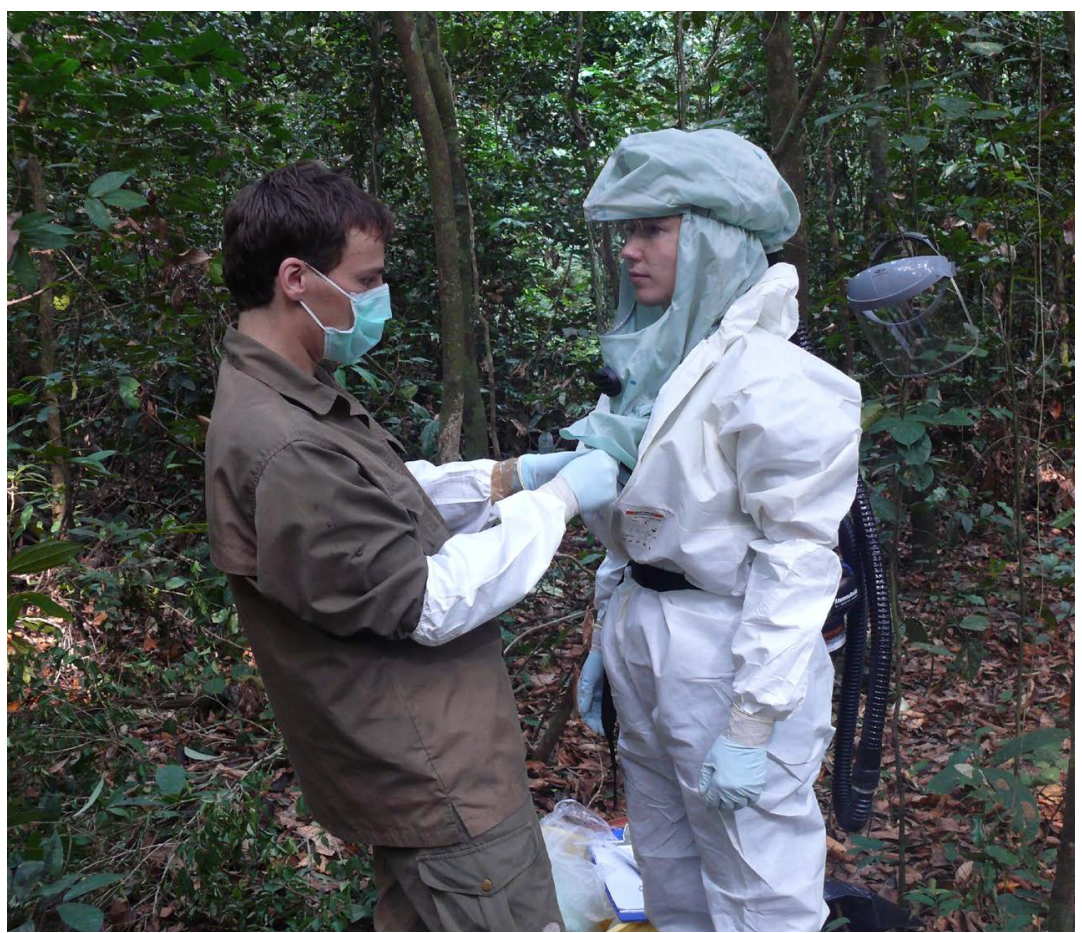

Personal protective equipment (PPE) is critical for conducting field procedures safely, and proper donning and removal of PPE requires training. The level of PPE shown here, which includes full body coverage (protective suit, layered gloves, face shield, boots) and a self-contained breathing apparatus, provides the highest level of protection against dangerous pathogens, such as Ebolavirus @ Wolfram Rietschel 


\subsubsection{Data to record with samples}

The minimum descriptive data that should be recorded when collecting biological specimens from great apes is:

\begin{tabular}{|l|l|}
\hline Data & Description \\
\hline Date & Date observation made \\
\hline Recorder name & Name of person collecting data \\
\hline Recorder affiliation & Affiliation of person collecting data \\
\hline Animal ID & Name or number by which animal is known \\
\hline Species scientific name & Genus, species, subspecies name \\
\hline Site name & Unique name of site where data were collected \\
\hline State/province/country & Self-explanatory \\
\hline Site longitude & Decimal degrees or UTM \\
\hline Site latitude & Decimal degrees or UTM \\
\hline
\end{tabular}

\subsubsection{Non-invasive collection and handling of biological samples}

Non-invasively collected biological samples are those obtained without chemical immobilisation and for which there is no direct contact with the animal. As such, these are the types of samples that PAA personnel or researchers might collect, because non-invasive sampling does not require the specialised training and knowledge of a veterinarian (which is essential for direct, invasive sampling opportunities). Nevertheless, it is important to bear in mind that such samples may pose a health risk to the handler and appropriate PPE should be worn (see Section 4.2.1 above). The most common samples collected non-invasively are:

- Faeces

- Urine

- Saliva

- Hair or blood on vegetation or soil.

To collect faeces - wearing gloves, collect fresh excreted faeces and place in a container with a sealable lid.

To collect urine or spilled blood - wearing gloves, use a sterile syringe or pipette of an appropriate size to aspirate liquid urine or blood from vegetation or the ground.

To collect saliva - wearing gloves, collect a dropped food item and place it in an airtight plastic bag or container.

For all above-listed samples: Depending on the purpose for collecting the sample, the container(s) may contain various types of liquid media to preserve the pathogen(s) of interest that might be in the sample and to enhance their detectability in the laboratory. Faecal, urine, blood or saliva samples should be kept cool in the field. Specimens slated for viral testing should ideally be frozen in the field (e.g., in a portable liquid nitrogen freezer when such specialised equipment is available) and/or transferred to a $-80^{\circ} \mathrm{C}$ freezer as soon as possible.

To collect hair - wearing gloves and using forceps, collect hair and place in a clean dry paper envelope or in a container with a sealable lid. Hair samples can be stored in the field and the laboratory at ambient temperatures in the short term, but transferred to a $-80^{\circ} \mathrm{C}$ freezer for long-term storage.

Research assistants at Ugalla, Tanzania, collect chimpanzee faecal samples, which can be analysed to detect exposure to pathogens, including viruses and parasites, as well as to study diet, hormones and genetics () Jim Moore

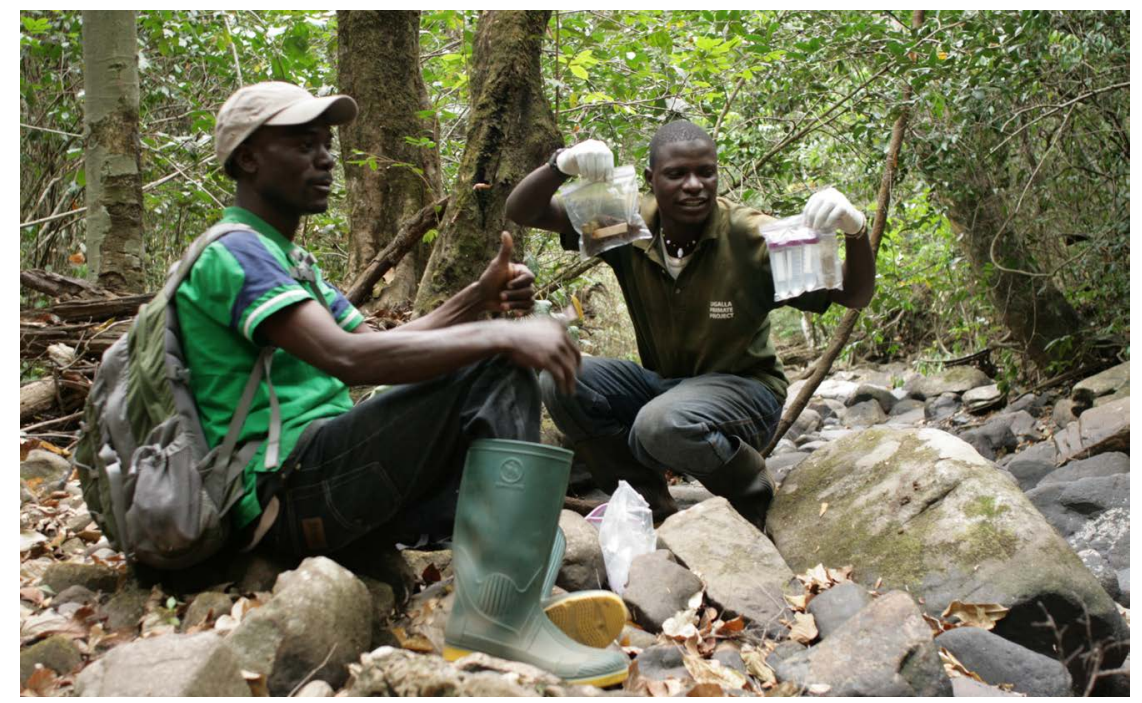




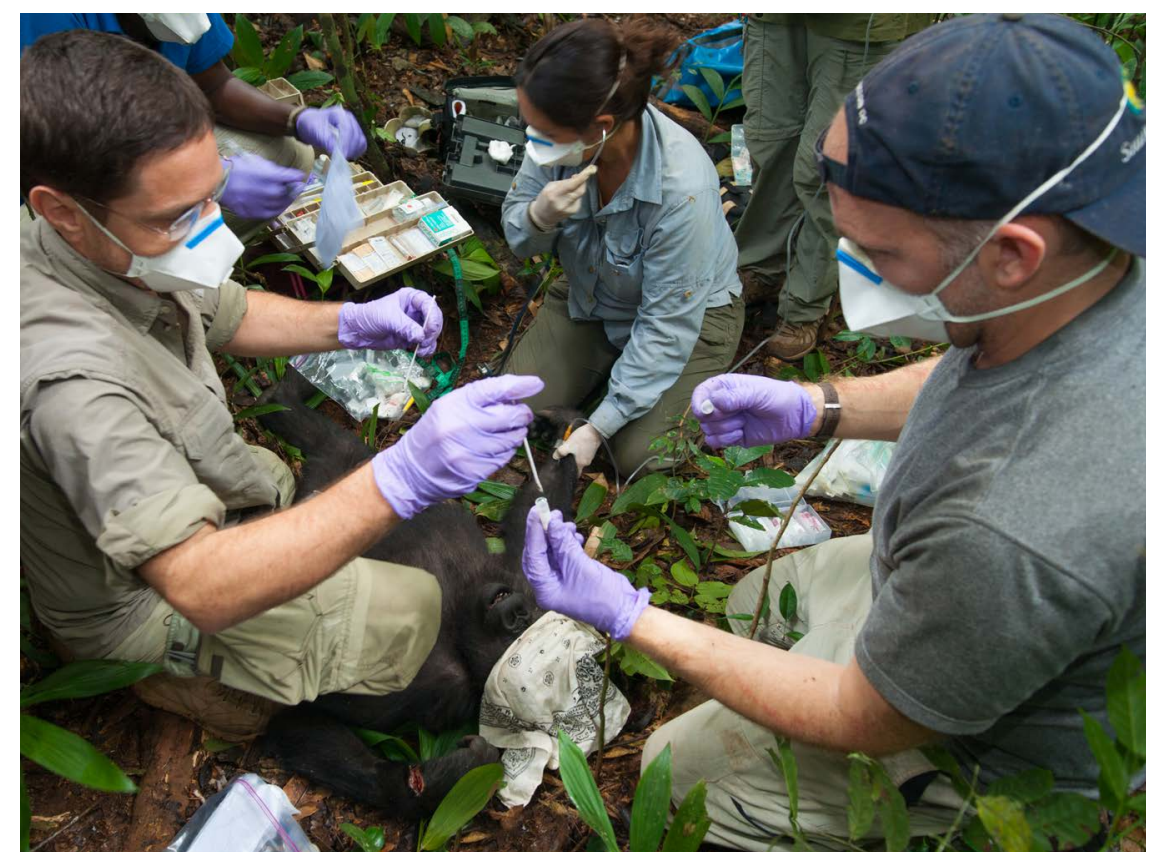

A juvenile western lowland gorilla in Dzanga-Ndoki NP, Central African Republic, is anaesthetised by a veterinary team to remove a poacher's snare from his wrist. His face is covered with a cloth to minimise visual stimulation during the intervention and biological samples collected (C) Jabruson 2015. All Rights Reserved. Team members are wearing masks and gloves for both their own and the gorilla's protection. When apes are being handled, long sleeves and trousers should also be worn to prevent direct skin-to-skin contact and possible disease transmission (see Section 4.2.1)

\subsubsection{Invasive collection of samples}

If a great ape is anaesthetised for a clinical procedure, a greater variety of samples can be collected to aid in the diagnosis of disease. Samples obtained from a living, anaesthetised ape are termed 'invasive' because the animal is being handled to facilitate sample collection. Anaesthesia performed for interventions such as snare removals should always be accompanied by systematic sample collection even if no infectious disease is suspected. Collection of samples from living apes should be performed only by highly-trained veterinarians or veterinary technicians, or if a trained veterinary professional is not present, be restricted to minimal sampling by specifically trained people.

\subsubsection{Collection of samples from ape carcasses}

Necropsy samples provide a key opportunity for determining the cause of death of a great ape. The opportunity to determine possible sources of infection will depend on quality and quantity of such samples. Ideally, every great ape carcass should be necropsied, regardless of known or suspected cause of death (e.g., predation), because the examination may yield important new information on pathogens or otherwise unrecognised disease processes that were affecting the dead animal.

Because many great ape pathogens are potentially lethal for humans, full necropsies should be performed only by highly-trained health professionals (e.g., veterinarians, veterinary technicians, physicians); therefore, comprehensive necropsy procedure instructions are not included in these guidelines, although a manual for conducting necropsies can be found online at: www.primate-sg.org/best_practice_disease. If a trained veterinarian is not present, minimal sampling should be restricted to specifically trained and experienced people.

When great apes are found dead, they are often in advanced stages of decomposition, thus samples should only be collected if human safety can be assured. However, the poorer the condition of the sample, the higher the risk that a diagnostic test may yield a false negative result. Consequently, results from samples recovered from carcasses not necropsied soon after death should be interpreted with care (unless stored under refrigeration soon after death).

In all cases, protective measures must be taken, including the wearing of full body protection, double gloves and an N95 mask, face shield, closed glasses or ventilated masks (see Section 4.2.1). As discussed throughout these guidelines, great apes should be considered potentially infectious for a wide variety of pathogens dangerous to people, and dead great apes should be sampled only when following all safety measures, including proper PPE use, proper work station decontamination and proper carcass disposal.

The extreme danger posed by Ebolavirus warrants the reiteration here of special precautions that should be taken whenever there is the least suspicion that an ape may have died from an Ebolavirus infection. One of the greatest risks of human exposure to Ebolavirus is through the handling of infected wildlife carcasses (e.g., bushmeat), especially primates. Transmission can occur through contact with infected tissues, secretions and body fluids and can 
be prevented through proper use of PPE and related barrier techniques. In such cases, sampling should only be conducted by a highly-trained health professional fully equipped with PPE.

\subsubsection{Sample identification and sample and data storage}

All tubes, containers or bags containing biological samples collected from great apes should be clearly labelled with a unique animal identifier and sample identification number that links it to other data, as recommended in Section 4.2.2. Storing samples frozen in liquid nitrogen or in a $-80^{\circ} \mathrm{C}$ freezer is best for many applications and has been accomplished in multiple studies of great apes, including at remote sites. Although not optimal, methods are available that allow sample storage even under conditions where no possibilities for storing them cold or frozen are available. These include storage in liquids designed for the conservation of DNA and RNA such as RNAlater ${ }^{\mathrm{TM}}$ (Qiagen $^{\mathrm{TM}}$ or Ambion ${ }^{\mathrm{TM}}$ ), dried on filter paper or over silica pearls, or stored in alcohol or formalin, depending on the plan for later analyses (Gillespie et al. 2008).

All samples collected from great apes not immediately needed for analyses should be stored for the long term ('biobanked') in biological resource centres for future studies that may aid the conservation and health of great apes. Bio-banked specimens provide the opportunity to examine changes in patterns of pathogen infection over time and pathogen diversity in wild great apes, including the introduction of novel pathogens. This capacity is enhanced when known individuals can be resampled over time. Further, bio-banking allows for the use of new technologies as they develop, to help resolve historical questions, or to test for unspecified organisms. Therefore, biological samples should be stored in a diverse array of preservatives and storage scenarios to maximise the opportunities for usefulness of samples in yet-to-be developed diagnostics.

\subsubsection{Analysing biological samples from great apes}

The specifics of clinical and molecular diagnostic testing of biological samples collected from great apes are beyond the scope of these guidelines. Diagnostic laboratories are often highly specialised and focus on specific pathogens. It is therefore critical that field projects establish agreements or memoranda of understanding with collaborating laboratories (such as those listed in Section 11) to ensure that samples once collected can be forwarded to laboratories to maximise pathogen screening. Furthermore, it is imperative that PA+ managers and organisations work with their governments to ensure that permits are in place to enable the collection of surveillance data and biological samples, and to facilitate the transfer of biological samples (including to other countries) to laboratories that can conduct diagnostics.

Data interpretation requires considerable experience. Laboratory results should be discussed with researchers and managers before any publication or public discussion with local communities is initiated, because interpretation of the data requires consideration of the demography, ecology, behaviour and conservation status of the great apes of interest. Interpretation of the direction of pathogen transmission among great apes and other species (including humans) requires an understanding of the exact place the great apes are living in and their living conditions, as well as genetic 'signatures' of relatedness that are best evaluated by virologists and other microbiologists and geneticists.

\subsection{Disease Outbreak Investigations}

The purpose of establishing a great ape monitoring and surveillance system is to detect life-threatening illness or injuries in individual apes and to recognise a disease outbreak when it is occurring. A disease outbreak is defined as the observation of a disease or clinical signs occurring at an above-normal or higher-than-expected frequency. In many wildlife populations, levels of 'normal' or 'expected' are unknown (which is further justification for creating disease surveillance and monitoring systems), and a 'working' definition for what constitutes an outbreak may need to be developed on a site-specific basis using whatever evidence is available. For example, a respiratory disease outbreak in mountain gorillas is defined as at least one third of the individuals in a group exhibiting clinically observable signs of illness for at least seven days (Spelman et al. 2013); for western chimpanzees (Pan troglodytes verus) in Taï National Park, Ivory Coast, the threshold for declaring a respiratory disease outbreak is generally lower.

Outbreak investigations follow basic epidemiologic principles, and first steps include:

i) Developing a 'case definition' using a suite of clinical signs, standard diagnostic test results, or a combination of both;

ii) Using the case definition to count the number of animals affected;

iii) Comparing the number of cases to the expected prevalence of the disease - if it is greater, than it is termed an 'outbreak'; and then 
iv) Collecting additional descriptive data about the outbreak, so that management or control measures can be considered and implemented and outbreak definitions can be revisited as needed.

The role of the PA+ manager in investigating a disease outbreak lies primarily in maintaining a high state of vigilance for disease patterns that may not be normal or usual and then prioritising daily collection of the following basic data for the duration of the outbreak, so that veterinarians and other health professionals can recommend disease control measures and assess the transmission pathways:

i) When was the first case seen (date, time)?

ii) Based on the data recorder's knowledge, is the number of cases above endemic levels?

iii) Where is the potential outbreak occurring (name of location, GPS coordinates, map)?

iv) What is the working case definition of this potential outbreak (e.g., bloody diarrhoea)?

v) How many animals and/or groups are affected?

vi) What is the age, sex, body condition, reproductive status and so on, of all affected individuals?

vii) Have any samples been collected for diagnostics? If so, what types, when and where, and how and where are they being stored?

viii) Have any humans or other animals sharing habitat with the sick apes shown signs of disease?

These data should be summarised in a daily 'Disease Outbreak Situation Report' (see Appendix Ild for a template) and shared as soon as possible with attending veterinarians and other wildlife health experts, so that disease control measures can be implemented by the authorities. The aim is to use the best available data to make good management decisions in the face of limited data, which is unfortunately often typical of a disease outbreak situation.

The importance of transparency when disease outbreaks occur cannot be overstated: the PAA must share information about great ape disease outbreaks with partners and other ministries in a timely and transparent fashion. This will facilitate a rapid response to control the outbreak and to protect the health of PA+ personnel and local communities. Conspecifics and other wildlife in the same habitat as any sick apes may also be at risk of acquiring the infection. PA+ managers must be committed to facilitating safe and effective sampling in such situations and to ensuring that biological samples can be transferred to diagnostic laboratories quickly, to enable a rapid and accurate diagnosis.

\section{Section 5. Best Practice in Health Interventions}

An important component of efforts to control and prevent the spread of infectious diseases in a great ape population is the ability to diagnose, treat and/or prevent disease in individual animals. Interventions can take the form of medicating an ill or injured great ape, anaesthetising it to administer a more intensive treatment and collect samples, or vaccinating a proportion of the population to prevent the acquisition or spread of an infectious disease.

\subsection{Developing an Intervention Policy}

The PAA or wildlife authority, preferably in collaboration with other great ape stakeholders, is advised to develop a health intervention policy before needing to make urgent decisions about ill or injured great apes. Ideally, a PAA will be able to declare whether it will take a conservative or a proactive approach to such decisions, based on its own conservation priorities and values, and in consideration of its available resources (Travis et al. 2008).

For example, a policy may commit the PAA to intervening on behalf of the health of an ill/injured great ape in order to sustain a valuable resource (e.g., for tourism). With mountain gorillas, a proactive intervention policy has proven to be a major contributing factor to recovery of the Virunga population (Robbins et al. 2011). For some PA+ managers, whether or not to clinically intervene to treat illness or injury in a great ape hinges on the degree to which they feel there is an obligation to do so: some argue that when a great ape's illness or injury is caused by humans (e.g., a snare wound), an intervention to assist that animal is mandatory, whereas a great ape suffering a 'natural' injury (e.g., a bite wound from a conspecific) may not warrant treatment and, in fact, intervention may interfere with natural processes that are important for overall evolutionary adaptability. It has also been argued that the potential consequences of not intervening to mitigate the effects of infectious disease in great apes places an even greater imperative on developing an intervention policy (Ryan \& Walsh 2011). A decision to intervene will also depend on whether the PAA has access to qualified, trained personnel with appropriate equipment at hand. 
That said, PAAs should bear in mind that intervening on behalf of the health of an ape individual or population will necessarily direct available resources away from other high priorities for the site (e.g., personnel assigned to assist with an intervention will be unavailable for tourism or antipoaching activities, and funds used for the intervention will not be available for other worthwhile endeavours). Furthermore, interventions are disruptive for great ape groups and not only cause stress, but may also have health and safety ramifications for the individual being treated (e.g., possible darting injury or adverse reaction to anaesthesia) and for personnel involved in the procedure (e.g., risk of being bitten).

Regardless of its reasoning, a PAA will choose an intervention policy that sits somewhere on an 'intervention decision continuum' (see Fig. 3). A policy may favour the philosophy that any animal that can be saved with a veterinary intervention should be saved, regardless of cause. Alternatively, given the myriad of challenges and threats to the long-term survival of its great apes, a policy may tend towards the philosophy that treatment of individual ill/injured great ape is not optimal use of limited resources needed to address other threats.

\subsection{Applying an Intervention Policy}

Once an intervention policy has been established, it will guide decision-making on a case-by-case basis. The remainder of this section is geared toward the PAA that has established a proactive intervention philosophy and is therefore going to be making decisions about whether or not, and how, to treat ill or injured great apes. An intervention is wholly in service to, and dependent on the consent, knowledge and assistance of, the PAA.

Interventions are separated into two categories: interventions requiring chemical immobilisation (anaesthesia) and interventions not requiring immobilisation (e.g., administration of medicine with a dart). The ability to treat individual great apes is completely dependent on the availability of trained and skilled veterinarians or veterinary technicians

Injuries and infections that are not usually treated, but which should be monitored: a silverback male mountain gorilla with severe bite wounds inflicted by another adult male gorilla (A), which two weeks later were healing well without veterinary intervention (B) (C) Chris Whittier

A blackback male western lowland gorilla with yaws-like lesions caused by bacterial infection (C), and a silverback male western lowland gorilla with herpes-like lesions around his mouth (D) () Damien Caillaud. Such lesions can be debilitating (Levréro et al. 2007), and are common in some gorilla populations in Gabon and Republic of Congo
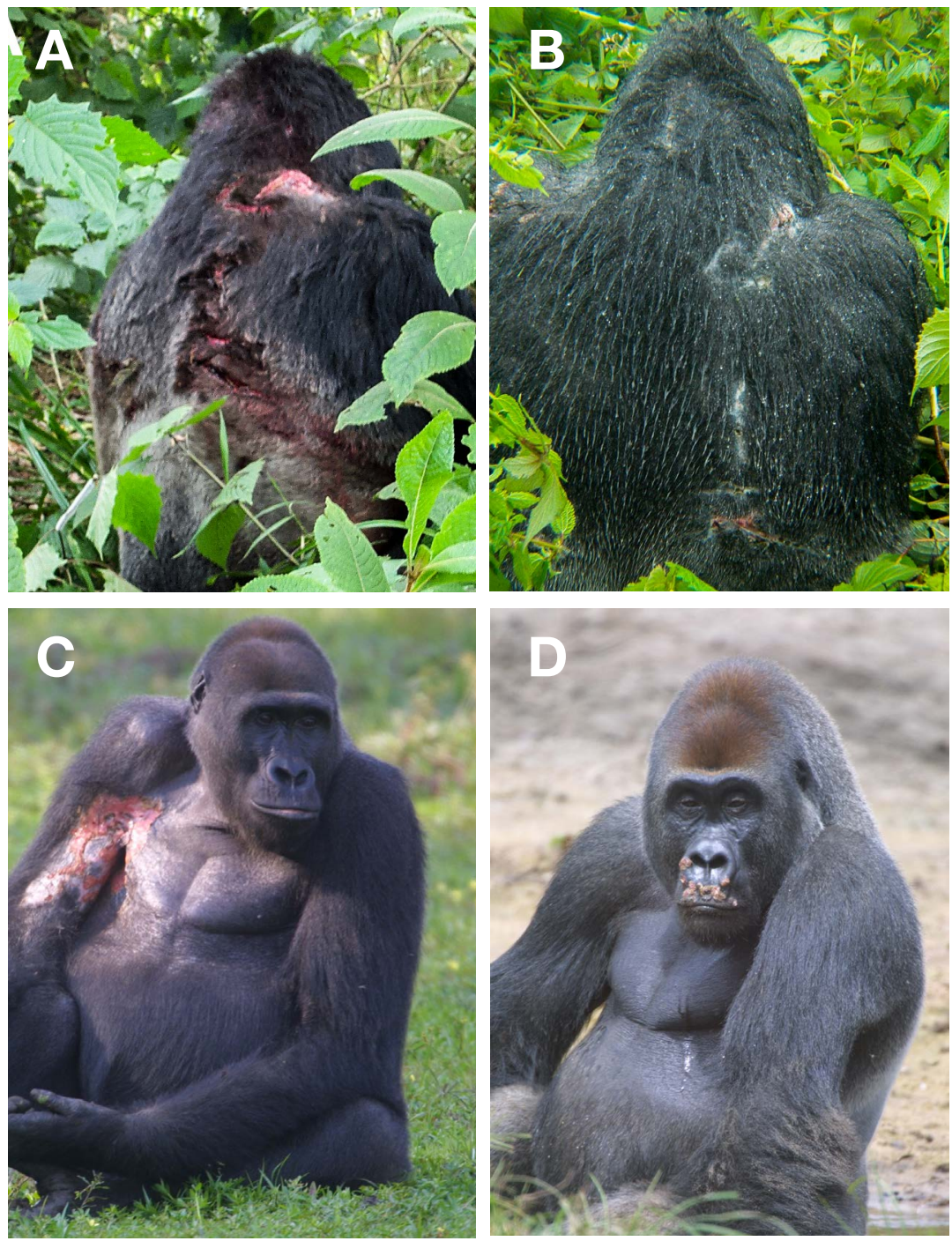


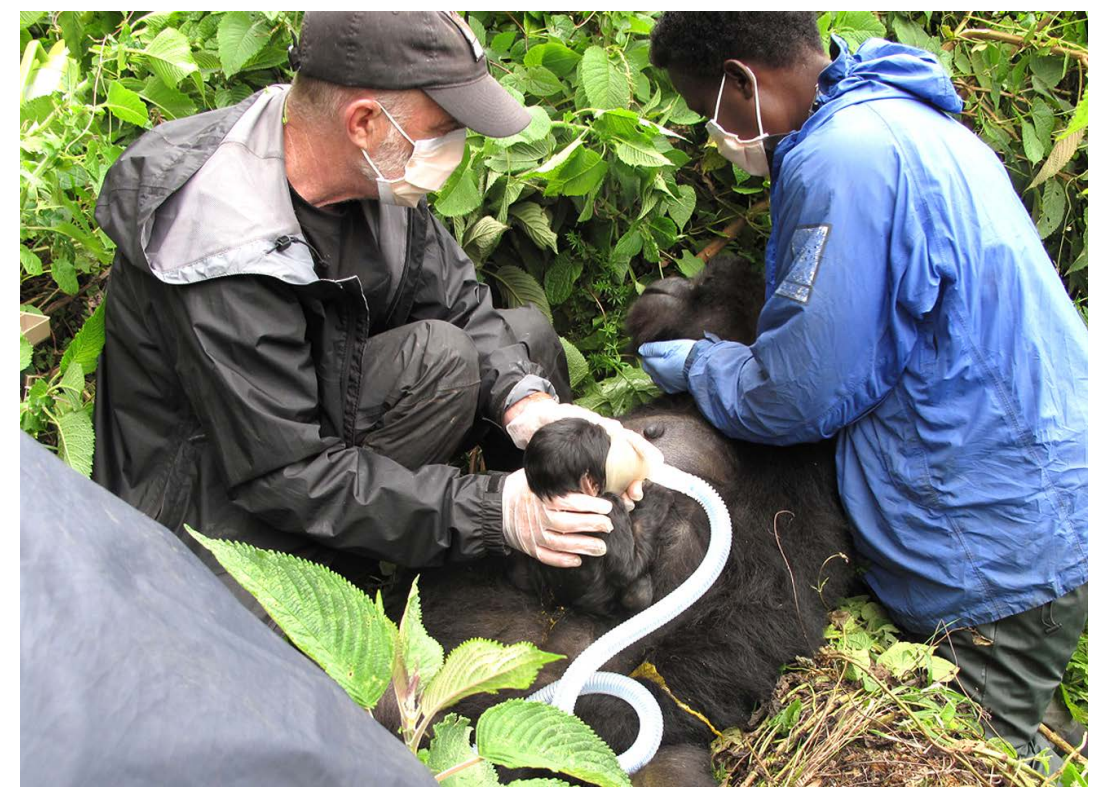

Interventions involving adult female great apes with infants are especially challenging and require extra coordination. Here a veterinarian positions an anaesthesia mask on an infant mountain gorilla while a veterinary technician tends to the anaesthetised mother $\odot$ Gorilla Doctors

who have the necessary knowledge, experience, equipment and supplies to safely and effectively treat a great ape, with or without immobilising it. Ideally, an intervention to treat an ill/injured great ape will be conducted in the animal's natural habitat to avoid unintended health and behavioural consequences of intense contact with human caretakers, abnormal diets and the social stress of separation from family members that would result from bringing the individual into temporary captivity for treatment purposes.

\subsubsection{Deciding to intervene}

In most cases, the decision as to whether or not to clinically intervene to treat an ill/injured great ape will be based on observation of clinical signs only. Because clinical signs are often nonspecific, the severity of the observed signs and the rate of spread among individuals will be the best indicators of the risk that the illness or injury is lifethreatening or causing great suffering. Clinical signs, as well as information gained from people with knowledge of the individual ape, may also allow for the classification of the illness or injury as likely to have been human-induced or not, and/or potentially infectious or not:

Low Risk: Not likely to be life-threatening and will probably resolve without treatment.

Medium Risk: Potential to be life-threatening and may benefit from treatment.

High Risk: Likely to be life-threatening and may benefit from treatment.

If an ill/injured great ape is suffering pain and discomfort, it may exhibit any or all of the following clinical signs:

- Unwillingness to move or play (lethargy);

- Inability to engage in normal movement;

- Disinterest in eating or inability to eat or drink;

- Consistent and excessive attention (touching, rubbing, holding) to a body part;

\begin{tabular}{|c|c|c|c|c|c|c|}
\hline \multicolumn{7}{|c|}{ Health Intervention/Treatment Spectrum } \\
\hline \multicolumn{5}{|c|}{$\begin{array}{l}\text { Conservative } \\
\text { "leave wildlife wild" }\end{array}$} & \multicolumn{2}{|c|}{$\begin{array}{r}\text { Proactive } \\
\text { "every animal matters" }\end{array}$} \\
\hline $\begin{array}{l}\text { Never } \\
\text { treat }\end{array}$ & $\begin{array}{l}\text { Only for } \\
\text { population } \\
\text { level threats }\end{array}$ & $\begin{array}{l}\text { Only if life } \\
\text { threatening } \\
\text { (individual) }\end{array}$ & $\begin{array}{l}\text { Only if } \\
\text { human } \\
\text { caused }\end{array}$ & $\begin{array}{c}\text { When } \\
\text { diagnostic } \\
\text { sampling } \\
\text { could be } \\
\text { beneficial }\end{array}$ & $\begin{array}{l}\text { Whenever } \\
\text { condition is } \\
\text { treatable }\end{array}$ & $\begin{array}{l}\text { Routine } \\
\text { sampling of } \\
\text { healthy } \\
\text { animal }\end{array}$ \\
\hline
\end{tabular}

Figure 3. Intervention Decision Continuum: A PAA should develop an intervention policy before needing to make urgent decisions regarding an ill or injured great ape, which will predetermine its approach to such situations somewhere on the continuum between a conservative, hands-off to a more pro-active, hands-on policy 
- Difficulty breathing (increased breathing, coughing, excessive nasal discharge).

A health intervention should be considered if:

- An illness or injury in an individual great ape is clearly human-induced;

- A group of great apes is experiencing a disease outbreak (such as a respiratory infection).

A health intervention may also be considered under other circumstances, depending on the species and/or the status of the population:

- An illness or injury is highly likely to lead to death and, even if not clearly human-induced, is affecting an individual of high reproductive value - a female with a nursing infant, or a young adult female with many years of reproduction ahead of her;

- An illness or injury is highly likely to lead to death and, even if not clearly human-induced, is affecting a key individual, the loss of whom could have significant negative consequences for other apes in the group or community (e.g., injury, death, group disbandment), although it should be noted that treating such individuals could have unintended consequences for social dynamics or long-term demographics in the group or community if the animal survives;

- An illness or injury may portend the onset of an infectious disease outbreak, the extent and severity of which could be minimised by treating ill animals so that they will not infect others.

A health intervention may not be warranted if:

- A great ape is experiencing a naturally acquired illness or injury (e.g., a wound sustained in a fight with another great ape);

- A great ape is showing only mild clinical signs of an illness or injury and does not appear to be suffering, even if the illness or injury is human-induced.

Appendix III is an example of clinical response decision tree.

\subsection{Conducting a Health Intervention}

The following describes what is typically involved in successfully conducting a great ape health intervention, whether it entails the remote delivery of a medication by dart, or requires anaesthetising an animal to provide hands-on veterinary care. This section is not intended to instruct on how to conduct an intervention, but rather to inform those involved in an intervention of what to expect.

\subsubsection{The intervention team}

Once the decision to intervene has been made, an intervention team should be assembled. At a minimum, the team should comprise:

- A veterinarian: the veterinarian should be experienced in great ape medicine and permitted to legally practice in the country; he/she will be in charge of all veterinary aspects of the intervention (ideally each animal to be anaesthetised, for example, two if a mother-infant pair, should be attended to by a veterinarian, so some situations will require more than one veterinarian on the team);

- A person knowledgeable about great apes: either a PAA or wildlife or natural resource agency representative or designee, or a researcher with designated approval from the PAA. This individual will assist in ensuring that all involved are performing their jobs and adhering to protocols.

The following individuals may also play a role, dependent upon the situation at hand:

- A veterinary technical assistant: this should be an individual with experience handling veterinary equipment and supplies, who may be needed to monitor apes under anaesthesia and to obtain biological specimens;

- Trackers: skilled trackers may be needed to ensure that darted individuals are followed until the onset of anaesthesia, and perhaps to help retrieve individuals that become anaesthetised while in elevated vegetation. If an orangutan is being darted, a team must prepared to catch them with a net as they fall from a tree;

- Sentinels: when an intervention involves a group of gorillas, sentinels are guides, trackers or researchers with intervention experience, who are familiar with the particular group; and who will monitor the group and screen and protect the team from other great apes during the intervention. They must be courageous and not run if charged by a gorilla, for example; 
- Porters: may also be needed to help carry necessary equipment and supplies into the field, and ensure that all equipment, supplies and waste are removed from the field.

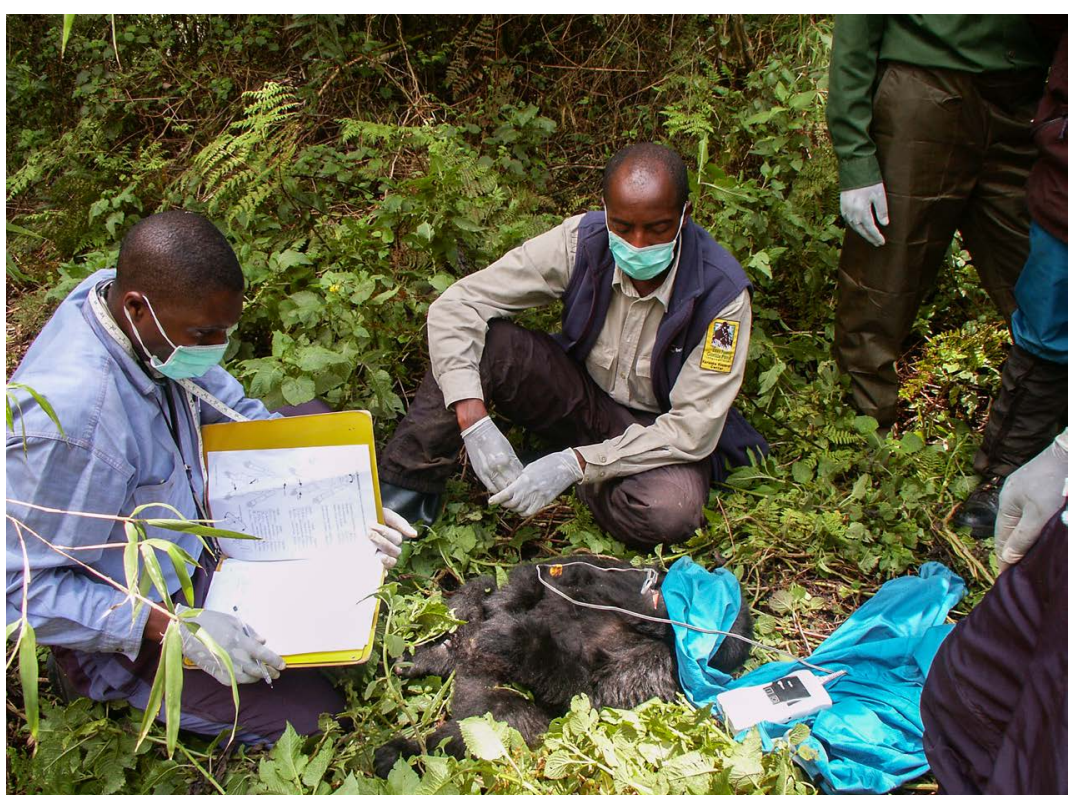

Post-intervention monitoring: while a young mountain gorilla recovers from a snare-removal procedure, his face is covered to minimise visual stimulation, his heart rate and blood oxygen levels are monitored using a portable device. Those values and other vital signs are recorded by a veterinarian $($ ) Chris Whittier

Intervention teams will be limited to as few people as are needed for a successful operation, to minimise stress for the great apes and to reduce the likelihood of accidents involving personnel. The entire intervention procedure will be conducted in as short a time as possible.

It is extremely important that all team members know their roles and understand that the veterinarian serves as the lead for all clinical decision-making regarding ill/injured great apes, including halting the intervention should it be deemed unsafe for the animal and/or the team to proceed.

All members of the intervention team who will have direct contact with the animal should be fully trained and equipped with proper PPE, including an N95 mask (see Section 4.2.1), disposable gloves, and clean outerwear and footwear. Other team members, such as sentinels and porters, should be equipped with masks. The intervention team should be composed of personnel who regularly work with great apes and who participate in an EHP (Section 3.2). To protect the ape(s) from human pathogens, people with any current or recent (within 7 days) clinical signs of illness (e.g., coughing, sneezing, fever, diarrhoea, rash, cold sores) should not take part in an intervention.

A clinical intervention is a complicated endeavour involving a number of people and usually substantial quantities of equipment and supplies. It can be socially very stressful for the great apes whose family member is being darted or immobilised, and when stressed, aggravated or frightened, great apes can become dangerous. Therefore, it is imperative that the intervention team remains calm, follows directions given by the veterinarian, and is ready to change course or plans at a moment's notice.

\subsubsection{Intervention activities}

It is important to remember that darting an animal is not necessarily the same as immobilisation. An ill/injured great ape can be darted with medicine-such as an antibiotic to treat a respiratory or gastrointestinal infection, or an antiinflammatory drug to reduce pain - or with an immobilising drug to cause it to become anaesthetised. Both types of procedure pose risks. While less training may be required to prepare a dart and shoot it to deliver medication, a great deal of training is required to safely and effectively chemically immobilise an animal, monitor anaesthesia during a procedure, and properly handle the recovery and post-procedure monitoring phases.

The drugs used to anaesthetise great apes are very dangerous to humans: they are very potent and often given in large doses (because of the size of the animal) that could be lethal to people. It is therefore extremely important that all members of the intervention team are aware of the danger of these drugs, and that only the veterinarian or the veterinary assistant handle these drugs and the darting equipment, including the retrieval and handling of any darts. All members of the intervention team should also be briefed by the veterinarian on what to do if someone is accidentally exposed to a drug. 


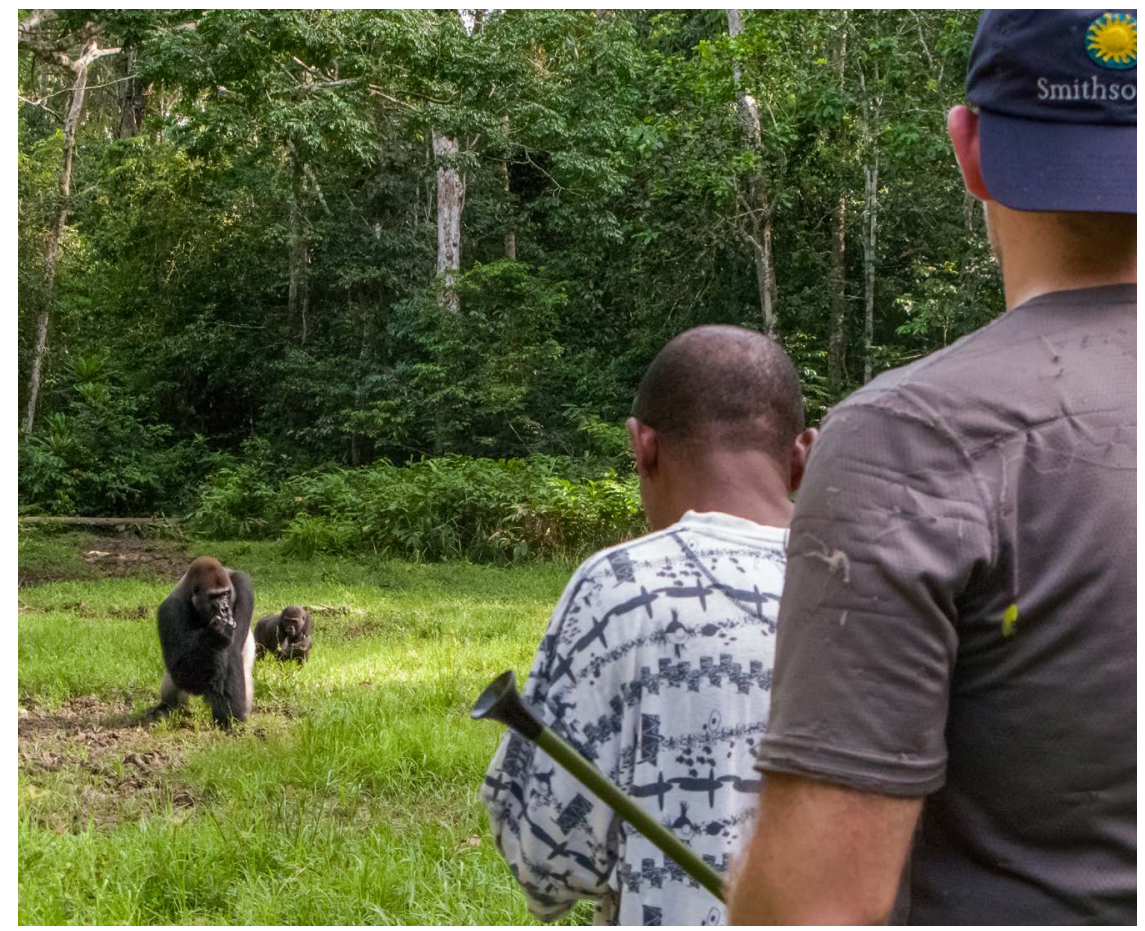

Safely darting great apes requires patience and experience. In Dzanga-Ndoki NP, Central African Republic, a veterinarian conceals a blowpipe behind his back to help minimise disturbance to the gorillas and allow for successful darting (c) Chris Whittier \& Angelique Todd. Intervention team members should stay close together and stand with experienced field staff to ensure personal safety

To administer medicine or an anaesthetic drug, the veterinarian will usually use a blowpipe, or a pipeshaped dart projector, or a projector that looks and operates like a regular firearm but instead of firing a bullet, it will shoot a dart syringe that is preloaded with the drug.

Typically the veterinarian needs to be close enough to the great ape that he/she can aim to dart the ape in a large muscle mass, such as its rump or upper leg. The animal may become uneasy or frightened if it sees the dart gun and move away from the veterinarian, and failed (as well as successful) darting-shots are likely to make it even warier. For these reasons, it can take hours or even days for the veterinarian to get into a good position to dart a great ape. Immobilising animals in trees should be avoided, but if necessary, animals darted in trees must be watched carefully and continuously once darted, and team members should be positioned under the tree with a net to catch the ape once it falls.

If the ape is successfully darted, the dart is designed to stay in it's muscle long enough to ensure that the syringe fully expels the drug. The animal will often move away from the perceived source of the dart and it may pull out the dart. Because the dart may still contain traces of the drug, it should only be picked up or removed from the animal's body (once anaesthetised) by the veterinarian or veterinary assistant, who can also judge whether the animal has received a sufficient dose.

While protocols for chemical immobilisation (anaesthesia) of great apes are well established, there is always a chance that an immobilisation will not go as planned; for example, an animal may be under-dosed with the anaesthetic drug because its body weight was underestimated, or the illness that is affecting the ape is also affecting its response to the drugs. In such situations, the veterinarian will decide how to proceed: he/she may give the animal a second dose of anaesthetic, or may decide to administer a drug that reverses the effects of the anaesthetic so that it will wake up more quickly.

If a great ape is darted with an immobilising drug, it will likely experience the effects of anaesthesia within 5-15 minutes, depending on the drug(s) used. Once it is immobile, the veterinarian will assess its level of anaesthesia and, if the animal is in a deep enough state of anaesthesia, the procedure can begin. If the animal is stable under anaesthesia, the veterinarian will conduct a physical examination, treat the animal as needed (e.g., remove a snare, clean and treat a wound), and take biological samples for health assessment and diagnostic testing (see Section 4.2.4). Throughout the operation, the veterinary assistant will monitor the animal closely to make sure that it is breathing well and that its heart rate and body temperature are within normal limits. The veterinary assistant will also record data, including physiologic information (e.g., body temperature, heart rate, blood pressure) and anatomic data (e.g., estimated or measured body weight, morphometric measurements, dental formulas), and will provide supplies and equipment to the veterinarian and label specimens.

When the examination, sampling and/or treatment has been completed, the team will gather up all equipment and supplies and waste, then-depending on the presence of other animals-retreat from the immediate area around 


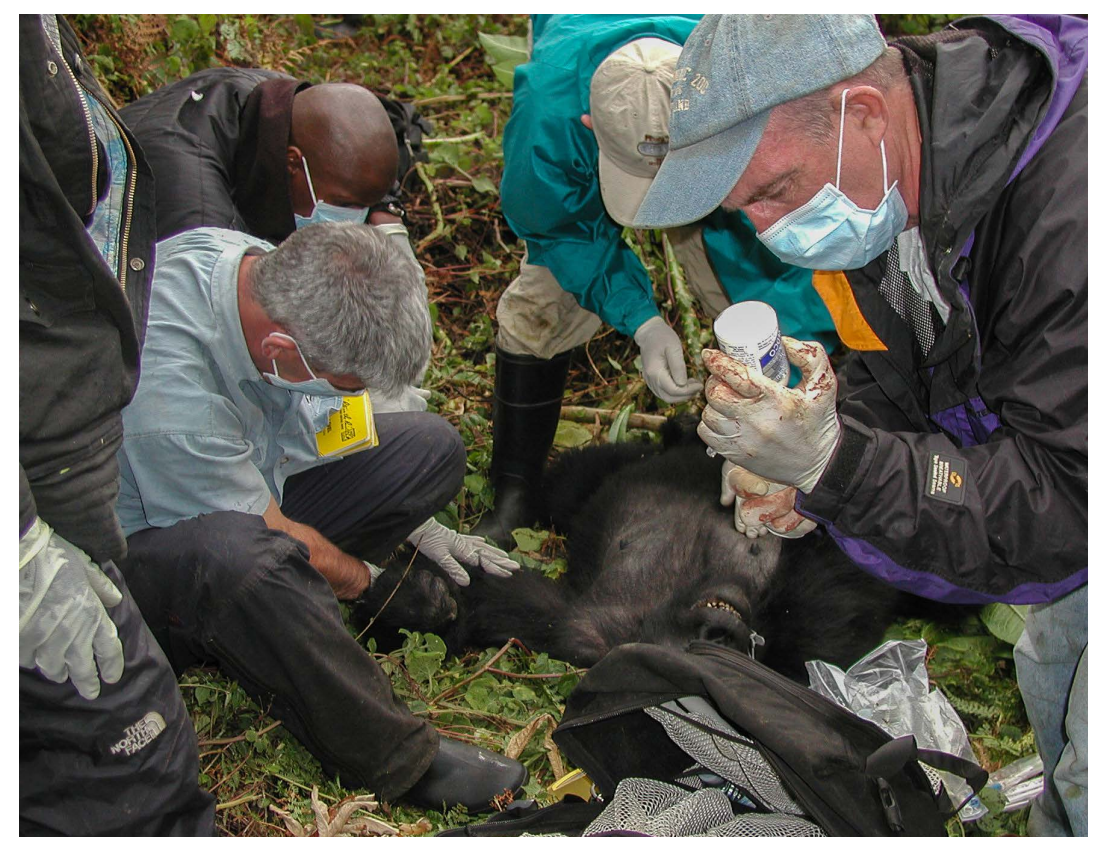

In Volcanoes NP, Rwanda, veterinarians treat and collect samples from an anaesthetised mountain gorilla that was suffering from significant hair loss and thought to be infected with scabies mites $\odot$ MGVP/DFGFI

the individual that has been treated. The veterinarian may then give the animal a dose of a drug that counteracts the effects of the anaesthetic, to help the animal recover more quickly.

\subsubsection{Biological sampling}

As stated in Section 4.2, it is vital to maximise the benefits of clinical interventions by safely and properly collecting diagnostic samples (e.g., hair, blood, urine, mucosal swabs). At a minimum, when a great ape is immobilised, the following samples should be collected by the veterinarian or an experienced technician or researcher during anaesthesia:

- Blood

- Nasal swab

- Mouth swab

If possible, the following samples should also be obtained from anaesthetised apes:

- Rectal swab

- Penile/vaginal swabs

- Ocular swab

- Urine

- Faeces

- Hair

- Milk

- Ectoparasites

It is crucial that great apes treated for any reason are properly monitored post-procedure by the veterinarian and technicians or researchers who are familiar with those individuals. This is the only way to evaluate treatment effectiveness, to make decisions about further treatment, and to improve future efforts with other animals. Post-procedure monitoring (within hours of the intervention) should verify whether the individual has successfully resumed normal behaviour (e.g., feeding, locomotion) and returned to its family members. Because the initial 24 hours post-procedure are the most critical for the patient's health and safety, short-term follow-up monitoring should occur within 12-24 hours and continue daily until the individual appears to be fully recovered from its illness or injury.

\subsection{Vaccination Considerations}

The purpose of vaccinating a person or animal is to increase the chance that, if infected with the pathogen targeted by the vaccine, the individual will already have developed a sufficient level of immunity due to vaccination that the infection can be eliminated before it causes illness and spreads to other individuals. Another important purpose of vaccinating a person or animal is to build up the immunity of a population. Vaccinating individuals ensures that there 
are sufficient numbers of immune individuals in the population such that, even if introduced, a pathogen cannot spread sufficiently within the population to cause an outbreak.

While domestic animals can be protected from many significant infectious diseases (e.g., rabies, distemper) in part through vaccination, the same cannot be said for protecting free-ranging individuals or populations. This is for a variety of reasons; for example, there is little incentive on the part of pharmaceutical companies to do the research, development and testing necessary to produce vaccines that are proven to be effective and safely applied to wildlife. Also, some vaccines require multiple booster doses administered over time to become effective. It is challenging enough to deliver a vaccine to a free-ranging animal once, let alone multiple times, which makes it extremely challenging to sufficiently vaccinate the majority of animals in a wild population under most circumstances. That said, vaccination should be carefully considered in certain situations, for example, if a disease is affecting an intensively-managed or rare wildlife species where vaccinating individuals is possible and justifiable, or if mass vaccination will help control disease transmission in a population and thereby save many animals.

\subsubsection{Vaccinating great apes}

Great apes in captivity are commonly vaccinated against human diseases (and with human vaccines, because vaccines are not formulated for great apes). In such situations, this is easily justified due to the risk to the animals through their close contact with people. However, to date, there are only rare examples of situations in which freeranging great apes have been vaccinated to protect them from disease. In the late 1980s, a severe outbreak of respiratory disease occurred in mountain gorillas in Rwanda, affecting three of the seven gorilla groups habituated at that time (Hastings et al. 1991). Evidence from dead gorillas suggested that the outbreak was perhaps due to measles virus. After close consultation with the government and wildlife veterinary experts from around the world, a decision was made to vaccinate as many of the remaining habituated gorillas as possible (excluding infants and pregnant females) with a human measles vaccine ${ }^{9}$. Anecdotally, elsewhere in the world, wild great apes have been vaccinated against measles, polio and anthrax with no immediately apparent adverse effects in situations where these diseases were either highly suspected or confirmed to be causing severe illness or mortality in a wild population.

Currently, the pathogens of great concern for African apes are the ebolaviruses, because most are highly lethal to great apes and ape populations at some sites have been devastated (see Section 6.1). Human clinical trials are underway to develop vaccines for Ebolavirus. Some experimental vaccines have proven effective at protecting primates in captivity from Ebola virus disease (EVD) after exposure and to be safe for administering to captive apes (e.g., Warfield et al. 2014; Ye \& Yang 2015). For this reason, there has been discussion of the feasibility of developing the means to vaccinate free-ranging chimpanzees and gorillas to try to prevent further disastrous losses (Ryan \& Walsh 2011). However, because immunisation campaigns are complicated, costly and may require multiple booster immunisations (requiring long-term commitment to the effort) the practicality of administering an Ebolavirus vaccine to even habituated great apes is debatable, although experimental vaccines for human health protection requiring just a single dose show promise (Henao-Restrepo et al. 2015). Furthermore, achieving a population-level effect would typically require vaccinating both habituated and unhabituated animals, and the latter could not be approached closely enough for safe vaccine administration. See Leendertz et al. (submitted) for a discussion of the feasibility of and challenges to vaccinating great apes against Ebolavirus and a review of candidate vaccines.

\subsubsection{Deciding to vaccinate}

Whether or not to vaccinate great apes in the wild should be considered very carefully, and performed only if a threat is evident, or if the consequences of not intervening to mitigate infectious disease would be catastrophic (see Ryan \& Walsh 2011). Vaccination may be considered if other disease prevention and control methods described elsewhere in this document have failed to reduce or eliminate the threat of a particular disease. More specifically, vaccination may be considered if the following criteria can be met:

i) A specific pathogen is known or suspected to be causing widespread and severe disease (past or present) in great apes;

ii) Members of the ape population are sufficiently habituated to the presence of humans that the vaccine can be safely and effectively delivered to identifiable individuals;

9 In 1988, 65 gorillas were vaccinated, and while no new cases of respiratory illness were observed after the vaccination campaign began, it was not determined whether this was due to vaccination or natural disease course. 
iii) A safe and effective vaccine for the specific pathogen has been developed for use in humans (or ideally, great apes);

iv) Any previous reports of significant adverse consequences of use of the vaccine in primates have been given due consideration; and

v) One or more skilled and experienced veterinary team(s) is/are available to plan, implement and then monitor the outcome of a vaccination programme, in close collaboration with PAA staff.

\subsection{Euthanasia Considerations}

Despite best efforts to effectively treat an illness or injury and thereby alleviate suffering and the risk of death in a great ape, it is always possible that such efforts will not alleviate suffering or will have little to no chance of averting death. For example, a severely injured adult or an extremely dehydrated and undernourished infant may be first encountered in the final stages of its injury or illness, at which point the medications and nursing care that could be delivered are insufficient to reverse the course of disease.

Euthanasia is defined as inducing death with minimal pain and distress. Euthanasia procedures are designed to make the death of an animal as painless, rapid and stress free as possible. Typically, an animal will first be heavily sedated or anaesthetised, and then be given an overdose of an anaesthetic agent that will cause it to stop breathing and the heart to stop beating.

It is extremely important that the PAA consults closely with site personnel, a veterinary team and any researchers who may be studying the affected animal to consider all possible actions for great apes suffering from an illness or injury that cannot be alleviated with clinical care. Collectively, the choice can be made to:

- Do nothing - 'let nature take its course';

- Conduct an emergency health intervention (see Section 5.3), acknowledging that the intervention may be futile in reversing the course of disease and may cause death;

- Humanely euthanise the animal to alleviate its suffering.

Euthanasia should be performed only by a veterinary team with the expertise, knowledge, equipment and supplies necessary for the procedure. This again involves proper contingency planning for proper execution. The drugs used for anaesthesia and euthanasia are extremely potent and therefore dangerous if used by people who do not have the experience and qualifications needed to handle and administer them.

If euthanasia is carried out by a veterinary team using an overdose of anaesthetic drugs, the team should attempt to collect ante-mortem samples and conduct a full post-mortem examination to determine the cause of illness or injury and to collect a full set of diagnostic samples (see Section 4.2.5). After the post-mortem examination, the carcass should be buried or burned to prevent scavenging by other animals, because the anaesthetic drugs remaining in the carcass could be toxic for scavengers.

\section{Section 6. Health Issues of Concern in Great Ape Populations}

Health monitoring and disease surveillance and research around the world have produced a significant body of scientific evidence of the impacts of disease on great apes. Information in the following sections is intended to provide the reader with an overview of diseases of particular concern at the human-great ape interface.

\subsection{Viral Diseases}

Numerous viral pathogens have been described in great apes and some of them have been linked to disease (Calvignac-Spencer et al. 2012). For example, the strain of simian immunodeficiency virus, SIVcpz, found in eastern chimpanzees (Pan troglodytes schweinfurthii) was long considered to be non-pathogenic, but through long-term monitoring and data collection, we now know that SIVcpz infection is associated with reduced reproduction, AIDSlike symptoms including susceptibility to infection with other pathogens, and increased mortality in some infected animals (Keele et al. 2009). Most viruses coevolve closely with their vertebrate hosts, but some viruses have the capacity for 'spillover' into other species. For example, SIVcpz did not originate as a chimpanzee virus, but rather resulted from the recombination of virus strains carried by two species of monkey. Another example of interspecies transmission of a virus is simian T-cell leukaemia virus-1 (STLV-1), which can be transmitted to chimpanzees when they eat red colobus monkeys (Leendertz et al. 2004). Conversely, human viruses have been reported to infect and 
kill great apes, including suspected poliovirus in eastern chimpanzees in Tanzania (Goodall 1986) and northern Democratic Republic of Congo (Kortlandt 1996), suspected measles in mountain gorillas (Hastings et al. 1991) and confirmed pneumoviruses in western chimpanzees and mountain gorillas (Köndgen et al. 2008; Palacios et al. 2011). Moreover, rescued great apes in rehabilitation and re-introduction facilities are at risk of contracting viruses from captive conspecifics, other wildlife and from human caretakers: eastern chimpanzees have been infected with human-related viruses such as adenoviruses, gamma herpesviruses and hepatitis B virus (Mugisha et al. 2011); bonobos (Pan paniscus) have suffered from disease due to encephalomyocarditis virus infection (Jones et al. 2011); Bornean (Pongo pygmaeus) and Sumatran (Pongo abelii) orangutans, as well as eastern gorillas (Gorilla beringei), have also shown evidence of exposure to, or infection with, several human viruses (Warren et al. 1999; Kilbourn et al. 2003; Whittier 2009). It is because of the high risk of contracting disease in captivity that strict re-introduction guidelines have been developed: when rescued apes are released into areas of natural habitat, disease prevention and control measures are critical to protecting resident wildlife (Beck et al. 2007).

\subsubsection{Ebolaviruses}

Ebolaviruses were first identified in 1976. Currently five species are recognised within the genus Ebolavirus, of which two - Zaire ebolavirus and Tai Forest ebolavirus - are highly lethal to chimpanzees and gorillas. Ebolavirus has not yet been detected in bonobos or orangutans ${ }^{10}$.

Ebola virus disease (EVD) is suspected to have caused the large-scale gorilla and chimpanzee losses in Gabon and Republic of Congo that coincided with confirmed EVD in other wildlife and/or humans (Leroy et al. 2004). While Ebolavirus has been confirmed in gorilla and chimpanzee carcasses (Wittman et al. 2007), the numbers of great apes that have died due to Ebolavirus infections can only be estimated through retrospective data analysis and mathematical modelling. These analyses, whether conducted on a national (Gabon) or population level (e.g., Lossi Sanctuary and Lokoué Bai) suggest substantial great ape population declines (e.g., Walsh et al. 2003; Bermejo et al. 2006; Genton et al. 2012). The challenge to more accurately measuring mortality due to pathogens like Ebolavirus is that in many situations, the total numbers of animals living in a population is unknown to begin with, so the proportion affected by a specific disease has to be estimated. Fortunately, new tools for detecting the presence of antibodies against Ebolavirus in gorilla and chimpanzee faeces may help us to better understand population level exposure (Reed et al. 2014; see also IUCN 2014).

Ebolaviruses are spread through direct contact with body fluids of infected animals or people. The route by which great apes become infected has not been confirmed, but is suspected to be direct or indirect contact with a reservoir species, likely fruit bats, and/or contact with an infected animal carcass (Leroy et al. 2004, 2009), or direct contact with other infected great apes (Caillaud et al. 2006). Fruit bats in southwestern Uganda, within kilometres of gorilla habitat, have been shown to be a wildlife reservoir for the closely related Marburg virus (Towner et al. 2009), which is known to cause mortality in humans and other primates.

The incubation period of Ebolavirus in great apes is unknown, although likely to be similar to human incubation periods, which average 11 days (WHO Ebola Response Team 2014). Clinical signs of diagnosed EVD outbreaks in great apes have not been seen during outbreaks; however, just prior to an EVD outbreak in Taï NP, researchers saw chimpanzees exhibiting signs of abdominal pain, lethargy and poor appetite from one to six days prior to their disappearance or death (Formenty et al. 1999). Ebolavirus can persist in primate carcasses for up to seven days following death (Prescott et al. 2015).

\subsection{Bacterial Diseases}

While a variety of bacteria are considered to be normal and non-pathogenic, some bacterial infections pose a threat to the health and survival of great apes. For example, a novel anthrax bacterium Bacillus cereus biovar anthracis is lethal to gorillas and chimpanzees and has been found in Cameroon, Central African Republic and Ivory Coast (Klee et al. 2010); Pasteurella multocida and Streptococcus pneumoniae played a role in a respiratory disease outbreak in western chimpanzees (Chi et al. 2007; Köndgen et al. 2008); potentially human-derived gastrointestinal bacteria and multi-drug-resistant bacteria have been detected in great apes living in human-disturbed habitat (Nizeyi et al. 2001; Rwego et al. 2008); and pathogenic strains of Staphylococcus aureus have been isolated in wild chimpanzees (Schaumburg et al. 2012), while Campylobacter jejuni associated with diarrhoea has been documented in mountain gorillas (Whittier et al. 2010).

10 Nidom et al. (2012) claimed evidence of Ebola in orangutans, but see PLoS One Editors (2013). 


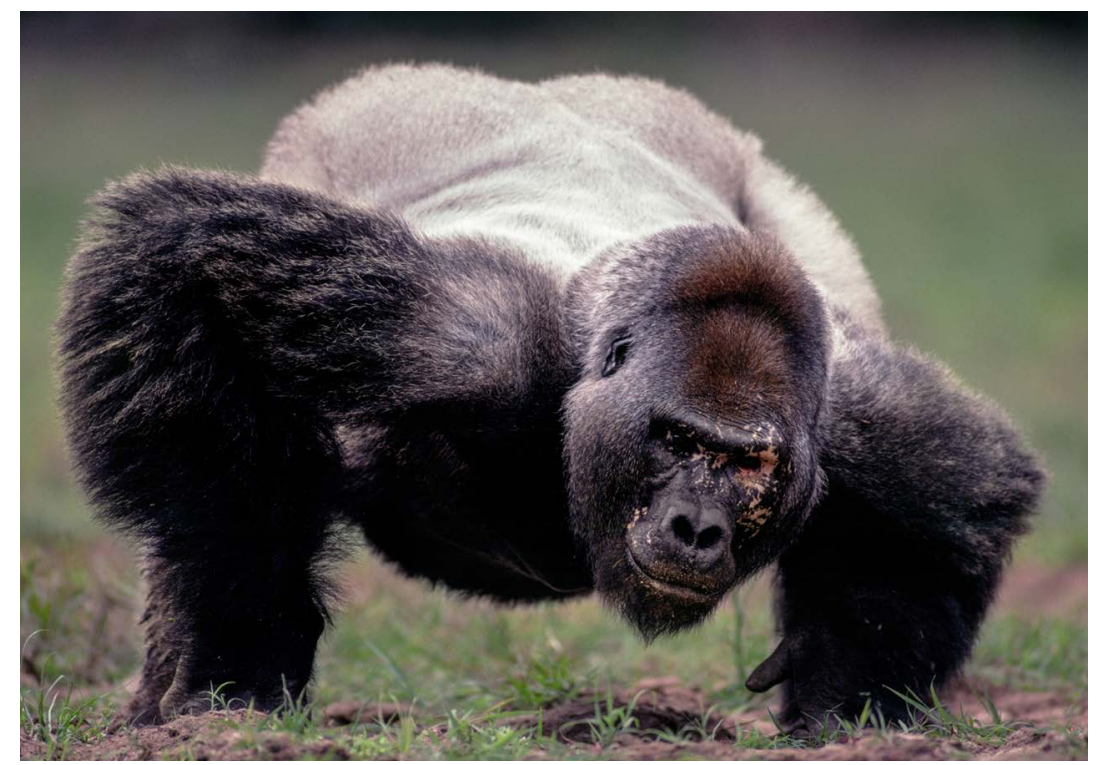

Silverback western lowland gorilla pauses while drinking water from an elephant footprint; his face shows distinct depigmented patches or scars, possibly caused by either a fungal infection, or a yaws-like infection caused by the spirochaete bacteria Treponema spp. Odzala-Kokoua NP, Republic of Congo () Jabruson 2015. All Rights Reserved

Tuberculosis (TB) is caused by Mycobacterium tuberculosis and is transmitted primarily through close contact with people suffering from the disease (although it can also be transmitted through contact with contaminated objects). A novel strain of Mycobacterium was recently confirmed in a western chimpanzee (Coscolla et al. 2013); nonetheless, transmission of TB from humans to great apes is far less likely in their natural habitat than it is in a captive setting (Wolf et al. 2014). However, Mycobacterium bovis-infected livestock are presumed to present a risk to wild great apes (Wolf et al. 2014).

Yaws is a disfiguring disease caused by a bacterium called Treponema pallidum pertenue that used to be prevalent among children in tropical Africa and Asia. A relatively localised outbreak of yaws was eradicated from a baboon (Papio hamadryas anubis) population in Tanzania using antibiotics (Wallis \& Lee 1999); however, a similar infection appears to be widespread in great apes in Gabon and Republic of Congo. Although not yet proven to be caused by Treponema, a yaws-like skin and bone disease causes significant physical impairment in gorillas and may influence the reproductive success of males (Levréro et al. 2007).

\subsection{Parasitic Diseases}

Generally speaking, parasite infections do not cause severe clinical signs of disease, or if they do, disease is usually chronic (i.e. a low-level, long-term illness) rather than acute. Gastrointestinal parasite infections in great apes occur through direct contact or ingestion of eggs or larvae of the parasite in contaminated food, water, faeces or soil. Among the most prevalent and important great ape nematode (worm) parasites are the strongyle worms, which have the capacity to cause disease and death, although degrees of pathogenicity vary (e.g., Labes et al. 2011). For example, while the nodular worm (Oesophagostomum spp.) is common in chimpanzees (Gillespie et al. 2010; Zommers et al. 2013), it is not always pathogenic: chimpanzees with nodular worms in Uganda and Ivory Coast do not exhibit clinical signs (Krief et al. 2008), whereas chimpanzees in Gombe NP and Mahale NP, Tanzania, suffer from nodular worm-related illness (Huffman et al. 1997). Similarly, gapeworms (Mammomonogamus sp.) infect the respiratory tract of orangutans and can cause severe disease, whereas in western gorillas gapeworms cause no visible illness (Collet et al. 1986; Mul et al. 2007; Masi et al. 2012).

The close phylogenetic relationship between humans and great apes results in opportunities for parasite exchange, as is the case with other microorganisms. There has been a common assumption that the presence of a parasite in both humans and primates implies transmission; however, only molecular techniques applied to the parasites can provide definitive information about whether human parasites are truly transmissible to great apes and vice versa (e.g., Ghai et al. 2014a; Hasegawa et al. 2014; Sak et al. 2014). For example, using molecular techniques, it is now known that some whipworms (Trichuris sp.) are shared by chimpanzees and people (Ghai et al. 2014b).

Several field-based studies have confirmed primate-human overlap in the distribution of pathogenic protozoa such as Giardia sp. and Cryptosporidium sp. (e.g., Gillespie et al. 2009; Hogan et al. 2014; Sak et al. 2014; Parsons et al. 2015). While most species of amoeba that infect great apes are nonpathogenic, there are exceptions: Entamoeba histolytica and Neobalantidium coli have been described in various free-ranging primates, including chimpanzees, gorillas and orangutans, using the same habitat as humans (e.g., Mul et al. 2007; Gillespie et al. 2010; Kuze et al. 2010; Hassell et al. 2013; Zommers et al. 2013). Both parasites have the potential to cause disease in great 
This adult female chimpanzee in Gombe NP, Tanzania, with severe mange (scabies) lost all her hair, which left her vulnerable to other infections and to environmental stresses, such as cold temperatures and sunlight $\odot$ Anne Pusey. Three suckling infants died during the 1997 outbreak (Wallis \& Lee 1999). Great apes are typically unable to recover from such a severe ectoparasite infection without treatment

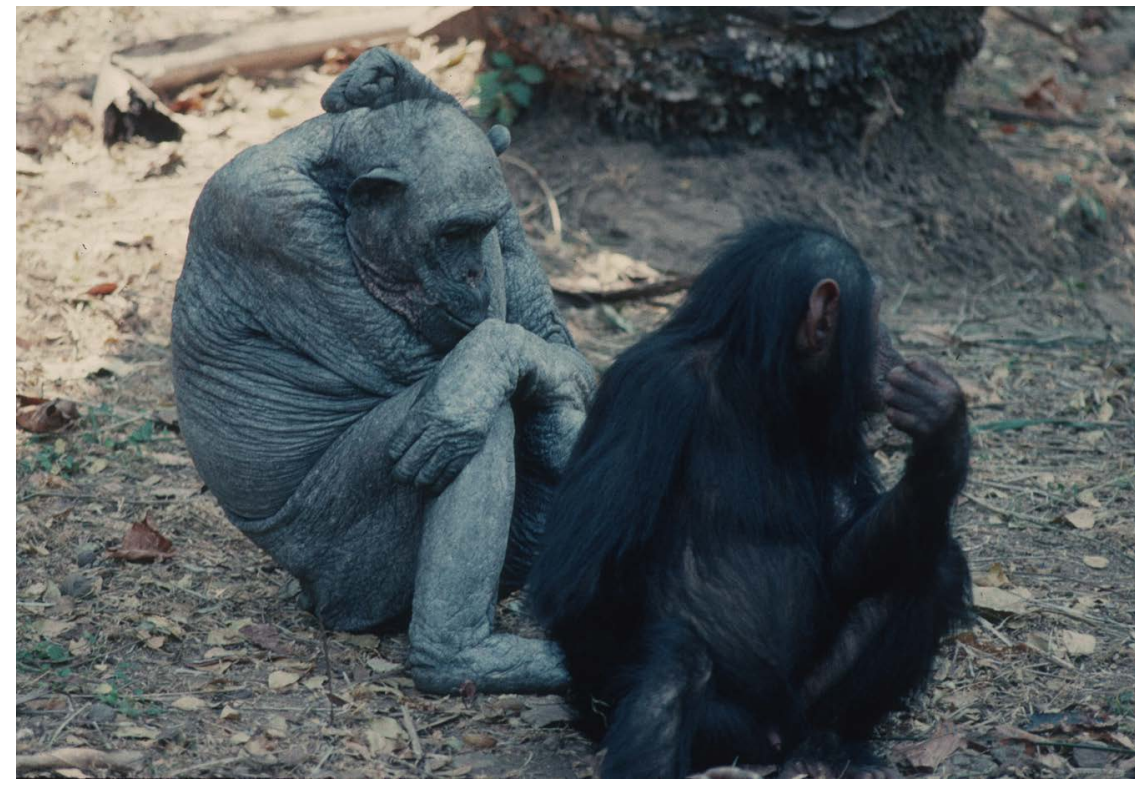

apes and people, but molecular techniques to determine the source of these parasites in great apes have not been applied to samples from great apes in the wild.

The parasite that causes malaria, Plasmodium, is a current focus of active research, with new information regarding the genetics of the various Plasmodium species in great apes helping scientists to better understand the origins of malaria in people. For the purposes of this document, it is important to understand that many species of the malaria parasite, which is borne by mosquitoes, infect many different primate hosts, including great apes, but the clinical effects and importance of these infections are under investigation (Krief et al. 2010; Liu et al. 2010; Kaiser et al. 2010; Rayner et al. 2011). In Africa, various species of the malaria parasite are endemic in chimpanzees (De Nys et al. 2013, 2014), western gorillas and eastern gorillas; and great apes are thought to be the reservoir for $P$. vivax, to which most Africans are resistant but which is dangerous for travellers in Africa. To date, no plasmodia have been detected in mountain gorillas (which live at high altitudes where mosquitoes are less prevalent). Malaria infections are common in orangutans in rehabilitation facilities and, while infections are sometimes associated with fever and anaemia, generally speaking Plasmodium does not appear to cause severe disease (Wolfe et al. 2002; Reid et al. 2006; Pacheco et al. 2012). Although the malaria parasite does not appear to cause lethal disease in great apes, plasmodia are able to cross species hosts (Singh et al. 2004; Liu et al. 2010), and human encroachment into forested areas likely facilitates host switching by malarial parasites (Cox-Singh \& Singh 2008). Alterations in animal density, particularly in rehabilitation centres, could contribute to the interchange of these various plasmodia.

Lastly, ectoparasite (e.g., tick and mite) infestations have been reported to cause disease in great apes. For example, mountain gorillas have been documented to suffer from severe skin disease and hair loss, causing mortality in infant gorillas, due to infection with the mite Sarcoptes scabiei, which causes scabies in humans, and Pangorillalges gorillae (Graczyk et al. 2000; Kalema-Zikusoka et al. 2002; Nutter et al. 2005).

\subsection{Special Topic: Respiratory Disease}

Respiratory disease, including 'influenza-like' illness, has long been recognised as an important cause of morbidity and mortality among great apes, particularly those habituated to human presence for tourism or research purposes (e.g., Hanamura et al. 2008; Morton et al. 2013). For example, a significant proportion of chimpanzee mortality in Gombe NP between 1960 and 2006 was associated with signs of respiratory disease (Wallis \& Lee 1999; Williams et al. 2008). Respiratory disease can be caused by a variety of pathogens (e.g., viruses, bacteria, fungi). Clinical signs observed in great apes suffering respiratory infections are similar to those seen in humans and include elevated respiratory rates, laboured breathing, sneezing, nasal discharge and coughing. When they are very ill with respiratory disease, great apes typically have little or no appetite and show signs of weakness, such as resting more than usual or not keeping up with other animals.

Respiratory pathogen transmission from humans is suspected to account for a number of outbreaks observed in habituated African apes. For example, a study of chimpanzees in Taï NP has demonstrated that human-associated respiratory viruses (human metapneumovirus, hMPV, and human respiratory syncytial virus, hRSV) have been repeatedly introduced into chimpanzee populations at this site, and investigations of multiple outbreaks revealed that chimpanzees have died from pneumonia caused by human viral and bacterial respiratory pathogens (Köndgen 
et al. 2008, 2010). Similarly, human metapneumovirus has been documented to cause illness in chimpanzees in Mahale NP (Kaur et al. 2008) and in mountain gorillas in Rwanda (Palacios et al. 2011). While infection with a respiratory virus alone is rarely fatal in great apes, it is often complicated by secondary infection with bacteria that contribute to pneumonia and death. For example, chimpanzees infected with hRSV or hMPV at Taï also became infected with the common bacterium Streptococcus pneumoniae, which causes pneumonia in humans and other species. A mountain gorilla that was infected with hMPV died of Streptococcus and Klebsiella bacterial pneumonia (ibid.).

\section{Synopses of Some Scientific Papers that Demonstrate Transmission of Disease from Humans to Great Apes and vice versa}

Kilbourn et al. 2003. Health evaluation of free-ranging and semi-captive orangutans (Pongo pygmaeus) in Sabah, Malaysia. Journal of Wildlife Diseases 39: 73-78. This report was one of the first comprehensive health assessments of wild orangutans, with samples obtained from 84 wild and 64 semi-captive live orangutans in Sabah, Malaysia. The authors used serologic tests to demonstrate that wild orangutans were exposed to a variety of infectious diseases of possible human origin. There were some significant differences in exposure between wild and semi-captive orangutans, with semi-captive orangutans showing more evidence of exposure to human pathogens than their wild counterparts. Interestingly, the authors also detected a change of exposure to mumps from $0 \%$ in 1996 and 1997 to $45 \%$ of animals positive for mumps antibodies in 1998 , suggesting that both wild and semi-captive orangutans were infected with the mumps virus, during a time when there was an increase of mumps cases in people in Malaysia.

Leroy et al. 2004. Multiple Ebola virus transmission events and rapid decline of Central African wildlife. Science 303: 387-390. This paper reviewed the history of several human Ebola outbreaks and described the extreme impact that these outbreaks were having on great ape populations. Based on the frequency with which researchers encountered freshly dead carcasses of western lowland gorilla and chimpanzees during random transects through the forest, they estimated that perhaps hundreds if not thousands of great apes died during Ebola outbreaks in the region. When they compared census counts of known populations of western lowland gorillas and chimpanzees before and after an Ebola outbreak, they documented 50-88\% declines in the numbers of animals present.

Köndgen et al. 2008. Pandemic human viruses cause decline of endangered great apes. Current Biology 18: 260-264. This paper directed the world's attention to the threat that human pathogens pose to great apes. It reported on the first proof that viruses had transmitted from humans to great apes. Specifically, tissues collected from chimpanzees that died during respiratory disease outbreaks in Taï National Park contained two human viruses (respiratory syncytial virus and metapneumovirus) known to cause upper respiratory infections in people. These chimpanzees had been habituated to the presence of humans for research purposes, and the viruses detected in their tissues were closely related to known human strains, sharing a common viral ancestor going back 3-8 years.

Palacios et al. 2011. Human metapneumovirus infection in mountain gorillas, Rwanda. Emerging Infectious Diseases 17: 711-713. This report described a group of mountain gorillas habituated for tourism purposes that was severely affected by a respiratory disease outbreak in Volcanoes National Park, Rwanda, in 2009. An adult female died during the outbreak; post-mortem evaluation and laboratory testing of tissues collected from her carcass showed that while the immediate cause of death was bacterial pneumonia, that the initial cause of the respiratory disease was a human metapneumovirus. A newborn infant gorilla born to another very ill adult female likely died of neglect, but post-mortem evaluation and laboratory testing on tissues collected from its carcass showed that multiple organs were infected with the same human virus. This was the first conclusive evidence for a human virus causing the deaths of Critically Endangered mountain gorillas.

Coscolla et al. 2013. Mycobacterium tuberculosis complex isolate from a wild chimpanzee. Emerging Infectious Diseases 19: 969-976. This publication documented for the first time a TB infection in a free-ranging great ape-a chimpanzee in Taï National Park. It was caused by a strain of the TB agent that was closely genetically related to a human-associated lineage of Mycobacterium africanum, a strain of Mycobacteria that infects people in West Africa. This finding was important because it established the fact that wild great apes could be infected with Mycobacteria. Prior to this report, all known cases of TB in great apes were in captive individuals living in artificial environments in very close contact with people. For example, orangutans in sanctuaries and rehabilitation facilities in Borneo and Sumatra have been diagnosed with TB (e.g., Kilbourn et al. 2003). The report from Taï catalysed a review of the potential for TB transmission to wild great apes (Wolf et al. 2014). 
Whether or not to intervene to mitigate disease in wild populations is a critical decision to be made by a PAA. While drugs are readily available to treat some diseases, such as scabies, medications for the specific treatment of viral infections are essentially not available-care for a sick great ape suffering from a viral infection is generally supportive (e.g., fluids, antibiotics to treat secondary bacterial infections) and can be intensive. As stated above, PAAs should develop an intervention policy before needing to make urgent decisions regarding whether or not to treat an ill/injured great ape (see Section 5.1).

\section{Section 7. Conclusions}

As people come into ever closer and more frequent contact with wild great apes around the world, the risk that human pathogens will be introduced to great apes becomes greater, and the potential for disease to decimate great ape populations is of paramount concern. It is, therefore, critical that all programmes involving close proximity between great apes and humans thoroughly assess the risks entailed in that high level of contact, and establish and implement disease prevention and control measures. Ideally, PAAs and great ape researchers, veterinarians, tourism operators and others who come into close proximity with great apes will embrace the following principles, which form the foundation for the best practice recommendations stated herein:

$\diamond$ Applying best practice to avoid transmission of human pathogens to great apes is an ethical obligation at all tourism and research sites.

$\diamond$ It is generally easier and more economical to prevent the transmission of a human pathogen to a great ape (individual or population) than to attempt to treat, control or eradicate a disease problem once introduced. Therefore, it is best practice for all Protected Area Authorities, and great ape tourism and research projects, to give the highest priority to the implementation of disease prevention programmes.

$\diamond$ It is not possible to achieve zero risk; however, the cumulative effect of making concerted efforts to comply with recommendations for disease prevention will substantially reduce the risk that human pathogens pose to great apes.

$\diamond$ Applying the precautionary principle to recommended best practices for great ape health is warranted. In other words, in the absence of scientific evidence that a disease agent or human action or policy is or is not a risk or harmful to great apes, it is safest to assume that such agents or actions do pose a health risk to great apes until scientifically proven otherwise.

$\diamond$ Assessing and improving the health of the people who work in great ape habitat, especially those who are frequently in close proximity to wild great apes, is imperative for protecting great ape health.

\section{Section 8. Acknowledgements}

First, we wish to convey our sincere appreciation to the following, whose original concepts and texts contributed significantly to the development of these guidelines: Ken Cameron, Mike Cranfield, Lynne Gaffikin, Gladys KalemaZikusoka, Sophie Köndgen, Siv Leendertz, Elizabeth Lonsdorf, Michael Muehlenbein, Lawrence Mugisha, John Bosco Nizeyi, Felicia Nutter, Klára Petrželková, Trish Reed, Innocent Rwego, Benard Ssebide and Steve Unwin. We are also very grateful to the reviewers who generously contributed their time and expertise to improving this document: Marc Ancrenaz, Caroline Asiimwe, Anna Behm Masozera, Thomas Breuer, Damien Caillaud, Chloe Cipolletta, Christelle Colin, Anthony Collins, Kay Farmer, Rosa Garriga, Tony Goldberg, David Greer, Kimberly Hockings, Jaco Homsy, David Hyeroba, William Karesh, Richard Kock, Linda Lowenstine, Magdalena Lukasik-Braum, Shelly Masi, Helen McCracken, Blake Morton, Sarah Olson, Steve Osofsky, Jan Ramer, Martha Robbins, Anne Russon, lan Singleton, Fransiska Sulistyo, Jo Thompson, Angelique Todd and Janette Wallis. As always, our gratitude to Anthony Rylands for his skilled editorial input.

For kindly allowing the use of their photographs, many thanks to the following: Luke Berman, Paco Bertolani, LuAnne Cadd, Damien Caillaud, Ronan Donovan, Gorilla Doctors, David Hyeroba, International Animal Rescue, Jabruson, Sonja Metzger, Jim Moore, Ian Nichols, Helen Parrish, Wolfram Rietschel, Erik Scully, lan Singleton, Taï Chimpanzee Project and Chris Whittier (with thanks to MGVP). And for assistance liaising with photographers, we thank Jessica Hartel, Karmele Llano Sánchez, Silent Heroes Foundation and Thomson Safaris. 
Compilation of these guidelines was made possible in part by the US Agency for International Development Emerging Pandemic Threats PREDICT project; contents are the responsibility of the authors and do not necessarily reflect the views of USAID or the US Government. Institutional support to the authors was provided by the Cummings School of Veterinary Medicine at Tufts University, Emory University, Robert Koch Institute, Smithsonian Institution and University of Minnesota. Publication was generously funded by the Arcus Foundation and the USFWS Great Ape Conservation Fund.

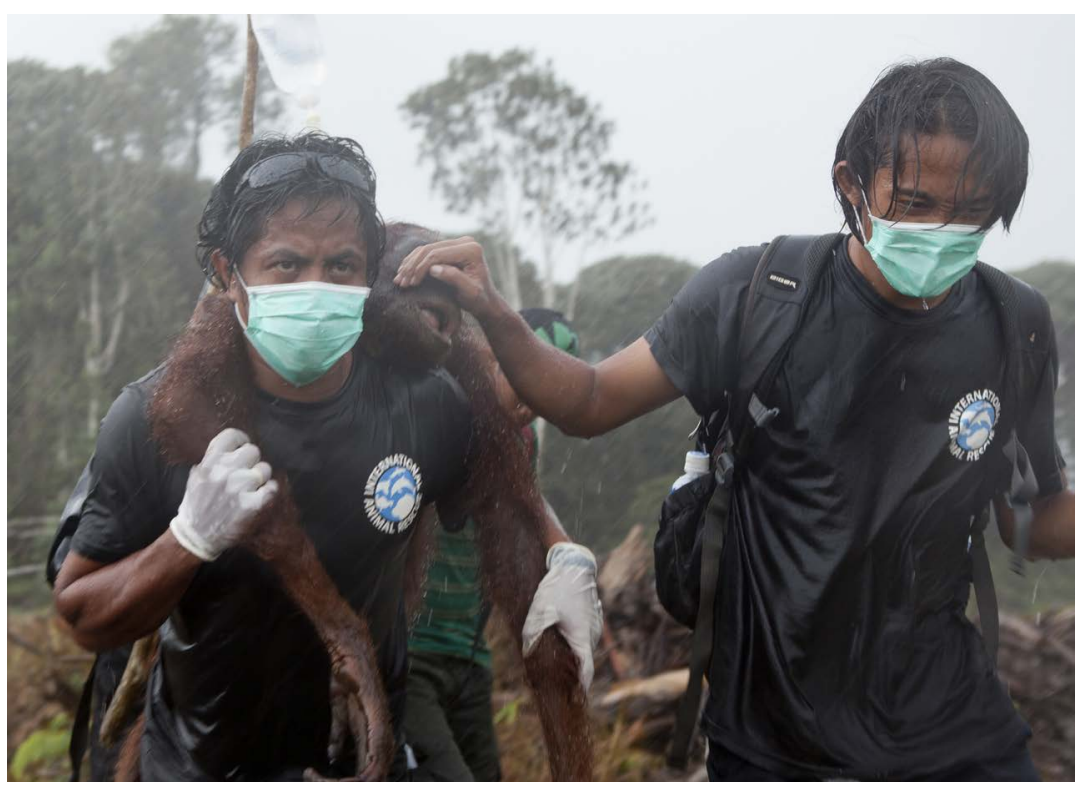

Rescue workers wearing masks evacuate an anaesthetised orangutan from a newly-created oil palm plantation in Indonesia (c) Alejo Sabugo. Disease prevention measures are also relevant to translocations-ideally both rescue workers would be wearing disposable gloves and long sleeves

\section{Section 9. Acronyms \& Glossary}

Acute - an illness with a rapid onset and a short duration

Chronic - an illness of prolonged duration

Clinical signs - objective evidence of disease as seen by an observer

Close proximity -7 to 10 metres

Disease - an abnormal condition of a body part or whole animal resulting in, and characterised by, an identifiable set of clinical signs

Endemic - naturally present in a population

Epidemic - an occurrence of disease in a population that exceeds normal levels of that disease

Epidemiology - the study of the patterns, causes and effects of health and disease conditions in defined populations Fomite - any object or substance capable of carrying infectious organisms, such as germs or parasites, and hence transferring them from one individual to another

Group - any great ape social unit. Gorillas reside in groups. Bonobos and chimpanzees live in communities, but are often found in parties or mother-infant pairs. Orangutans are usually solitary, except for mother-infant units

Health - a state of sound physical well-being, generally characterised by an absence of disease (illness or injury)

Incubation period - the time elapsed between infection and when symptoms of illness are first apparent

Infectious period - the time period during which an infected individual can transmit a pathogen to another individual

Morbidity - the state of being ill or diseased

Naïve - not previously exposed to a particular pathogen and therefore possibly lacking immunity to the pathogen

Non-invasive - not requiring direct contact with (touching) an animal 
NP - National Park

NTFP - non-timber forest product

Outbreak - occurrence of a disease in a population at a greater than normal or expected level

Pathogen - a bacterium, virus or other microorganism, including some parasites, that can cause disease

Pathogenic - causing disease

Pathology - the study of disease

Phylogenetic relatedness - close evolutionarily ancestor

PA - Protected Area

PA+ manager - PAA or conservation project or research site manager

PA+ personnel - PAA or project staff

PA+ site - Protected Area or great ape conservation project or research site in a non-protected area

PAA - Protected Area Authority

PPE - personal protective equipment: gloves, masks, face shields, coveralls, boots, etc.

Reservoir - a species that naturally harbours a disease agent which is transmissible to other species

TB - tuberculosis

Vector - any agent (person, animal or microorganism) that carries and transmits an infectious pathogen into another living organism

Visitors - guides, guards, trackers, tourists, researchers, veterinarians, film crews, journalists

Zoonosis/zoonotic - a disease agent transmissible between animals and humans

This adult male chimpanzee in Kibale NP, Uganda, lost his hand in a snare injury when he was a juvenile $\odot$ Ronan Donovan. Snare removal teams carry out the essential work of searching for and disabling illegal snares, which are indiscriminate and capable of causing permanent handicap

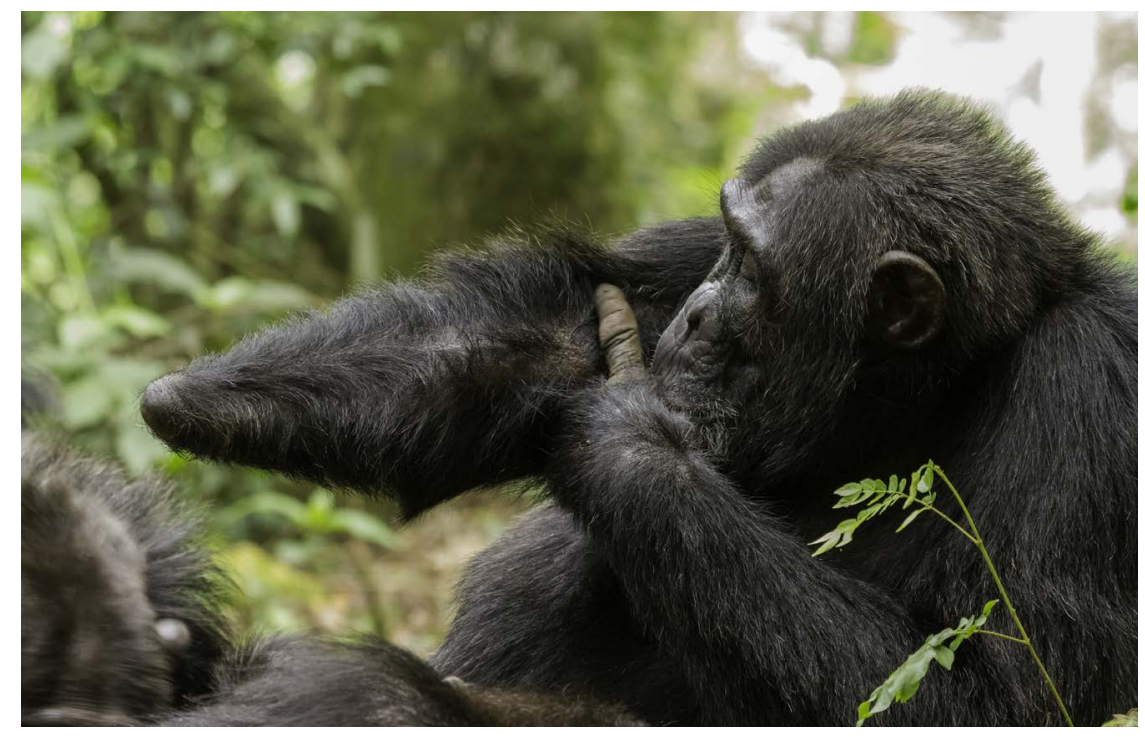

\section{Section 10. Literature Cited}

Ali, R., Cranfield, M., Gaffikin, L., Mudakikwa, T., Ngeruka, L. \& Whittier, C. (2004). Occupational health and gorilla conservation in Rwanda. International Journal of Occupational Environmental Health 10: 319-325.

Beck, B., Walkup, K., Rodrigues, M., Unwin, S., Travis, D. \& Stoinski, T. (2007). Best Practice Guidelines for the Re-introduction of Great Apes. IUCN/SSC Primate Specialist Group, Gland, Switzerland.

Bermejo, M., Rodríguez-Teijeiro, J.D., Illera, G., Barroso, A., Vilà, C. \& Walsh, P.D. (2006). Ebola outbreak killed 5000 gorillas. Science 314: 1564.

Caillaud, D., Levréro, F., Cristescu, R., Gatti, S., Dewas, M., Douadi, M., Gautier-Horn, A., Raymond, M. \& Menard, N. (2006). Gorilla susceptibility to Ebola virus: the cost of sociality. Current Biology 16: R489-R491.

Calvignac-Spencer, S., Leendertz, S.A., Gillespie, T.R. \& Leendertz, F.H. (2012). Wild great apes as sentinels and sources of infectious disease. Clinical Microbiology and Infection 18: 521-527.

Carne, C., Semple, S., Morrogh-Bernard, H., Zuberbühler, K. \& Lehmann, J. (2014). The risk of disease to great apes: simulating disease spread in orang-utan (Pongo pygmaeus wurmbii) and chimpanzee (Pan troglodytes schweinfurthii) association networks. PLoS One 9: e95039. 
Chi, F., Leider, M., Leendertz, F., Bergmann, C., Boesch, C., Schenk, S., Pauli, G., Ellerbok, H. \& Hakenbeck, R. (2007). New Streptococcus pneumonia clones in deceased wild chimpanzees. Journal of Bacteriology 189: 6085-6088.

Collet, J.Y., Galdikas, B.M.F., Sugarjito, J. \& Jojosudharmo, S. (1986). A coprological study of parasitism in orangutans (Pongo pygmaeus) in Indonesia. Journal of Medical Primatology 15: 121-129.

Coscolla, M., Lewin, A., Metzger, S., Maets-Rennsing, K., Calvignac-Spencer, S. et al. (2013). Novel Mycobacterium tuberculosis complex isolate from a wild chimpanzee. Emerging Infectious Diseases 19: 969-976.

Cox-Singh, J. \& Singh, B. (2008). Knowlesi malaria: newly emergent and of public health importance? Trends in Parasitology 24: 406-410.

Cranfield, M. \& Minnis, R. (2007). An integrated health approach to the conservation of mountain gorillas Gorilla beringei beringei. International Zoological Yearbook 41: 110-121.

Decision Tree Writing Group (2006). Clinical response decision tree for the mountain gorilla (Gorilla beringei) as a model for great apes. American Journal of Primatology 68: 909-927.

De Nys, H.M., Calvignac-Spencer, S., Thiesen, U., Boesch, C., Wittig, R.M., Mundry, R. \& Leendertz, F.H. (2013). Age-related effects on malaria parasite infection in wild chimpanzees. Biology Letters 9: 20121160.

De Nys, H.M., Calvignac-Spencer, S., Boesch, C., Darny, P., Wittig, R.M., Mundry, R. \& Leendertz, F.H. (2014). Malaria parasite detection increases during pregnancy in wild chimpanzees. Malaria Journal 13: 413.

Foley, J., Clifford, D., Castle, K., Cryan, P. \& Ostfeld, R.S. (2011). Investigating and managing the rapid emergence of whitenose syndrome, a novel, fatal infectious disease of hibernating bats. Conservation Biology 25: 223-231.

Formenty, P., Boesch, C., Wyers, M., Steiner, C., Donati, F., Dind, F., Walker, F. \& Le Guenno, B. (1999). Ebola virus outbreak among wild chimpanzees living in a rain forest of Côte d'Ivoire. Journal of Infectious Diseases 179: S120-126.

Gao, F., Bailes, E., Robertson, D.L., Chen, Y., Rodenburg, C.M. et al. (1999). Origin of HIV1 in the chimpanzee Pan troglodytes troglodytes. Nature 387: 436-441.

Genton, C., Cristescu, R., Gatti, S., Levréro, F., Bigot, E., Caillaud, D., Pierre, J.S. \& Menard, N. (2012). Recovery potential of a western lowland gorilla population following a major Ebola outbreak: results from a ten year study. PLoS One 7: e37106.

Ghai, R.R., Chapman, C.A., Omeja, P.A., Davies, T.J. \& Goldberg, T.L. (2014a). Nodule worm infection in humans and wild primates in Uganda: cryptic species in a newly identified region of human transmission. PLoS Neglected Tropical Diseases 8: e2641.

Ghai, R.R., Simons, N.D., Chapman, C.A., Omeja, P.A., Davies, T.J., Ting, N. \& Goldberg, T.L. (2014b). Hidden population structure and cross-species transmission of whipworms (Trichuris sp.) in humans and non-human primates in Uganda. PLoS Neglected Tropical Diseases 8: e3256.

Gilardi, K.V.K., Oxford, K., Gardner-Roberts, D., Kinani, J.F., Spelman, L., Barry, P., Cranfield, M.R. \& Lowenstine, L.J. (2014). Human herpes simplex virus type 1 in a confiscated gorilla. Emerging Infectious Diseases 20: 1883-1886.

Gillespie, T.R., Nunn, C.L. \& Leendertz, F.H. (2008). Integrative approaches to the study of primate infectious disease: implications for biodiversity conservation and global health. American Journal of Physical Anthropology 51: 53-69.

Gillespie, T.R., Lonsdorf, E.V., Cranfield, E.P., Meyer, D.J., Nadler, Y. et al. (2010). Demographic and ecological effects on patterns of parasitism in eastern chimpanzees (Pan troglodytes schweinfurthii) in Gombe National Park, Tanzania. American Journal of Physical Anthropology 143: 534-544.

Gillespie, T.R., Morgan, D., Deutsch, J.C., Kuhlenschmidt, M.S., Salzer, J.S., Cameron, K., Reed, P. \& Sanz, C. (2009). A legacy of low impact logging does not elevate prevalence of potentially pathogenic protozoa in free-ranging chimpanzees and lowland gorillas in the Republic of Congo. EcoHealth 6: 557-564.

Goldberg, T.L., Gillespie, T.R., Rwego, I.B., Wheeler, E., Estoff, E.L. \& Chapman, C.A. (2007). Patterns of gastrointestinal bacterial exchange between chimpanzees and humans involved in research and tourism in western Uganda. Biological Conservation 135: 511-517.

Goodall, J. (1986). The Chimpanzees of Gombe: Patterns of Behavior. Harvard University Press, Cambridge, MA.

Graczyk, T.K., Mudakikwa, A.B., Cranfield, M.R. \& Eilenberger, U. (2001). Hyperkeratotic mange caused by Sarcoptes scabiei (Acariformes: Sarcoptidae) in juvenile human-habituated mountain gorillas (Gorilla gorilla beringei). Parasitology Research 87: 1024-1028.

Guschanski, K., Vigilant, L., McNeilage, A., Gray, M., Kagoda, E. \& Robbins, M.M. (2009). Counting elusive animals: comparing field and genetic census of the entire mountain gorilla population of Bwindi Impenetrable National Park, Uganda. Biological Conservation 142: 290-300.

Hanamura, S., Kiyono, M., Lukasik-Braum, M., Mlengeya, T., Fujimoto, M., Nakamura, M. \& Nishida, T. (2008). Chimpanzee deaths at Mahale caused by a flu-like disease. Primates 49: 77-80.

Hasegawa, H., Modry, D., Kitagawa, M., Shutt, K.A., Todd, A., Kalousova, B., Profousova, I. \& Petrzelkova, K. (2014). Humans and great apes cohabitating the forest ecosystem in Central African Republic harbour the same hookworms. PLoS Neglected Tropical Diseases 8: e2715.

Hassell, J.M., Blake, D.P., Cranfield, M.R., Ramer, J., Hogan, J.N., Noheli, J.B., Waters, M. \& Hermosilla, C. (2013). Occurrence and molecular analysis of Balantidium coli in mountain gorillas (Gorilla beringei beringei) in the Volcanoes National Park, Rwanda. Journal of Wildlife Diseases 49: 1063-1065.

Hastings, B.E., Kenny, D., Lowenstine, L.J. \& Foster, J.W. (1991). Mountain gorillas and measles: ontogeny of a wildlife vaccination program. In: Proceedings of the American Association of Zoo Veterinarians and American Association of Wildlife Veterinarians, R.E. Junge (ed.), Oakland, CA, pp. 301-302.

Henao-Restrepo, A., Longini, I.M., Egger, M., Dean, N.E., Edmunds, W.J. et al. (2015). Efficacy and effectiveness of an rVSVvectored vaccine expressing Ebola surface glycoprotein: interim results from the Guinea ring vaccination cluster-randomised trial. The Lancet 386: 857-866.

Hockings, K. \& Humle, T. (2009). Best Practice Guidelines for the Prevention and Mitigation of Conflict between Humans and Great Apes. IUCN/SSC Primate Specialist Group, Gland, Switzerland.

Hogan, J.N., Miller, W.A., Cranfield, M.R., Ramer, J., Hassell, J., Noheri, J.B., Conrad, P.A. \& Gilardi, K.V.K. (2014). Giardia in mountain gorillas (Gorilla beringei beringei), forest buffalo (Syncerus caffer), and domestic cattle in Volcanoes National Park, Rwanda. Journal of Wildlife Diseases 50: 21-30.

Homsy, J. (1999). Ape Tourism and Human Diseases: How Close Should We Get? International Gorilla Conservation Programme, Nairobi. 
Huffman, M.A., Gotoh, S., Turner, L.A., Hamai, M. \& Yoshida, K. (1997). Seasonal trends in intestinal nematode infection and medicinal plant use among chimpanzees in the Mahale Mountains, Tanzania. Primates 38: 111-125.

IUCN (2014). Regional Action Plan for the Conservation of Western Lowland Gorillas and Central Chimpanzees 2015-2025. IUCN SSC Primate Specialist Group, Gland, Switzerland. www.primate-sg.org/action_plans

IUCN (2015). IUCN Red List of Threatened Species. Version 2015.4. www.iucnredlist.org

IUCN \& OIE (2014). Guidelines for Wildlife Disease Risk Analysis. World Organisation for Animal Health (OIE), Paris. www.iucnwhsg.org/DRA

Janatova, M., Albrechtova, K., Petrzelkova, K.J., Dolejska, M., Papousek, I. et al. (2014). Antimicrobial-resistant Enterobacteriaceae from humans and wildlife in Dzanga-Sangha Protected Area, Central African Republic. Veterinary Microbiology 171: 422-431.

Jensen, S.A., Mundry, R., Nunn, C.L., Boesch, C. \& Leendertz, F.H. (2009). Non-invasive body temperature measurement of wild chimpanzees using fecal temperature decline. Journal of Wildlife Diseases 45: 542-546.

Johnson, D.F., Druce, J.D., Birch, C. \& Grayson, M.L. (2009). A quantitative assessment of the efficacy of surgical and N95 masks to filter influenza virus in patients with acute influenza infection. Clinical Infectious Diseases 49: 275-277.

Jones, P., Cordonnier, N., Mahamba, C., Burt, F.J., Rakotovao, F., Swanepoel, R., André, C., Dauger, S. \& Bakkali Kassimi, L. (2011). Encephalomyocarditis virus mortality in semi-wild bonobos (Pan paniscus). Journal of Medical Primatology 40: 157-163.

Jones, R.M. \& Brosseau, S.D. (2015). Aerosol transmission of infectious disease. Journal of Occupational and Environmental Medicine 57: 501-508.

Kaiser, M., Löwa, A., Ulrich, M., Ellerbok, H., Goffe, A.S. et al. (2010). Wild chimpanzees infected with 5 Plasmodium species. Emerging Infectious Diseases 16: 1956-1959.

Kalema-Zikusoka, G, Kock, R.A. \& Macfie, E.J. (2002). Scabies in free-ranging mountain gorillas (Gorilla beringei beringei) in Bwindi Impenetrable National Park, Uganda. Veterinary Record 150: 12-15.

Karesh, W.B. \& Cook, R.A. (2005). The human-animal link. Foreign Affairs 84: 38-50.

Kaur, T., Singh, J., Tong, S., Humphrey, C., Clevenger, D. et al. (2008). Descriptive epidemiology of fatal respiratory outbreaks and detection of a human-related metapneumovirus in wild chimpanzees (Pan troglodytes) at Mahale Mountains National Park, western Tanzania. American Journal of Primatology 70: 755-765.

Keele, B.F, Jones, J.H., Terio, K.A., Estes, J.D., Rudicell, R.S. et al. (2009). Increased mortality and AIDS-like immunopathology in wild chimpanzees infected with SIVcpz. Nature 460: 515-519.

Kilbourn, A.M., Karesh, W.B., Wolfe, N.D., Bosi, E.J., Cook, R.A. \& Andau, M. (2003). Health evaluation of free-ranging and semicaptive orangutans (Pongo pygmaeus pygmaeus) in Sabah, Malaysia. Journal of Wildlife Diseases 39: 73-83.

Klee, S.R., Brzuszkiewicz, E.B., Nattermann, H., Brüggemann, H., Dupke, S. et al. (2010). The genome of a Bacillus isolate causing anthrax in chimpanzees combines chromosomal properties of B. cereus with B. anthracis virulence plasmids. PLoS One 5: e10986.

Knott, C.D. (1998). Changes in orangutan caloric intake, energy balance, and ketones in response to fluctuating fruit availability. International Journal of Primatology 19: 1061-1079.

Köndgen, S., Kühl, H., N'Goran, P.K., Walsh, P.D., Schenk, S. et al. (2008). Pandemic human viruses cause decline in endangered great apes. Current Biology 18: 260-264.

Köndgen, S., Schenk, S., Pauli, G., Boesch, C. \& Leendertz, F.H. (2010). Noninvasive monitoring of respiratory viruses in wild chimpanzees. EcoHealth 7: 332-341.

Kortlandt, A. (1996). An epidemic of limb paresis (polio?) among the chimpanzee population at Beni (Zaire) in 1964, possibly transmitted by humans. Pan Africa News 3: 9-10.

Krief, S., Escalante, A.A., Pacheco, M.A., Mugisha, L., André, C. et al. (2010). On the diversity of malaria parasites in African apes and the origin of Plasmodium falciparum from bonobos. PLoS Pathogens 6: e1000765.

Krief, S., Jamart, A., Mahe, S., Leendertz, F.H., Matz-Rensing, K., Crespeau, F., Bain, O. \& Guillot, J. (2008). Clinical and pathologic manifestation of oesophagostomosis in African great apes: does self-medication in wild apes influence disease progression? Journal of Medical Primatology 37: 188-195.

Kuze, N., Kanamori, T., Malim, T.P., Bernard, H., Zamma, K., Kooriyama, T., Morimoto, A. \& Hasegawa, H. (2010). Parasites found from the feces of Bornean orangutans in Danum Valley, Sabah, Malaysia, with a redesciption of Pongobius hugoti and the description of a new species of Pongobius (Nematoda; Oxyuridae). Journal of Parasitology 96: 954-960.

Labes, E.M., Nurcahyo, W., Deplazes, P. \& Mathis, A. (2011). Genetic characterization of Strongyloides spp. from captive, semicaptive and wild Bornean orangutans (Pongo pygmaeus) in Central and East Kalimantan, Borneo, Indonesia. Parasitology 138: 1417-1422.

Leendertz, F.H., Boesch, C., Rietschel, W., Ellerbrok, H. \& Pauli, G. (2004). Non-invasive testing reveals a high prevalence of STLV-1 antibodies in wild adult chimpanzees of the Taï National Park, Côte d'Ivoire. Journal of General Virology 85: 3305-3312.

Leendertz, F.H., Pauli, G., MaetzRensing, K., Boardman, W., Nunn, C., Ellerbrok, H., Jensen, S.A., Junglen, S. \& Boesch, C. (2006). Pathogens as drivers of population declines: the importance of systematic monitoring in great apes and other threatened mammals. Biological Conservation 131: 325-337.

Leendertz, S.A.J., Metzger, S., Skjerve, E., Deschner, T., Boesch, C., Riedel, J. \& Leendertz, F.H. (2010). A longitudinal study of urinary dipstick parameters in wild chimpanzees (Pan troglodytes verus) in Côte d'Ivoire. American Journal of Primatology 72: 689-698.

Leendertz, S.A.J., Wich, S.A., Ancrenaz, M., Bergl, R.A., Gonder, M.K., Humle, T. \& Leendertz, F.H. (submitted). Ebola in great apes - current knowledge, possibilities for vaccination and the implications for conservation and human health.

Leroy, E.M., Rouquet, P., Formenty, P., Souquiére, S., Kilbourn, A. et al. (2004). Multiple Ebola virus transmission events and rapid decline of central African wildlife. Science 303: 387-390.

Leroy, E.M., Epelboin, A., Mondonge, V., Pourrut, X., Gonzalez, J.P., Muyembe-Tamfum, J.J. \& Formenty, P. (2009). Human Ebola outbreak resulting from direct exposure to fruit bats in Luebo, Democratic Republic of Congo, 2007. Vector-Borne and Zoonotic Diseases 9: 723-728.

Lessler, J., Reich, N.G., Brookmeyer, R., Perl, T.M., Nelson, K.E. \& Cummings, D.A.T. (2009). Incubation periods of acute respiratory viral infections: a systematic review. Lancet Infectious Diseases 9: 291-300.

Levréro, F., Gatti, S., Gautier-Hion, A. \& Ménard, N. (2007). Yaws disease in a wild gorilla population and its impact on the reproductive status of males. American Journal of Physical Anthropology 132: 568-575. 
Liu, W.M., Li, Y.Y., Learn, G.H., Rudicell, R.S., Robertson, J.D. et al. (2010). Origin of the human malaria parasite Plasmodium falciparum in gorillas. Nature 467: 420-427.

Lonsdorf, E.V., Travis, D., Pusey, A.E. \& Goodall, J. (2006). Using retrospective health data from the Gombe chimpanzee study to inform future monitoring efforts. American Journal of Primatology 68: 897-908.

Macfie, E.J. \& Williamson, E.A. (2010). Best Practice Guidelines for Great Ape Tourism. IUCN/SSC Primate Specialist Group, Gland, Switzerland.

Masi, S., Chauffour, S., Bain, O., Todd, A., Guillot, J. \& Krief, S. (2012). Seasonal effects on great ape health: a case study of wild chimpanzees and western gorillas. PLoS One 7: e49805.

MGVP 2002 Employee Health Group (2004). Risk of disease transmission between conservation personnel and the mountain gorillas. EcoHealth 1: 351-361.

Monto, A.S. (2002). Epidemiology of viral respiratory infections. American Journal of Medicine 112(6A): 4S-12S.

Morgan, D., Sanz, C., Greer, D., Rayden, T., Maisels, F. \& Williamson, E.A. (2013). Great Apes and FSC: Implementing 'Ape Friendly' Practices in Central Africa's Logging Concessions. IUCN/SSC Primate Specialist Group, Gland, Switzerland.

Morton, F.B., Todd, A.F., Lee, P. \& Masi, S. (2013). Observational monitoring of clinical signs during the last stage of habituation in a wild western gorilla group at Bai Hokou, Central Africa Republic. Folia Primatologica 84: 118-133.

Muehlenbein, M.P., Ancrenaz, M., Sakong, R., Ambu, L. \& Prall, S. (2012). Ape conservation physiology: fecal glucocorticoid responses in wild Pongo pygmaeus morio following human visitation. PLoS One 7: e33357.

Mugisha, L., Kücherer, C, Ellerbrok, H., Junglen, S., Opuda-Asibo, J., Joseph, O., Pauli, G., Ehlers, B. \& Leendertz, F.H. (2011). Multiple viral infections in confiscated wild born semi-captive chimpanzees (Pan troglodytes schweinfurthii) in a sanctuary in Uganda: implications for sanctuary management and conservation. Proceedings of the 2011 Annual Conference of the American Association of Zoo Veterinarians, Yulee, Florida, pp.190-195.

Mul, I.F., Paembonan, W., Singleton, I., Wich, S.A. \& van Bolhuis, H.G. (2007). Intestinal parasites of free-ranging, semicaptive, and captive Pongo abelii in Sumatra, Indonesia. International Journal of Primatology 28: 407-420.

Murray, C.M., Heintz, M.R., Lonsdorf, E.V., Parr, L.A. \& Santymire, R.M. (2013). Validation of a field technique and characterization of fecal glucocorticoid metabolite analysis in wild chimpanzees (Pan troglodytes). American Journal of Primatology 75: 57-64.

Nidom, C.A., Nakayama, E., Nidom, R.V., Alamudi, M.Y., Daulay, S. et al. (2012). Serological evidence of Ebola virus infection in Indonesian orangutans. PLoS One 7: e40740.

Nizeyi, J.B., Rwego, I.B., Erume, J., Kalema, G.R.N.N., Cranfield, M.R. \& Graczyk, T.K. (2001). Campylobacteriosis, salmonellosis, and shigellosis infections in human-habituated mountain gorillas of Uganda. Journal of Wildlife Diseases 37: 239-244.

Nutter, F.B., Whittier, C.A., Lowenstine, L.J. \& Cranfield, M.R. (2005). Mange caused by Pangorillalges gorillae (Fain 1962) in three Virunga mountain gorillas (Gorilla beringei beringei). Proceedings of the Wildlife Disease Association International Conference, Cairns, Australia, pp. 276-277.

Pacheco, M.A., Reid, M.J.C., Schillaci, M.A., Lowenberger, C.A., Galdikas, B.M.F., Jones-Engel, L. \& Escalante, A.A. (2012). The origin of malarial parasites in orangutans. PLoS One 7: e34990.

Palacios, G., Lowenstine, L.J., Cranfield, M.R., Gilardi, K.V., Spelman, L. et al. (2011). Human metapneumovirus infection in wild mountain gorillas, Rwanda. Emerging Infectious Diseases 17: 711-713.

Parsons, M.B., Travis, D., Lonsdorf, E.V., Lipende, I., Roellig, D.M., Collins, A., Kamenya, S., Zhang, H., Xiao, L. \& Gillespie, T.R. (2015). Epidemiology and molecular characterization of Cryptosporidium spp. in humans, wild primates, and domesticated animals in the Greater Gombe Ecosystem, Tanzania. PLoS Neglected Tropical Diseases 9: e0003529.

PLoS One Editors (2013). Expression of concern: serological evidence of Ebola virus infection in Indonesian orangutans. PLoS One 8: e60289.

Prescott, J., Bushmaker, T., Fischer, R., Miazgowicz, K., Judson, S. \& Munster, V.J. (2015). Postmortem stability of Ebola virus. Emerging Infectious Disease 21: 856-859.

Prugnolle, F., Durand, P., Neel, C., Ollomo, B., Ayala, F.J. et al. (2010). African great apes are natural hosts of multiple related malaria species, including Plasmodium falciparum. Proceedings of the National Academy of Sciences 107: 1458-1463.

Rayner, J.C., Liu, W.M., Peeters, M., Sharp, P.M. \& Hahn, B.H. (2011). A plethora of Plasmodium species in wild apes: a source of human infection? Trends in Parasitology 27: 222-229.

Reed, P.E., Cameron, K.N., Ondzie, A.U., Joly, D., Karesh, W.B. et al. 2014. A new approach for monitoring Ebolavirus in wild great apes. PLoS Neglected Tropical Diseases 8: e3143. doi:10.1371.

Reid, M.J.C., Ursic, R., Cooper, D., Nazzari, H., Griffiths, M., Galdikas, B.M., Skinner, M., Lowenberger, C. \& Garriga, R.M. (2006). Transmission of human and macaque Plasmodium spp. to ex-captive orangutans in Kalimantan, Indonesia. Emerging Infectious Diseases 12: 1902-1908.

Robbins, M.M., Gray, M., Fawcett, K.A., Nutter, F.B., Uwingeli, P. et al. (2011). Extreme conservation leads to recovery of the Virunga mountain gorillas. PLoS One 6: e19788.

Rushmore, J., Caillaud, D., Matamba, L., Stumpf, R.M., Borgatti, S.P. \& Altizer, S. (2013). Social network analysis of wild chimpanzees provides insights for predicting infectious disease risk. Journal of Animal Ecology 82: 976-986.

Rwego, I.B., Isabirye-Basuta, G., Gillespie, T.R. \& Goldberg, T.L. (2008). Gastrointestinal bacterial transmission among humans, mountain gorillas, and livestock in Bwindi Impenetrable National Park, Uganda. Conservation Biology 22: 1600-1607.

Ryan, S.J. \& Walsh, P.D. (2011). Consequences of non-intervention for infectious disease in African great apes. PLoS One 6: e29030.

Sak, B., Petrželková, K.J., Květoňová, D., Mynářová, A., Pomajbíková, K., Modrý, D., Cranfield, M.R., Mudakikwa, A. \& Kváč, M. (2014). Diversity of microsporidia, Cryptosporidium and Giardia in mountain gorillas (Gorilla beringei beringei) in Volcanoes National Park, Rwanda. PLoS One 9: e109751.

Schaumburg, F., Mugisha, L., Peck, B., Becker, K., Gillespie, T.R., Peters, G. \& Leendertz, F.H. (2012). Drug-resistant human Staphylococcus aureus in sanctuary apes pose a threat to endangered wild ape populations. American Journal of Primatology 74: 1071-1075.

Schaumburg, F., Mugisha, L., Kappeler, P., Fichtel, C., Köck, R. et al. (2013). Evaluation of non-invasive biological samples to monitor Staphylococcus aureus colonization in great apes and lemurs. PLoS One 8: e78046. 
Shutt, K., Heistermann, M., Kasim, A., Todd, A., Kalousova, B., Profosouva, I., Petrzelkova, K., Fuh, T., Dicky, J.-F., Bopalanzognako, J.-B. \& Setchell, J.M. (2014). Effects of habituation, research and ecotourism on faecal glucocorticoid metabolites in wild western lowland gorillas: implications for conservation management. Biological Conservation 172: 72-79.

Singh, B., Sung, L.K., Radhakrishnan, A., Shamsul, S.S.G., Cox-Singh, J., Matusop, A., Thomas, A. \& Conway, D.J. (2004). A large focus of naturally acquired Plasmodium knowlesi infections in human beings. Lancet 363: 1017-1024.

Skerratt, L.F., Berger, L., Speare, R., Cashins, S., McDonald, K.R., Phillott, A.D., Hines, H.B. \& Kenyon, N. (2007). Spread of chytridiomycosis has caused the rapid global decline and extinction of frogs. EcoHealth 4: 125-134.

Sleeman, J.M. \& Mudakikwa, A.B. (1998). Analysis of urine from free-ranging mountain gorillas (Gorilla gorilla beringei) for normal physiologic values. Journal of Zoo and Wildlife Medicine 29: 432-434.

Smiley Evans, T., Barry, P.A., Gilardi, K.V., Goldstein, T., Deere, J.D. et al. (2015). Optimization of a novel non-invasive oral sampling technique for zoonotic pathogen surveillance in nonhuman primates. PLoS Neglected Tropical Diseases. 9: e0003813.

Spelman, L.H., Gilardi, K.V.K., Lukasik-Braum, M., Kinani, JF., Nyirakaragire, E., Lowenstine, L.J. \& Cranfield, M.R. (2013). Respiratory disease in mountain gorillas (Gorilla beringei beringei) in Rwanda, 1990-2010: Outbreaks, clinical course and medical management. Journal of Zoo and Wildlife Medicine 44: 1027-1035.

Towner, J.S., Amman, B.R., Sealy, T.K., Reeder Carroll, S.A., Comer, J.A. et al. (2009). Isolation of genetically diverse Marburg viruses from Egyptian fruit bats. PLoS Pathogens 5: e1000536.

Travis, D.A., Hungerford, L., Engel, G.A. \& Jones-Engel, L. (2006). Disease risk analysis: a tool for primate conservation planning and decision making. American Journal of Primatology 68: 855-867.

Travis, D., Lonsdorf, E.V., Mlengeya, T. \& Raphael, J. (2008). A science-based approach to managing disease risks for ape conservation. American Journal of Primatology 70: 745-750.

UN (2009). The Millennium Development Goals Report. United Nations, New York, NY. www.refworld.org/docid/4a534f722.html

UNDP (2014). Human Development Report 2014. United Nations Development Program, New York, NY. http://hdr.undp.org/en/ content/human-development-report-2014

Wallis, J, \& Lee, D.R. (1999). Primate conservation: the prevention of disease transmission. International Journal of Primatology 20: 803-826.

Walsh, P.D., Abernethy, K.A., Bermejo, M., Beyers, R., de Wachter, P. et al. (2003). Catastrophic ape decline in western equatorial Africa. Nature 422: 611-614.

Walsh, P.D., Tutin, C.E.G., Baillie, J.E.M., Maisels, F., Stokes, E.J. \& Gatti, S. (2008). Gorilla gorilla ssp. gorilla. The IUCN Red List of Threatened Species. Version 2015.4. www.iucnredlist.org

Warfield, K.L., Goetzmann, J.E., Biggins, J.E., Kasda, M.B., Unfer, R.C., Vu, H., Aman, M.J., Olinger, G.G. \& Walsh, P.D. (2014). Vaccinating captive chimpanzees to save wild chimpanzees. Proceedings of the National Academy of Science 111: 8873-8876.

Warren, K.S., Heeney, J.L., Swan, R.A., Heriyanto \& Verschoor, E.J. (1999). A new group of hepadnaviruses naturally infecting orangutans (Pongo pygmaeus). Journal of Virology 73: 7860-7865.

Whittier, C.A. (2009). Diagnostics and Epidemiology of Infectious Agents in Mountain Gorillas. Ph.D. thesis, North Carolina State University, Raleigh, NC. www.lib.ncsu.edu/resolver/1840.16/6215

Whittier, C.A., Cranfield, M.R. \& Stoskopf, M.K. (2010). Real-time PCR detection of Campylobacter spp. in free-ranging mountain gorillas (Gorilla beringei beringei). Journal of Wildlife Diseases 46: 791-802.

WHO Ebola Response Team (2014). Ebola Virus Disease in West Africa - The first nine 9 months of the epidemic and forward projections. New England Journal of Medicine 371: 1481-1494.

Williams, J.M., Lonsdorf, E.V., Wilson, M.L., Schumacher-Stankey, J., Goodall, J. \& Pusey, A.E. (2008). Causes of death in the Kasekela chimpanzees of Gombe National Park, Tanzania. American Journal of Primatology 70: 766-777.

Williamson, E.A. \& Feistner, A.T.C. (2011). Habituating primates: processes, techniques, variables and ethics. In: Field and Laboratory Methods in Primatology: A Practical Guide. 2nd Edition. J.M. Setchell \& D.J. Curtis (eds.). Cambridge University Press, Cambridge, pp. 33-49. http://hdl.handle.net/1893/3158

Wittmann, T.J., Biek, R., Hassanin, A., Rouquet, P., Reed, P., Yaba, P., Pourrut, X., Real, L.A., Gonzalez, J.P. \& Leroy, E.M. (2007). Isolates of Zaire ebolavirus from wild apes reveal genetic lineage and recombinants. Proceedings of the National Academy of Sciences 104: 17123-17127.

Wolf, T.M., Sreevatsan, S., Travis, D., Mugisha, L. \& Singer, R.S. (2014). The risk of tuberculosis transmission to free-ranging great apes. American Journal of Primatology 76: 2-13.

Wolfe, N.D., Karesh, W.B., Kilbourn, A.M., Cox-Singh, J., Bosi, E.J., Rahman, H.A., Prosser, A.T., Singh, B., Andau, M. \& Spielman, A. (2002). The impact of ecological conditions on the prevalence of malaria among orangutans. Vector-Borne and Zoonotic Diseases 2: 97-103.

Woodford, M.H., Butynski, T.M. \& Karesh, W.B. (2002). Habituating the great apes: the disease risks. Oryx 36: 153-160.

Xie, X., Li. Y., Chwang, A.T.Y., Ho, P.L. \& Seto, H.W. (2007). How far droplets can move in indoor environments - revising the Wells evaporation-falling curve. Indoor Air 17: 211-225.

Ye, L. \& Yang, C. (2015). Development of vaccines for prevention of Ebola virus infection. Microbes and Infection 17: 98-108.

Yoshida, T., Takemoto, H., Enomoto, Y., Sakamaki, T., Sato, E. et al. (submitted). Epidemiological surveillance of lymphocryptovirus infection in wild bonobos.

Zommers, Z., Macdonald, D.W., Johnson, P.J. \& Gillespie, T.R. (2013). Impact of human activities on chimpanzee ground use and parasitism (Pan troglodytes). Conservation Letters 6: 264-273. 
Section 11. Contacts \& Resources for Further Information

\subsection{Laboratories}

Robert Koch Institute: Great Ape Health Monitoring Unit (Berlin, Germany)

Director: Fabian Leendertz

Testing: Pathogens (viruses, bacteria, parasites)

www.rki.de/EN/Content/Institute/DepartmentsUnits/ProjectGroups/P3/project_group_3.html

Emory University: Gillespie Lab (Atlanta, Georgia, USA)

Director: Thomas Gillespie

Testing: Gastrointestinal parasites and bacteria

www.envs.emory.edu/faculty/GILLESPIE/Lab.html

University of California, Davis: One Health Institute Laboratory (Davis, California, USA)

Director: Tracey Goldstein

Testing: Pathogens (viruses, bacteria)

www.vetmed.ucdavis.edu/ohi/ohi-lab/index.cfm

California National Primate Research Center: Pathogen Detection Laboratory (Davis, California, USA)

Director: Jeffrey Roberts

Testing: Viral serology

www.cnprc.ucdavis.edu/our-services/core-services/pathogen-detection-laboratory-core-2

Columbia University Center for Infection \& Immunity (New York, New York, USA)

Director: W. Ian Lipkin

Testing: Pathogens (viral)

http://cii.columbia.edu

\subsection{Global Health Information \& Reporting Websites}

Centers for Disease Control

www.cdc.gov

www.cdc.gov/healthywater/hygiene/etiquette/coughing_sneezing.html

HealthMap - Real-time information on infectious disease outbreaks

http://healthmap.org

ProMED - a real-time disease outbreak reporting system

www.promedmail.org

World Health Organization (WHO)

www.who.int

World Organization for Animal Health/Organisation Mondiale de la Santé Animale (OIE)

www.oie.int

www.oie.int/wahis_2/wah/health_v7_en.php

11.3 Additional Information

Gorilla Friendly Pledge

www.gorillafriendly.org

IUCN SSC Primate Specialist Group

www.primate-sg.org

IUCN SSC Wildlife Health Specialist Group

www.iucn-whsg.org

Supplementary information to these guidelines

www.primate-sg.org/best_practice_disease 
Appendix I. An Example of Quarantine \& Hygiene Procedures (Wittig \& Leendertz 2014 Taï Chimpanzee Project)

\section{Quarantine Camp}

For everyone: compulsory 5-day* quarantine before going to the chimpanzee research camps.

The quarantine period starts on Friday afternoon, when assistants come back to the park after their week off, and ends five days later on Wednesday afternoon. In normal routines, no one should join the quarantine later than Friday, as it will interrupt the quarantine cycle, in which case quarantine needs to start all over again. Travellers arriving on days other than Friday (international travellers or coming from Abidjan) can start their quarantine in north camp so as not to interrupt the routine quarantine.

\section{Quarantine rules}

- People showing any symptoms of illness on Friday are not allowed to enter the quarantine or any of the other camps, but must stay in the village until recovery, and then join the next quarantine period.

- People in quarantine have to wear masks when in proximity of non-quarantined people. Masks must be renewed at least once every day.

- They are allowed to do forest work except for chimpanzee and mangabey monitoring (maintenance of the trails, botany, etc.). They are not allowed to work together with people that have passed the quarantine.

- When not working, they must be in the quarantine camp and minimise contact with people from the research camps.

- Equipment attributed to the quarantine camp (kitchenware, buckets, cleaning equipment) is restricted to this camp and must not be used in the research camps.

Monitoring of respiratory virus infections

Throat swabs from every person in quarantine will be tested for two respiratory viruses (RSV and HMPV) on Day 1 (Saturday) and on Day 5 (Wednesday) of their quarantine. If all results are negative and there are no symptoms, people can move to the research camps.

What to do if someone tests positive during quarantine?

A positive result means that the first PCR screening AND the confirmation PCR are positive for RSV or HMPV.

\section{Positive result on Day 1:}

- The positive individual goes back to the village or, if not possible, can be isolated in north camp, which is then in quarantine (see north camp procedure).

- Other members from the quarantine camp are tested on Day 5 and if negative they can move to the research camps. If positive, see below.

\section{Positive result on Day 5:}

- The positive individual goes back to the village or, if not possible, can be isolated in north camp, which is then in quarantine (see north camp procedure).

- Negative individuals: quarantine is prolonged until Friday (Day 7) (ideally until Saturday if quarantine camp is free). Tests will be performed again on that day and if negative, staff can move to the research camps. If positive, apply same procedure and extend quarantine for 3 more days. If not possible because quarantine camp is not free, improvise with north camp.

\footnotetext{
* N.B. The best practice recommendation in these guidelines is that quarantine should be a minimum of 7 days
} 


\section{Throat swab testing during quarantine}

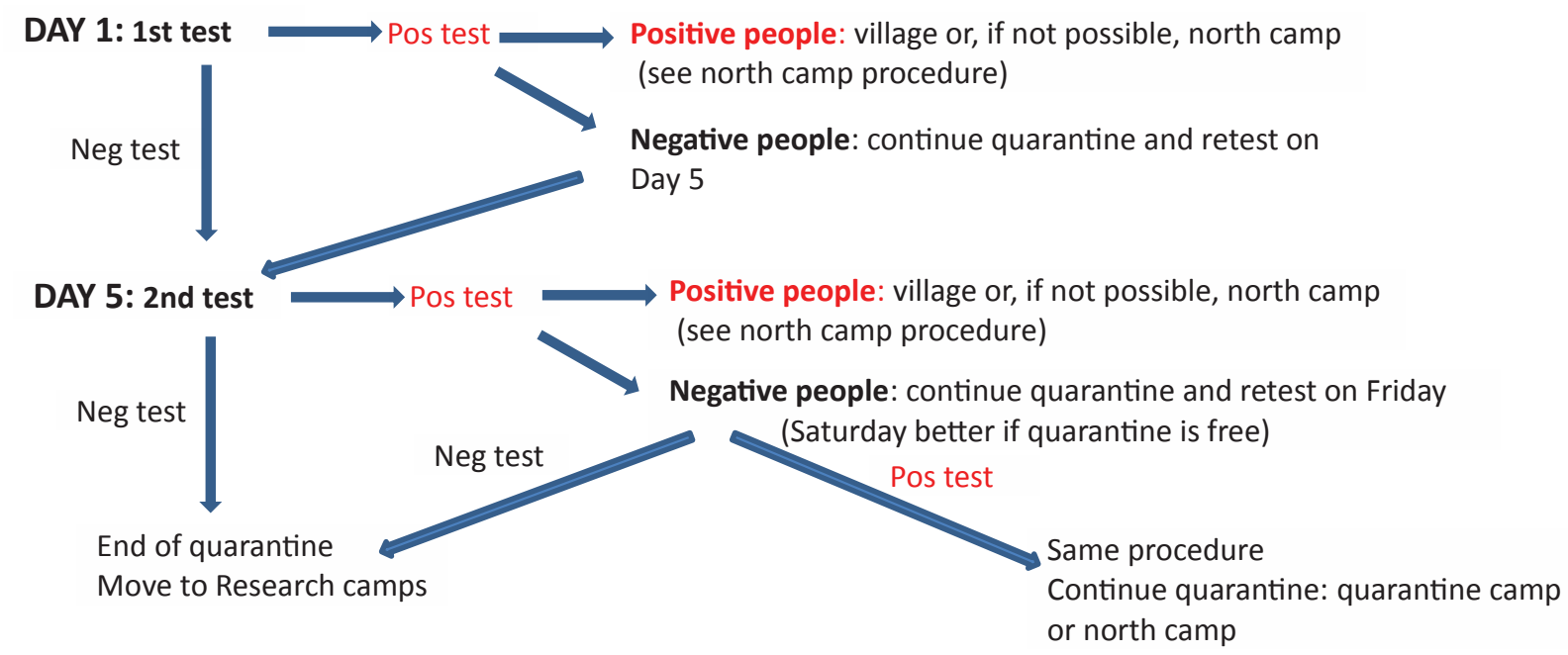

What to do if someone falls ill during quarantine?

- Isolate ill individual: any individual showing symptoms of high-risk infectious disease (definition below) must go back to the village until recovery and until he/she can join the next quarantine period (and be isolated in camp until he/she can be driven out, wearing a mask, staying in his/her room). A throat swab will be collected prior to departure and if symptoms suggest a respiratory disease (runny nose, sneezing, coughing or fever), test everyone from quarantine camp for respiratory viruses (RSV, HMPV, coronavirus, influenza, parainfluenza). If return to the village is not possible (students, volunteers, visitors), the ill individual can be isolated in north camp (see north camp procedures).

- The others continue the quarantine for 5 days after the departure of the ill individual OR until Friday if the quarantine camp is not free (arrival of a new team). On the last day, they will be tested for the virus found in the ill person (or all respiratory viruses if no specific one was found). If no symptoms are present AND tests are negative, quarantine ends and they can go to the research camps. If positive or symptoms, apply same procedure and retest after 3 days. If quarantine camp is not free, improvise with north camp.

\section{Quarantine in North Camp}

North camp can either:

a) Follow the same rhythm as the quarantine camp, in which case north camp and quarantine camp are considered as one same camp and follow the same rules (which implies they'll be quarantined every week from Friday to Wednesday); or

b) Be separate from the quarantine camp, which means:

- Minimise contact with people from quarantine camp and wear masks if in proximity

- Separate kitchen, kitchenware, bathroom and food from quarantine camp

In scenario b) the north camp will then generally not be in quarantine but can be used:

i) As a 5-day quarantine for travellers arriving on days other than Friday (international travellers or from Abidjan). In this case, everybody in north camp is quarantined together with the newly arrived person for the next 5 days. Follow the same rules and procedure as for the normal quarantine in the quarantine camp, except that people tested positive will usually have to stay in camp (visitors, students, volunteers) (see below). One EXCEPTION: if the camp manager needs to visit one of the research camps (walk to south camp/east camp/barrage to install something or talk with someone) and the new arrival interrupts his quarantine, he can semi-isolate himself from the others until he finishes his quarantine and can move to the research camps. Semi-isolation can be done by wearing a mask and following 
basic hygiene rules, bearing in mind that transmission of respiratory pathogens can occur by contamination of food and kitchenware (do not touch, do not eat together, do not socialise)!

ii) To host people who cannot go back to the village (students, volunteers, visitors) when they are ill (coming from the research camps or quarantine) or who tested positive during quarantine.

What to do if someone tests positive during quarantine in north camp?

- The positive person must wear a mask and follow basic hygiene rules (i.e. should not cook for the others, use separate kitchenware, stay mostly in room) to minimise risk of contamination of others and subsequent extension of quarantine.

- Positive on Day 1: Everybody continues quarantine and is retested on Day 5. If negative they can move to the research camps. If positive, see below.

- Positive on Day 5: Quarantine prolonged until Saturday. Tests will be performed again on that day and if negative, staff can move to the research camps. If positive, apply same procedure and extend quarantine again for 3 days.

What to do if someone falls ill during quarantine in north camp?

- The ill person must wear a mask and follow basic hygiene rules (i.e. should not cook for the others, use separate kitchenware, stay mostly in room) to minimise risk of contamination of others and subsequent extension of quarantine.

- If symptoms suggest a respiratory disease (runny nose, sneezing, coughing or fever), test everybody for respiratory viruses (RSV, HMPV, coronavirus, influenza, parainfluenza).

- Everybody continues quarantine and is tested again three days after the symptoms have disappeared. If negative the quarantine ends. If positive: continue quarantine and retest after 3 days.

What to do if someone positive from quarantine camp is sent to north camp?

- Everybody in north camp is quarantined.

- The positive person must wear a mask and follow basic hygiene rules (i.e. should not cook for the others, use separate kitchenware, stay mostly in room) to minimise risk of contamination of others and subsequent extension of quarantine.

- Everybody continues quarantine and is tested on Day 5. If negative the quarantine ends. If positive, extend quarantine and test 3 days later again.

What to do if someone ill from research camps or quarantine camp is sent to north camp?

- Everybody in north camp is quarantined.

- The ill person must wear a mask and follow basic hygiene rules (i.e. should not cook for the others, use separate kitchenware, stay mostly in room) to minimise risk of contamination of others and subsequent extension of quarantine.

- If symptoms suggest a respiratory disease (runny nose, sneezing, coughing or fever), the ill person as well as everybody from the research camp are tested for respiratory viruses (RSV, HMPV, coronavirus, influenza, parainfluenza).

- Everybody from north camp is tested three days after the symptoms have disappeared. If negative the quarantine ends. If positive: continue quarantine and retest after 3 days.

What to do if someone from north camp falls ill?

- Everybody in north camp is quarantined.

- The ill person must wear a mask and follow basic hygiene rules (i.e. should not cook for the others, use separate kitchenware, stay mostly in room) to minimise risk of contamination of others and subsequent extension of quarantine.

- If symptoms suggest a respiratory disease (runny nose, sneezing, coughing or fever), everybody from north camp is tested for respiratory viruses (RSV, HMPV, coronavirus, influenza, parainfluenza).

- Everybody from north camp is tested three days after the symptoms have disappeared, and if negative the quarantine ends. If positive: continue quarantine and retest after 3 days. 
What to do if someone falls ill in a research camp?

- Any individual showing symptoms of high-risk infectious disease (definition below) must go back to the village (and be isolated in camp until he/she can get out: wear a mask, stay in room). A throat swab will be collected prior to departure and if symptoms suggest a respiratory disease (runny nose, sneezing, coughing or fever), everyone from the research camp is tested for respiratory viruses (RSV, HMPV, coronavirus, influenza, parainfluenza). In case return to the village is not possible (students, volunteers, visitors), the ill individual can be isolated in north camp (see north camp procedures).

- Other people from the research camp must STOP working with the chimpanzees for 3 days. Other forest work can continue (cutting trails, botanic... but it is always necessary to carry a mask in case one comes across chimpanzees!). They are retested on the third day and if negative, chimpanzee work can resume. If positive, same procedure and retest everybody again 3 days later.

Symptoms of illness

As a general guideline (but any symptoms should be communicated to the vet asap, who can then decide in which category they belong):

High risk symptoms: runny nose, coughing, sneezing, fever (fever without other symptoms or fever with diarrhoea, vomiting, generalised skin rash...)

- Isolate ill person and send to the village or north camp a.s.a.p.

- In some instances people with high-risk symptoms might not be able to walk out straight away (i.e. high fever). If this is the case they need to isolate themselves in their room, wear a mask, and the camp is then in quarantine until 3 days after the ill person has left and until tests are negative.

Low risk symptoms: headache, fatigue, non-severe diarrhoea (no fever, no blood)

- Sometimes might just be due to tiredness, dehydration, bad food...

- III person must wear a mask and stay in room

- Re-evaluate the next day, if worse, send out.

\section{Movement by the Camp Manager}

The camp manager is supposed to organise and represent TCP inside and outside the forest. This implies movement between camps and also outside the forest. In order to complete his/her objectives, the camp manager will have the freedom of several exceptions from the quarantine rules. This, however, means the camp manager needs to be especially careful to monitor his/her own health. Also, the camp manager needs to plan trips and visits to the research camps as much as possible in advance in order to minimise the number of exceptions that need to be given.

- Generally: the camp manager has to pass through the quarantine before he/she can move to the research camps.

- If the quarantine of the camp manager is interrupted by a new arrival in the north camp and the manager needs to visit one of the research camps (walk to south camp/east camp/barrage to install something or discuss with someone), he/she can semi-isolate himself from the others until he/she finishes his/her quarantine and can move to the research camps. Semi-isolation can be done by wearing a mask and following basic hygiene rules, bearing in mind that transmission of respiratory pathogens can occur by contamination of food and kitchenware (do not touch, do not eat together, do not socialise)!

- If, during the quarantine, the camp manager has to attend important matter in one of the research camps, the camp manager can move to the specific research camp to solve the problem while wearing a mask and keeping to the hygiene rules (washing/disinfecting hands, etc.). During these visits it is important not to touch, not to eat together and not to socialise with the staff in the research camp.

- If there is an important need for a meeting, that involves staff from inside and outside the quarantine, then people can be brought together but all wearing masks and keeping considerable distance $(7 \mathrm{~m})$ between the 'in' and 'out' groups. Here, as well, the rule is: do not touch, do not eat together, do not socialise! 
Appendix I (cont.)

Vaccinations

Several vaccinations and tests/treatments are necessary for anyone to be allowed to observe chimpanzees and mangabeys at TCP:

- measles

- poliomyelitis

- yellow fever

- a tuberculosis antibody test that proves negative

- an annual worm treatment

General Hygiene Rules for Business as Usual

1) It is strictly forbidden to go into the forest when sick (cold, cough or any other symptom...). There is no exception to this rule.

2) Quarantine is mandatory for all to ensure infectious diseases are not transmitted to chimpanzees or co-workers. Quarantine applies to apparently healthy people as they could be healthy carriers of a number of agents.

3) Research assistants and students who are sick should stay in isolation in the quarantine camp until they are cleared and constantly wear a mask. If assistants exhibit respiratory symptoms, they can only head back to their village after the director agrees. Do not go to the village without the formal agreement of the director. If you intend to get a treatment from the medical doctor in Taï, please discuss this with the director. Sick assistants and students should have their throat and nose swabbed by the veterinarian of the project.

4) Co-workers who have been following the same chimpanzees as a person who has become sick should stop working for 3 days. These people, as well as all others staying at the same camp, should be tested (swabbed) on the day of the outset of the symptoms and 2 days later. Co-workers can resume work on the 4th day after the onset of the symptoms if they are not sick and the tests reveal they are not infected with a respiratory virus. Other people staying at the same camp but following different chimpanzees do not need to stop working.

5) Always wear a facemask covering your nose and mouth when you see chimpanzees. Respiratory droplets routinely reach out to 3 metres and sneezing can propagate them over 10 metres. Keep in mind you can infect chimpanzees without even noticing it. If you have to sneeze, turn away from the chimpanzees and sneeze in your hand so everything is blocked. Change your mask every day after lunch, so this measure effectively has a protective effect. You should always have a back-up mask in case you would sneeze strongly. In such cases, change your mask immediately and wash your hands. Back at your camp, dispose of all masks used in the forest in the trash bin located in the hygiene zone at the entrance of the camp.

6) Always maintain a 7-metre distance when following a chimpanzee. Your target chimpanzee should never watch you; if it does, you are too close. If your target leaves, always carefully move around the other chimpanzees, without ever pushing or disturbing them in anyway. If chimpanzees come to be less than 7 metres from you, you should discretely walk away to restore a 7-metre distance.

7) Never turn your flashlight on under a chimpanzee nest. If you go under nests in the morning, turn your light off 50 metres before reaching the nests.

8) There should never be more observers than adult chimpanzees. If this happens, priority is given to students. In the case where an assistant and a student follow the same target all day long and the target is alone, the assistant should stay 10 metres behind the student, i.e. at a 17-metre distance from the target.

9) Never leave any food in the forest. Everything should be brought back to camps and disposed of in trash bins.

10) Never defaecate in the forest. Faecal worms can be dangerous for chimpanzees. In case you are unable to avoid defaecating in the forest (e.g. diarrhoea), you should have with you two plastic bags and two rubber gloves to collect your faeces and bring them back to camp to throw into the toilet.

11) If you have to urinate in the forest, remove leaves from the ground beforehand, pee and cover it all up with leaves afterwards. Do not urinate in view of the chimpanzees and never where fruits could be collected by chimpanzees.

12) Never spit in the forest. Saliva contains a lot of bacteria that can be very dangerous for chimpanzees.

13) Always clean your boots with bleach when entering or going out of the camp; when entering the camp take them off and put them under the shed at the entrance of the camp. This should be respected by everyone. Use 
flip-flops in the camps. You should wash them, as well as any other kind of shoes you may have and use, before leaving for the forest. The bleach in the buckets should be changed every second week. In case of infectious disease outbreak in the forest, it should be changed every second day.

14) Wash your hands after you put your boots on as well as immediately before going in the forest and after coming from the forest. Water buckets should be prepared and available near the boot washing spot. Also wash your hands before and after eating in the forest, out of sight of the chimpanzees; bring a bit of liquid soap in a tube for that.

15) Field clothes should be hung on a wire in the shed at the entrance of the camp (hygiene zone) and should never be used in the camp. If they are to be used in the camp, they should be washed. Field clothes worn for more than 3 days should be washed. You cannot use the same field clothes when observing chimpanzees from different groups, unless the clothes are washed beforehand. Field clothes washed at the camp should be tidied up to avoid contamination.

16) Field boots and clothes must never leave the camps/forest. A fine will be charged to those not respecting that rule and they will have to cover $50 \%$ of the cost of new boots.

17) Camps and their surroundings should be clean. The camp manager will check this out and enforce it. It is everybody's business to keep the camps clean, for example, by properly using rubbish bins, toilets, and so on. More specifically, the camp crew will control trash bins and toilets.

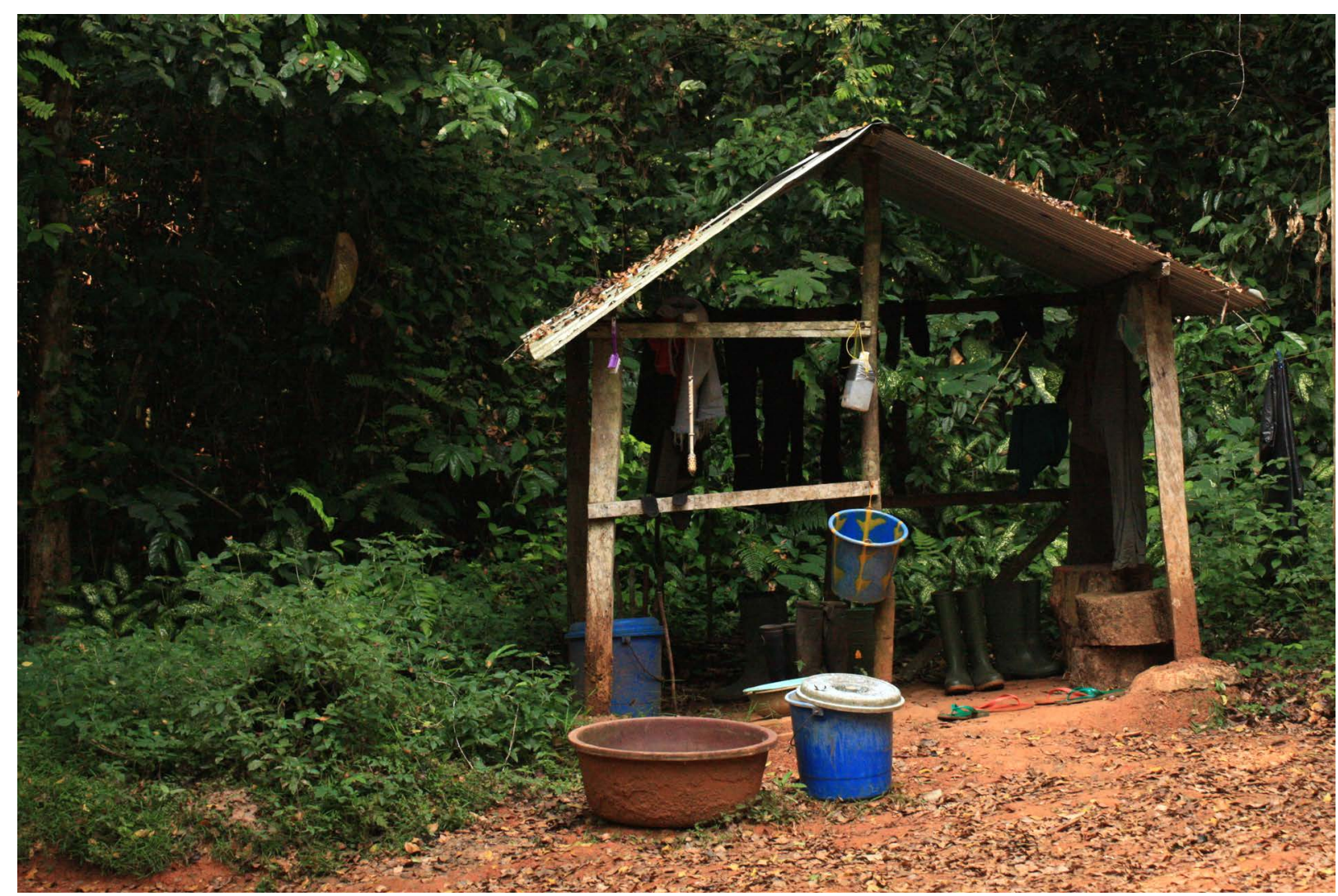

A hygiene station at the entrance to a research camp in Taï NP, Ivory Coast. Project staff and researchers wash their hands, disinfect their boots and change clothes before going into the forest and again upon return ๑ Sonja Metzger/TCP 


\section{Appendix II. Examples of Data Sheets and Forms}

Appendix Ila. Health-monitoring checksheet used at Gombe Stream Research Centre, Tanzania, as part of daily focal data collection

CHIMP DAILY HEALTH SHEET

(To be filled out for every target, plus any other chimp found ill)

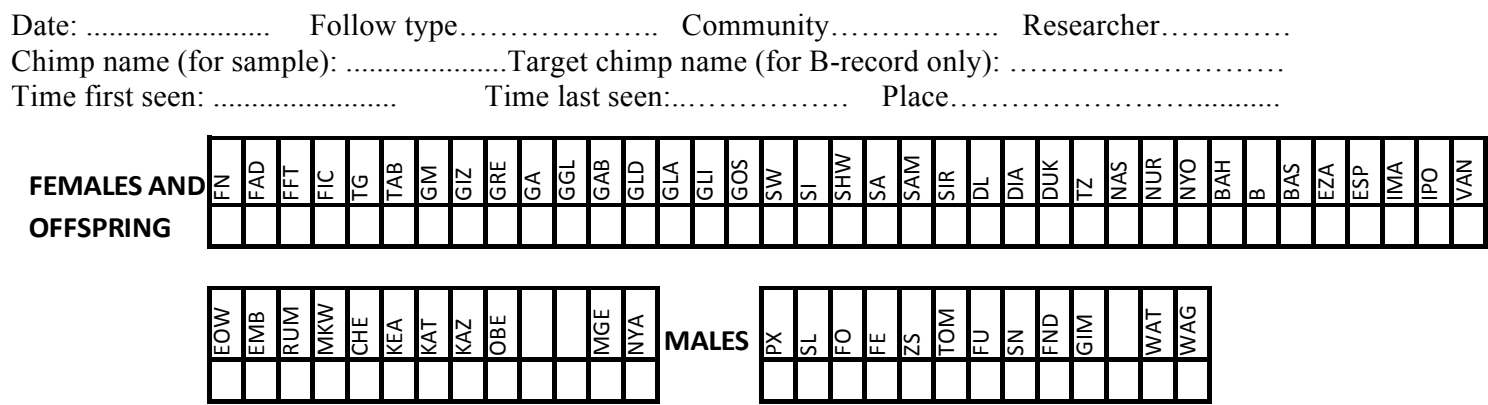

Other observations and explanations:

CHIMP BEHAVIOUR (tick the appropriate):

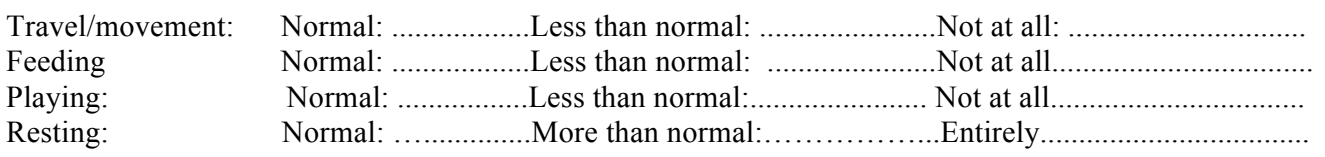

GENERAL BODY CONDITION (tick the appropriate):

Weight:

Skin:

Wound:

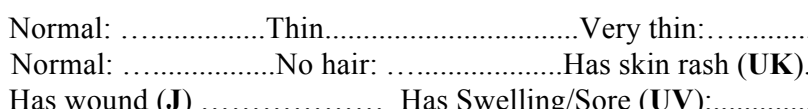

(For skin rash(es), put UK on the corresponding body area in the picture below; for wound, put $\mathrm{J}$ on the corresponding part on the picture below; for swelling/sore put UV)
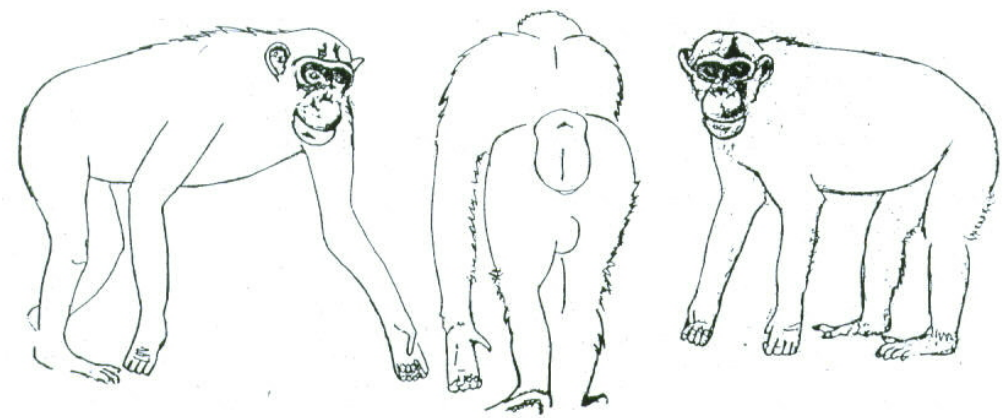

LAME WALKING:

Absent: ................... Slightly.....

If lame walking is present, tick the appropriate here:

Hind limb, left? right?.

Front limb, left?. right?

FAECALS:

Total number of defecations observed:.....

\begin{tabular}{|c|c|c|c|c|c|c|}
\hline & Faecal 1 & Faecal 2 & Faecal 3 & Faecal 4 & Faecal 5 & Faecal 6 \\
\hline Colour & & & & & & \\
\hline Consistency & & & & & & \\
\hline ars to use: & White (A) & Yellow (E & $\operatorname{Grey}(\mathrm{C})$ & Green (D) & $\operatorname{Red}(\mathrm{E})$ & Black (F) \\
\hline
\end{tabular}

COUGHING: Not at all: .......1-5 per hour: 5-10 per hour : more than 10 per hour:

SNEEZING: Not at all: ........1-5 per hour: ... .5-10 per hour :.......more than 10 per hour:........ RUNNING NOSE: Not at all: .......Some: ... lot....

SAMPLES COLLECTED (tick the appropriate) :

Faecals :

Urine : Vials................ Dipstick

No sample collected (please give reason). 


\section{Gorilla Visual Health Observation Form}

To be completed for each individual during each observation period.

Gorilla ID: Group ID:

Sex: M F Age Class:

SB YSB YSSB SSB AD SAD JUV INF
Date:$$
1
$$

Day (Jour) / Month (Mois) / Year (Année)

Site:

Habitat Type: Ter Can Swa Bai
Observer(s):

Time of first observation:

(24-hour)

Time form completed:

(24-hour)

Visibility: $\begin{array}{lllll}1 & 2 & 3 & 4 & 5\end{array}$

Photos? Y / N
No. of people present: Res _ Tr/G_ Tour _ Oth _

Time of last observation: (24-hour)

GPS Position:

Distance: m

\begin{tabular}{|c|c|c|c|c|}
\hline Obs & & & Photos: & Notes: \\
\hline & & \begin{tabular}{|l} 
Defecation \\
Défécation
\end{tabular} & $\begin{array}{l}\text { Time of Occurrence: ——: } \\
\text { I'Heure d'Occurrence: } \quad \text { (24-hour) } \\
\text { (24-heure) }\end{array}$ & \\
\hline & & Behaviour & Normal / Straining & \\
\hline & Stool & Comportement & Normal / Difficulté & \\
\hline & Crotte & Colour & Brown / Green / Black / Red / Yellow / Other: & \\
\hline & & Couleur & Brune /Vert / Noir / Rouge / Jaune / Autres: & \\
\hline & & Consistency & Solid / Soft / Liquid & \\
\hline & & Consistance & Solide / Pâteuse / Liquide & \\
\hline & & & Time of Occurrence: ___ & \\
\hline & & & I'Heure d'Occurrence: $=$ (24-heure) & \\
\hline & Orine & Colour & Clear / Dark / Bloody & \\
\hline & & Couleur & Claire / Sombre / Sanglante & \\
\hline & & & Time of Occurrence: ___ _ $^{\text {(24-hour) }}$ & \\
\hline & & & l'Heure d'Occurrence: __: (24-heure) & \\
\hline & Vomiting & Frequency & None / Once / Multiple times & \\
\hline & Vomissement & Fréquence & Rien / Une fois / Plusieurs fois & \\
\hline & & Colour & Bloody red / Dark red / Clear / Other & \\
\hline & & Couleur & Rouge sanglant / Brune / Claire / Autres: & \\
\hline & & Specimen ID: & & \\
\hline & Specimens Collected & ID du Spécimen: & & \\
\hline & Spécimen Collecté & Type Collected & Parasite (FOR) / Genetics (ALC) / Endocrine (ALC) / Other & \\
\hline & & Collecté pour & & \\
\hline & & Body Condition & Fat / Normal / Thin / Very thin & \\
\hline & & Condition Corporelle & Gros / Normal / Mince, maigre / Très maigre & \\
\hline & & Abdomen & Distended / Normal / Flat / Sunken & \\
\hline & & Abdomen & Distendu / Normal / Plat / Concave & \\
\hline & $\begin{array}{l}\text { General Pysical } \\
\text { Condition Condition }\end{array}$ & Skin condition & Normal / Blisters / Scaly / Ulcerated / Swellings / Other: & \\
\hline & Condition Condition & Condition de la peau & Normal / Ampoules / Squameau / Ulcérée/ Gonflements / Autres: & \\
\hline & & Skin Colour & Normal / Depigmented / Other: & \\
\hline & & Couleur de la peau & Normal / Dépigmentée / Autres: & \\
\hline & & Hair & Normal / Hair loss / Other: & \\
\hline & & Poils & Normal / Manque de poils / Autres: & \\
\hline & & Attitude & Normal / Abnormal & \\
\hline & & Attitude & Normale / Anormale & \\
\hline & & Movement & Normal / Less than normal / Not at all & \\
\hline & & Mouvement & Normal / Moins que d'habitude / Pas du tout & \\
\hline & & Limp & None / Slight / Severe & \\
\hline & & Boiter & Rien / Un peu / Beaucoup & \\
\hline & & Leg / Foot & Right / Left & \\
\hline & & Jambe / Pied & Droite / Gauche & \\
\hline & & Arm / Hand & Right / Left & \\
\hline & Behaviour & Bras/Main & Droit/Gauche & \\
\hline & Comportement & Eating & Normal / Less than normal / Not at all & \\
\hline & & Manger & Normalement / Moins que d'habitude / Pas du tout & \\
\hline & & Social & Normal / Less than normal / Not at all & \\
\hline & & Social & Normal / Moins que d'habitude / Pas du tout & \\
\hline & & Play (inf / juv) & Normal / Less than normal / Not at all & \\
\hline & & Jouer (enf / juv) & Normalement / Moins que d'habitude / Pas du tout & \\
\hline & & Rest & Normal / Less than normal / Not at all & \\
\hline & & Reposer & Normalement / Moins que d'habitude / Pas du tout & \\
\hline & & Being Groomed & Y/N Injured Area Eyes Other_ & \\
\hline & & Nettoyage & O/N Blessure Yeux Autres & \\
\hline
\end{tabular}




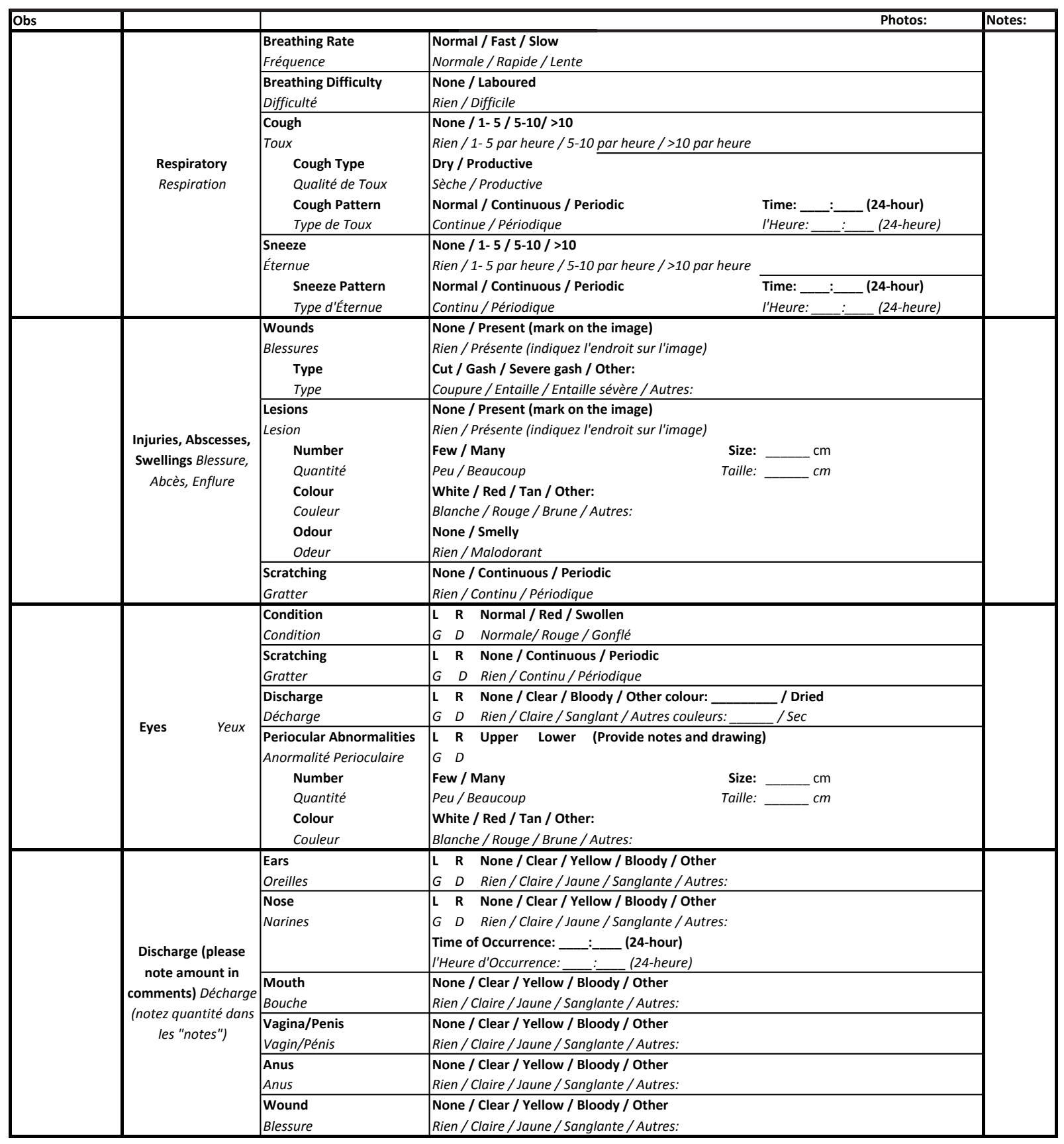
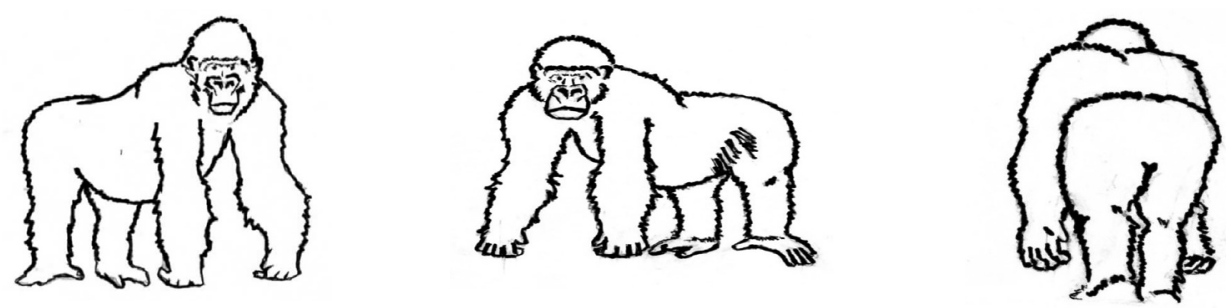


\begin{tabular}{l|l|l|l|l}
\hline Observer: & Date: Y/M/D & Start time: & End time: & $\begin{array}{l}\text { Total number of people: } \\
\text { (within 20 metres) }\end{array}$ \\
\hline Observation location: RBM & Altitude $\quad \mathrm{m}$ & ZONE: $35 \mathrm{M}$ & 0 & \\
\hline
\end{tabular}

General comments (remarks on the day's tracking exercise): name of place and vegetation, etc.

\begin{tabular}{|c|c|c|c|c|c|c|c|c|c|}
\hline Gorilla & Seen & Activity & $\begin{array}{c}\text { Body } \\
\text { condition }\end{array}$ & $\begin{array}{c}\text { Discharge } \\
\text { (head) }\end{array}$ & $\begin{array}{c}\text { Discharge } \\
\text { (other) }\end{array}$ & Respiratory & Skin / Hair & Stool & $\begin{array}{c}\text { Other } \\
\text { abnormals }\end{array}$ \\
\hline Ganza & $\begin{array}{c}\text { NS } \\
\text { S }\end{array}$ & $\begin{array}{l}\text { NS } \\
\text { SA }\end{array}$ & $\begin{array}{l}\text { NS SN } \\
\text { SA }\end{array}$ & $\begin{array}{l}\mathrm{NS} \\
\mathrm{SA}\end{array}$ & $\begin{array}{l}\mathrm{NS} \\
\mathrm{SA}\end{array}$ & $\begin{array}{l}\mathrm{NS} \\
\mathrm{SA}\end{array}$ & $\begin{array}{l}\text { NS } \\
\text { SA }\end{array}$ & $\begin{array}{l}\mathrm{NS} \\
\text { SA }\end{array}$ & $\begin{array}{c}\text { NS } \\
\text { S }\end{array}$ \\
\hline Gihishamwotsi & $\begin{array}{c}\text { NS } \\
\text { S }\end{array}$ & $\begin{array}{l}\text { NS SN } \\
\text { SA }\end{array}$ & $\begin{array}{l}\text { NS SN } \\
\text { SA }\end{array}$ & $\begin{array}{l}\text { NS } \\
\text { SA }\end{array}$ & $\begin{array}{l}\mathrm{NS} \text { SN } \\
\text { SA }\end{array}$ & $\begin{array}{l}\text { NS } \\
\text { SA }\end{array}$ & $\begin{array}{l}\mathrm{NS} \text { SN } \\
\mathrm{SA}\end{array}$ & ${ }_{\mathrm{SA}}^{\mathrm{NSN}}$ & $\begin{array}{c}\text { NS } \\
\text { S }\end{array}$ \\
\hline Guhonda & $\begin{array}{c}\text { NS } \\
\text { S }\end{array}$ & $\begin{array}{c}\text { NS SN } \\
\text { SA }\end{array}$ & $\begin{array}{l}\mathrm{NS} \text { SN } \\
\text { SA }\end{array}$ & $\begin{array}{l}\mathrm{NS} \text { SN } \\
\text { SA }\end{array}$ & $\begin{array}{l}\mathrm{NS} \text { SN } \\
\text { SA }\end{array}$ & $\begin{array}{l}\text { NS } \\
\text { SA }\end{array}$ & $\begin{array}{l}\mathrm{NS} \text { SN } \\
\text { SA }\end{array}$ & $\mathrm{NS}_{\mathrm{SA}}^{\mathrm{SN}}$ & $\begin{array}{c}\text { NS } \\
\text { S }\end{array}$ \\
\hline Gukunda & $\begin{array}{c}\mathrm{NS} \\
\mathrm{S} \\
\end{array}$ & $\begin{array}{l}\text { NS SN } \\
\text { SA }\end{array}$ & $\begin{array}{l}\text { NS SN } \\
\text { SA }\end{array}$ & $\begin{array}{l}\text { NS } \\
\text { SA }\end{array}$ & $\begin{array}{l}\mathrm{NS}_{\mathrm{SA}} \mathrm{SN} \\
\end{array}$ & $\begin{array}{l}\text { NS } \\
\text { SA }\end{array}$ & $\begin{array}{l}\mathrm{NS} \text { SN } \\
\text { SA }\end{array}$ & $\begin{array}{l}\mathrm{NS} \text { SN } \\
\text { SA }\end{array}$ & $\begin{array}{c}\text { NS } \\
\text { S }\end{array}$ \\
\hline Itabaza & $\begin{array}{c}\text { NS } \\
\text { S }\end{array}$ & $\begin{array}{l}\mathrm{NS} \text { SN } \\
\text { SA }\end{array}$ & $\begin{array}{l}\text { NS SN } \\
\text { SA }\end{array}$ & $\begin{array}{l}\text { NS SN } \\
\text { SA }\end{array}$ & $\begin{array}{l}\mathrm{NS} \text { SN } \\
\text { SA }\end{array}$ & $\begin{array}{l}\mathrm{NS} \text { SN } \\
\text { SA }\end{array}$ & $\begin{array}{l}\mathrm{NS} \text { SN } \\
\text { SA }\end{array}$ & $\begin{array}{c}\mathrm{NS} \text { SN } \\
\text { SA }\end{array}$ & $\begin{array}{c}\text { NS } \\
\text { S }\end{array}$ \\
\hline Icyerekezo & $\begin{array}{c}\mathrm{NS} \\
\mathrm{S}\end{array}$ & $\mathrm{NS}_{\mathrm{SA}} \mathrm{SN}$ & $\mathrm{NS}_{\text {SA }}$ SN & $\mathrm{NS}_{\text {SA }}$ SN & $\mathrm{NS}_{\mathrm{SA}} \mathrm{SN}$ & $\mathrm{NS}_{\mathrm{SA}} \mathrm{SN}$ & $\mathrm{NS}_{\mathrm{SA}} \mathrm{SN}$ & $\mathrm{NS}_{\mathrm{SA}} \mathrm{SN}$ & $\begin{array}{c}\mathrm{NS} \\
\mathrm{S}\end{array}$ \\
\hline Isheja Big Ben & $\begin{array}{c}\text { NS } \\
\text { S }\end{array}$ & $\begin{array}{l}\mathrm{NS}_{\mathrm{SA}} \mathrm{SN} \\
\end{array}$ & $\begin{array}{l}\text { NS SN } \\
\text { SA }\end{array}$ & $\begin{array}{l}\mathrm{NS} \\
\text { SA }\end{array}$ & $\mathrm{NS}_{\mathrm{SA}} \mathrm{SN}$ & $\mathrm{NS}_{\mathrm{SA}} \mathrm{SN}$ & $\mathrm{NS}_{\mathrm{SA}} \mathrm{SN}$ & $\mathrm{NS}_{\mathrm{SA}} \mathrm{SN}$ & $\begin{array}{c}\mathrm{NS} \\
\mathrm{S}\end{array}$ \\
\hline Umutungo & $\begin{array}{c}\text { NS } \\
\text { S }\end{array}$ & $\begin{array}{l}\text { NS SN } \\
\text { SA }\end{array}$ & $\begin{array}{c}\text { NS SN } \\
\text { SA }\end{array}$ & $\begin{array}{l}\text { NS } \\
\text { SA }\end{array}$ & $\begin{array}{l}\mathrm{NS} \text { SN } \\
\text { SA }\end{array}$ & $\begin{array}{l}\mathrm{NS} \text { SN } \\
\text { SA }\end{array}$ & $\begin{array}{l}\text { NS SN } \\
\text { SA }\end{array}$ & $\begin{array}{l}\mathrm{NS} \text { SN } \\
\text { SA }\end{array}$ & $\begin{array}{c}\text { NS } \\
\text { S }\end{array}$ \\
\hline Kampanga & $\begin{array}{c}\text { NS } \\
\text { S }\end{array}$ & $\begin{array}{l}\text { NS SN } \\
\text { SA }\end{array}$ & $\begin{array}{l}\text { NS SN } \\
\text { SA }\end{array}$ & $\begin{array}{l}\text { NS } \\
\text { SA }\end{array}$ & ${ }_{\text {SA }}^{\text {NS }}$ SN & 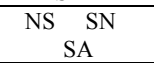 & $\begin{array}{l}\text { NS } \\
\text { SA }\end{array}$ & ${ }_{\text {SA }}$ SN & $\begin{array}{c}\text { NS } \\
\text { S }\end{array}$ \\
\hline Karema & $\begin{array}{c}\text { NS } \\
\text { S }\end{array}$ & $\begin{array}{l}\text { NS SN } \\
\text { SA }\end{array}$ & $\begin{array}{l}\text { NS } \\
\text { SA }\end{array}$ & $\mathrm{NS}_{\mathrm{SA}}^{\mathrm{SN}}$ & ${ }_{\text {SA }}^{\text {NS }}$ & $\mathrm{NS}_{\mathrm{SA}} \mathrm{SN}$ & ${ }_{\text {SA }}^{\text {NS }}$ & ${ }_{\text {SA }}^{\text {NS }}$ & $\begin{array}{c}\text { NS } \\
\text { S }\end{array}$ \\
\hline Karema infant & $\begin{array}{l}\text { NS } \\
\text { S }\end{array}$ & ${ }_{\mathrm{SA}}^{\mathrm{NS}}$ & ${ }_{\text {SA }}^{\text {NA }}$ & $\mathrm{NS}_{\mathrm{SA}}^{\mathrm{SN}}$ & $\mathrm{NS}_{\mathrm{SA}} \mathrm{SN}$ & $\mathrm{NS}_{\mathrm{SA}} \mathrm{SN}$ & ${ }_{\mathrm{SA}}^{\mathrm{NN}}$ & $\mathrm{NS}_{\mathrm{SA}} \mathrm{SN}$ & $\begin{array}{c}\text { NS } \\
\text { S }\end{array}$ \\
\hline Sacola & $\begin{array}{c}\mathrm{NS} \\
\mathrm{S}\end{array}$ & $\mathrm{NS}_{\mathrm{SA}} \mathrm{SN}$ & ${ }_{\text {SA }}^{\text {SN }}$ & $\mathrm{NS}_{\mathrm{SA}} \mathrm{SN}$ & $\mathrm{NS}_{\mathrm{SA}}^{\mathrm{SN}}$ & $\mathrm{NS}_{\mathrm{SA}} \mathrm{SN}$ & $\mathrm{NS}_{\mathrm{SA}} \mathrm{SN}$ & $\mathrm{NS}_{\mathrm{SA}} \mathrm{SN}$ & $\begin{array}{c}\text { NS } \\
\text { S }\end{array}$ \\
\hline Shirimpumu & $\begin{array}{l}\text { NS } \\
\text { S }\end{array}$ & ${ }_{\text {SA }}^{\text {NS }}$ & $\begin{array}{l}\text { NS SN } \\
\text { SA }\end{array}$ & ${ }_{\text {SA }}^{\text {NS }}$ & ${ }_{\text {SA }}^{\text {NS }}$ & ${ }_{\text {SA }}^{\text {NS }}$ & ${ }_{\text {SA }}^{\text {NS }}$ & ${ }_{\text {SA }}^{\mathrm{NSN}}$ & $\begin{array}{c}\text { NS } \\
\text { S }\end{array}$ \\
\hline Umulinzi & $\begin{array}{l}\text { NS } \\
\text { S }\end{array}$ & ${ }_{\text {SA }}^{\text {NS }}$ & ${ }_{\text {SA }}^{\text {NS }}$ & ${ }_{\text {SA }}^{\text {NS }}$ & ${ }_{\mathrm{SA}}^{\mathrm{NSN}}$ & ${ }_{\text {SA }}^{\mathrm{NSN}}$ & ${ }_{\text {SA }}^{\mathrm{NSN}}$ & ${ }_{\mathrm{SA}}^{\mathrm{SN}}$ & $\begin{array}{c}\text { NS } \\
\text { S }\end{array}$ \\
\hline Umulinzi Infant & $\begin{array}{c}\mathrm{NS} \\
\mathrm{S}\end{array}$ & $\mathrm{NS}_{\mathrm{SA}} \mathrm{SN}$ & $\begin{array}{l}\text { NS } \\
\text { SA }\end{array}$ & $\mathrm{NS}_{\mathrm{SA}}{ }^{\mathrm{SN}}$ & $\mathrm{NS}_{\mathrm{SA}}^{\mathrm{SN}}$ & $\mathrm{NS}_{\mathrm{SA}} \mathrm{SN}$ & $\mathrm{NS}_{\mathrm{SA}} \mathrm{SN}$ & $\mathrm{NS}_{\mathrm{SA}} \mathrm{SN}$ & $\begin{array}{c}\text { NS } \\
\text { S }\end{array}$ \\
\hline Gukina & $\begin{array}{c}\mathrm{NS} \\
\mathrm{S}\end{array}$ & $\begin{array}{l}\mathrm{NS} \\
\mathrm{SA}\end{array}$ & $\begin{array}{l}\text { NS } \\
\text { SA }\end{array}$ & $\begin{array}{l}\text { NS } \\
\text { SA }\end{array}$ & $\begin{array}{l}\mathrm{NS} \\
\mathrm{SA}\end{array}$ & $\mathrm{NS}_{\mathrm{SA}} \mathrm{SN}$ & $\begin{array}{l}\mathrm{NS} \\
\text { SA }\end{array}$ & $\mathrm{NS}_{\mathrm{SA}} \mathrm{SN}$ & $\begin{array}{c}\text { NS } \\
\text { S }\end{array}$ \\
\hline Kampanga Infant & $\begin{array}{c}\mathrm{NS} \\
\mathrm{S}\end{array}$ & $\begin{array}{l}\mathrm{NS} \text { SN } \\
\mathrm{SA}\end{array}$ & $\begin{array}{l}\text { NS } \\
\text { SA }\end{array}$ & $\begin{array}{l}\text { NS } \\
\text { SA }\end{array}$ & $\begin{array}{l}\mathrm{NS} \\
\mathrm{SA}\end{array}$ & $\begin{array}{l}\text { NS } \\
\text { SA }\end{array}$ & $\begin{array}{l}\text { NS } \\
\text { SA }\end{array}$ & $\begin{array}{l}\text { NS } \\
\text { SA }\end{array}$ & $\begin{array}{c}\text { NS } \\
\text { S }\end{array}$ \\
\hline
\end{tabular}

\begin{tabular}{|l|l|l}
\hline Gorilla & System & Comment (details of abnormal system) \\
\hline Big Ben & Skin/Hair* & Alopecia - top of head, chronic condition since 2006 \\
\hline Karema & Other* & Missing left hand \\
\hline Umurinzi & Other* & Ankylosis of digits 4 and 5 of left hand \\
\hline Guhonda & Other* & Chronic cough \\
\hline Kampanga & Other* & Alopecia (right side of the neck) \\
\hline
\end{tabular}

*Chronic

abnormality

\section{Parameter definitions}

1. Activity: observe the animal for at least two to three minutes; if activity is in normal context with the other animals, enter "seen" and "normal".

2. Body condition: you must see the chest and abdomen.

3. Discharge head: you must see both eyes, ears, nostrils, and mouth.

4. Discharge other: discharge from any other orifice or lesion other than from the head.

5. Respiratory: you must be able to see the nostrils and chest.

6. Skin/Hair: you must see at least both arms and the front and back of the animal's torso.

7. Stool: one has to observe the animal defecating to answer seen.

8. Other Abnormalities: this is a free category and will be left "not seen", unless you see something that is unusual but not included in the other parts of the form. 
[Name of Outbreak] in [Location] Month, Year

\begin{tabular}{|l|l|}
\hline Information & Report \\
\hline 1. Today's date & \\
\hline $\begin{array}{l}\text { 2. Date of first observation, or first notification of PAA, by } \\
\text { observers of outbreak }\end{array}$ & \\
\hline 3. Species affected & \\
\hline 4. Numbers of animals affected & \\
\hline $\begin{array}{l}\text { 5. Describe clinical signs } \\
\text { 6. Summarise actions taken to date to investigate and/or } \\
\text { ameliorate the outbreak }\end{array}$ & \\
\hline $\begin{array}{l}\text { 7. If samples have been collected from ill or dead apes, where } \\
\text { are samples being stored and/or have they been shipped to a } \\
\text { diagnostic laboratory (name, place, date of shipment) }\end{array}$ & \\
\hline 8. Other organisations involved in outbreak response & \\
\hline 9. Did great apes die? How many and what species? & \\
\hline $\begin{array}{l}\text { 10. Were other animals (wildlife or livestock) or people in the area } \\
\text { also exhibiting signs of a disease outbreak? If yes, describe }\end{array}$ & \\
\hline
\end{tabular}

Outbreak Action Timeline:

\begin{tabular}{|l|l|l|}
\hline Date & Day \# & Action Taken and Daily Summary \\
\hline & & \\
\hline & & \\
\hline
\end{tabular}

Individuals, agencies, organisations receiving report:

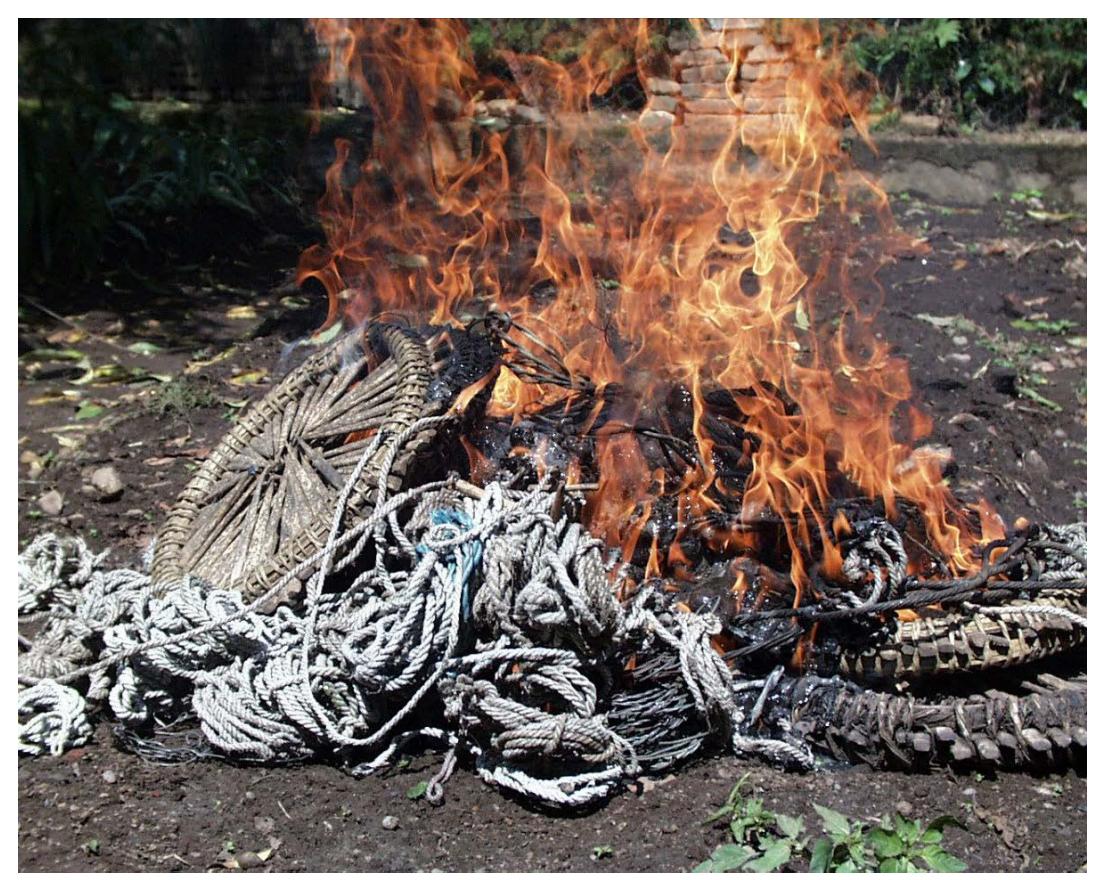

Anti-poaching patrols operate in many national parks. In the Volcanoes NP, Rwanda, thousands of wire and rope snares are removed and destroyed every year. This reduces the chances that a gorilla will become trapped. Once caught, great apes often injure themselves in the struggle to break free. Deep cuts caused by a wire snare can become infected and even gangrenous if a veterinary team is not on hand to intervene (c) Liz Williamson/DFGFI 
Legend: N/A: not applicable; \pm : decision on individual case basis; reg: regional or in-country veterinarians can handle situation; inter: international help needed; PA: protected area authority; PD: project director; PH: public health official; SH: stakeholders; S: subsequent groups; Approp Inst: appropriate institution (e.g., NIH or CDC). Reproduced from Decision Tree Writing Group (2006) with permission of the copyright holder (c) 2006 Wiley-Liss, Inc.

Level 1

Routine Sentinel Health Monitoring and Review
Daily Observation by Trackers and Guides - Basic Form

Paper or PDA

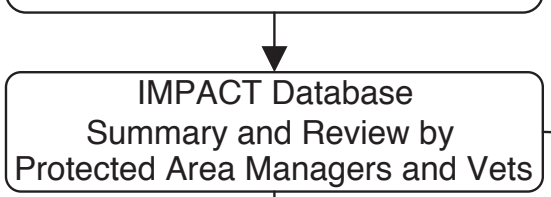

Summary and Review by

Abnormal

Parameters

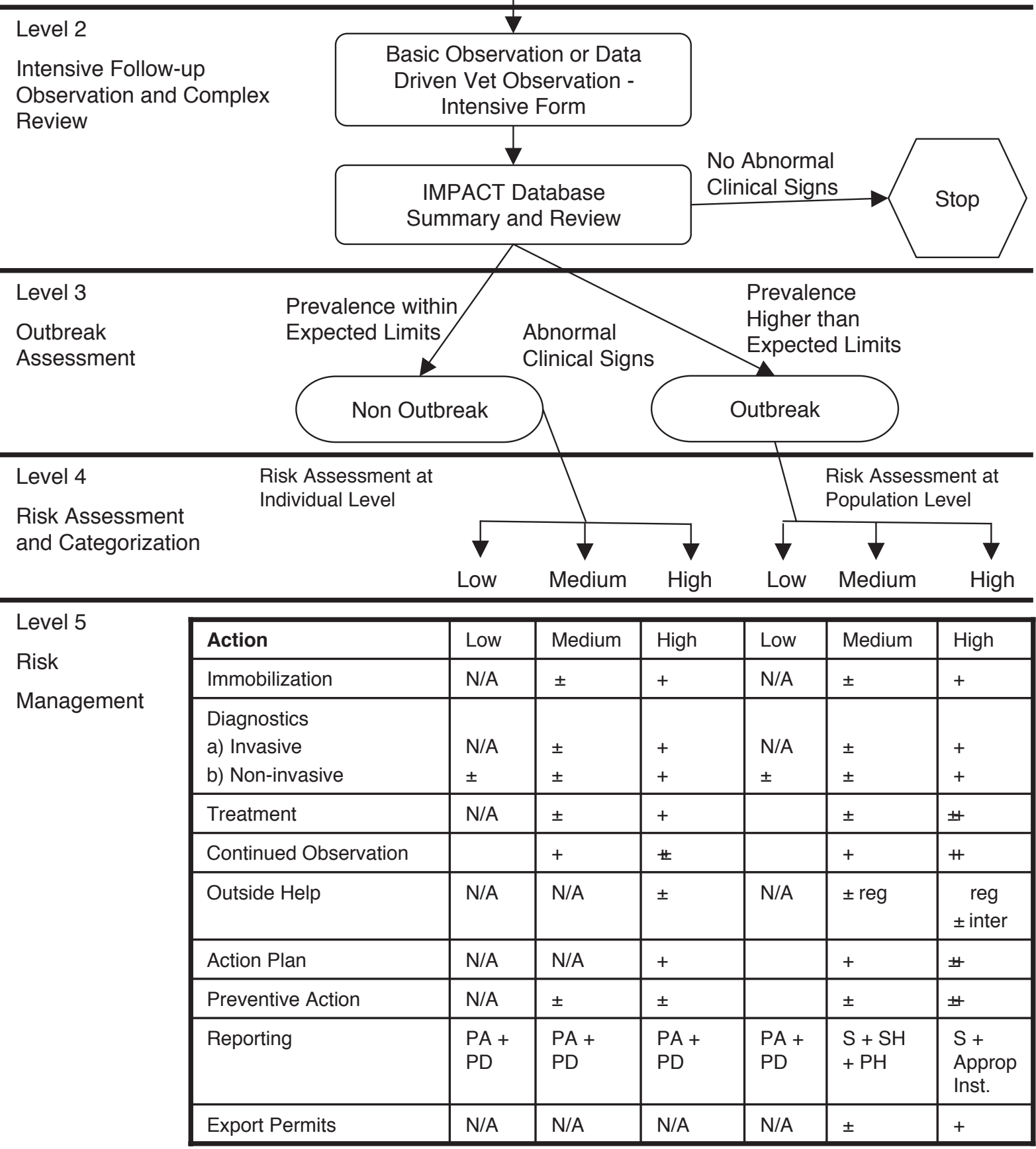




\section{Occasional Papers of the IUCN Species Survival Commission}

1. Species Conservation Priorities in the Tropical Forests of Southeast Asia: Proceedings of a Symposium held at the 58th Meeting of the IUCN Species Survival Commission, October 4, 1982, Kuala Lumpur. Malaysia. Edited by R.A. Mittermeier and W.R. Konstant, 1985, 58pp. [Out of print]

2. Priorités en matière de conservation des espèces à Madagascar. Edited by R.A. Mittermeier, L.H. Rakotovao, V. Randrianasolo, E.J. Sterling and D. Devitre, 1987, 167pp. [Out of print]

3. Biology and Conservation of River Dolphins. Edited by W.F. Perrin, R.K. Brownell, Zhou Kaiya and Liu Jiankang, 1989, 173pp. [Out of print]

4. Rodents. A World Survey of Species of Conservation Concern. Edited by W.Z. Lidicker, Jr., 1989, 60pp.

5. The Conservation Biology of Tortoises. Edited by I.R. Swingland and M.W. Klemens, 1989, 202pp. [Out of print]

6. Biodiversity in Sub-Saharan Africa and its Islands: Conservation, Management, and Sustainable Use. Compiled by S.N. Stuart and R.J. Adams, with a contribution from M.D. Jenkins, 1991, 242pp.

7. Polar Bears: Proceedings of the Tenth Working Meeting of the IUCN/ SSC Polar Bear Specialist Group, Sochi, Russia 1988. Edited by S. C. Amstrup and Ø. Wiig, 1991, 107pp.

8. Conservation Biology of Lycaenidae (Butterflies). Edited by T.R. New, 1993, 173pp. [Out of print]

9. The Conservation Biology of Molluscs: Proceedings of a Symposium held at the 9th International Malacological Congress, Edinburgh, Scotland, 1986. Edited by A. Kay, including a status report on molluscan diversity by A. Kay, 1995, 81 pp.

10. Polar Bears: Proceedings of the Eleventh Working Meeting of the IUCN/ SSC Polar Bear Specialist Group, January 25-28 1993, Copenhagen, Denmark. Compiled by Ø. Wiig, E.W. Born and G.W. Garner, 1995, 192pp.

11. African Elephant Database 1995. By M.Y. Said, R.N. Chunge, G.C. Craig, C.R. Thouless, R.F.W. Barnes and H.T. Dublin, 1995, 225pp.

12. Assessing the Sustainability of Uses of Wild Species: Case Studies and Initial Assessment Procedure. Edited by R. and C. Prescott-Allen, 1996, $135 \mathrm{pp}$

13. Tecnicas para el Manejo del Guanaco [Techniques for the Management of the Guanaco]. Edited by S. Puig, 1995, 231pp.

14. Tourist Hunting in Tanzania. Edited by N. Leader-Williams, J.A. Kayera and G.L. Overton, 1996, 138pp.

15. Community-based Conservation in Tanzania. Edited by N. LeaderWilliams, J.A. Kayera and G.L. Overton, 1996, 226pp.

16. The Live Bird Trade in Tanzania. Edited by N. Leader-Williams and R.K. Tibanyenda, 1996, 129pp.

17. Sturgeon Stocks and Caviar Trade Workshop: Proceedings of a Workshop, 9-10 October 1995 Bonn, Germany. Federal Ministry for the Environment, Nature Conservation and Nuclear Safety and the Federal Agency for Nature Conservation. Edited by V.J. Birstein, A. Bauer and A. Kaiser-Pohlmann, 1997, 88pp.

18. Manejo y Uso Sustentable de Pecaries en la Amazonia Peruana. By R. Bodmer, R. Aquino, P. Puertas, C. Reyes, T. Fang and N. Gottdenker, 1997, 102pp.

19. Proceedings of the Twelfth Working Meeting of the IUCN/SSC Polar Bear Specialist Group, 3-7 February 1997, Oslo, Norway. Compiled by A.E. Derocher, G.W. Garner, N.J. Lunn and Ø. Wiig, 1998, 159pp.

20. Sharks and their Relatives-Ecology and Conservation. Compiled by M. Camhi, S. Fowler, J. Musick, A. Bräutigam and S. Fordham, 1998, 39pp. [Also in French]

21. African Antelope Database 1998. Compiled by R. East and the IUCN/ SSC Antelope Specialist Group, 1999, 434pp.

22. African Elephant Database 1998. By R.F.W. Barnes, G.C. Craig, H.T. Dublin, G. Overton, W. Simons and C.R. Thouless, 1999, 249pp.

23. Biology and Conservation of Freshwater Cetaceans in Asia. Edited by R.R. Reeves, B.D. Smith and T. Kasuya, 2000, 152pp.

24. Links between Biodiversity Conservation, Livelihoods and Food Security: The Sustainable Use of Wild Species for Meat. Edited by S.A. Mainka and M. Trivedi, 2002, 137pp. [Also in French]

25. Elasmobranch Biodiversity, Conservation and Management. Proceedings of the International Seminar and Workshop, Sabah, Malaysia, July 1997. Edited by S.L. Fowler, T.M. Reed and F.A. Dipper, 2002, 258pp.

26. Polar Bears: Proceedings of the Thirteenth Working Meeting of the IUCN/ SSC Polar Bear Specialist Group, 23-28 June 2001, Nuuk, Greenland. Compiled by N.J. Lunn, S. Schliebe and E.W. Born, 2002, 153pp.

27. Guidance for CITES Scientific Authorities: Checklist to Assist in Making Non-detriment Findings for Appendix // Exports. Compiled by A.R. Rosser and M.J. Haywood, 2002, 146pp.

28. Turning the Tide: The Eradication of Invasive Species. Proceedings of the International Conference on Eradication of Island Invasives. Edited by C.R. Veitch and M.N. Clout, 2002, 414pp.

29. African Elephant Status Report 2002: An Update from the African Elephant Database. By J.J. Blanc, C.R. Thouless, J.A. Hart, H.T. Dublin, I. Douglas-Hamilton, C.G. Craig and R.F.W. Barnes, 2003, 302pp.

30. Conservation and Development Interventions at the Wildife/Livestock Interface: Implications for Wildlife, Livestock and Human Health.
Compiled by S.A. Osofsky and S. Cleaveland, W.B. Karesh, M.D. Kock, P.J. Nyhus, L. Starr and A. Yang, 2005, 220pp.

31. The Status and Distribution of Freshwater Biodiversity in Eastern Africa. Compiled by W. Darwall, K. Smith, T. Lower and J.-C. Vié, 2005, 36pp.

32. Polar Bears: Proceedings of the 14th Working Meeting of the IUCN/SSC Polar Bear Specialist Group, 20-24 June 2005, Seattle, Washington, USA. Compiled by J. Aars, N.J. Lunn and A.E. Derocher, 2006, 189pp.

33. African Elephant Status Report 2007: An Update from the African Elephant Database. Compiled by J.J. Blanc, R.F.W. Barnes, C.G. Craig, H.T. Dublin, C.R. Thouless, I. Douglas-Hamilton and J.A. Hart, 2007, 275pp.

34. Best Practice Guidelines for Reducing the Impact of Commercial Logging on Great Apes in Western Equatorial Africa. By D. Morgan and C. Sanz, 2007, 32pp. [Also in French]

35. Best Practice Guidelines for the Re-introduction of Great Apes. By B. Beck K. Walkup, M. Rodrigues, S. Unwin, D. Travis, and T. Stoinski, 2007, 48pp. [Also in French at http://www.primate-sg.org/BP.reintro. $\mathrm{htm}]$

36. Best Practice Guidelines for Surveys and Monitoring of Great Ape Populations. H. Kühl, F. Maisels, M. Ancrenaz and E.A. Williamson, 2008, 32 pp. [Also in French]

37. Best Practice Guidelines for the Prevention and Mitigation of Conflict between Humans and Great Apes. By K. Hockings and T. Humle, 2009, 48pp. [Also in French and Bahasa Indonesia]

37. Best Practice Guidelines for Great Ape Tourism. By E.J. Macfie and E.A Williamson, with contributions by M. Ancrenaz, C. Cipolletta, D. Cox, C. Ellis, D. Greer, C. Hodgkinson, A. Russon and I. Singleton, 2010, 78pp. [Also in French and Bahasa Indonesia]

39. Guidelines for the In-situ Re-introduction and Translocation of African and Asian Rhino. Edited by R.H. Emslie, R. Amin and R. Kock Jr., 2009, $125 \mathrm{pp}$.

40. Indo pacific Bottlenose Dolphins (Tursiops aduncus) Assessment Workshop Report. Edited by R.R. Reeves and R.L Brownell Jr., 2009, $61 \mathrm{pp}$.

41. Guidelines for the Reintroduction of Galliformes for Conservation Purposes. Edited by the World Pheasant Association and IUCN/SSC Re-introduction Specialist Group, 2009, 86pp.

42. Island Invasives: Eradication and Management: Proceedings of the International Conference on Island Invasives. Edited by C.R. Veitch, M.N. Clout and D.R. Towns, 2011, $542 \mathrm{pp}$.

43. Polar Bears: Proceedings of the 15th Working Meeting of the IUCN/ SSC Polar Bear Specialist Group. 29 June-3 July 2009, Copenhagen, Denmark. Compiled and edited by M.E. Obbard, G.W Thiemann, E. Peacock and T.D DeBruyn, 2010, 235pp.

44. Sustainability Assessment of Beluga (Delphinapterus leucas) Live Capture Removals in the Sakhalin-Amur Region, Okhotsk Sea, Russia: Report of an Independent Scientific Review Panel. By R.R. Reeves, R.L. Brownell, Jr., V. Burkanov, M.C.S. Kingsley, L.F. Lowry, and B.L. Taylor, 2011, 34pp.

45. Elephant Meat Trade in Central Africa: Summary Report. By D. Stiles, 2011, 103pp.

46. CITES and CBNRM: Proceedings of an International Symposium on "The Relevance of CBNRM to the Conservation and Sustainable Use of CITES-listed Species in Exporting Countries." By M. Abensperg-Traun, D. Roe and C. O'Criodain, 2011, 157 pp.

47. IUCN Situation Analysis on East and Southeast Asian Intertidal Habitats, with Particular Reference to the Yellow Sea (Including the Bohai Sea). By J. MacKinnon, Y.I. Verkuil and N. Murray, 2012, 70 pp.

48. Vital but vulnerable: Climate change vulnerability and human use of wildlife in Africa's Albertine Rift. By J.A. Carr, W.E. Outhwaite, G.L. Goodman, T.E.E. Oldfield and W.B. Foden, 2013, 214 pp.

49. Great Apes and FSC: Implementing 'Ape Friendly' Practices in Central Africa's Logging Concessions. By D. Morgan, C. Sanz, D. Greer, T. Rayden, F. Maisels and E.A. Williamson, 2013, 36 pp.

50. Assessment of python breeding farms supplying the international high- end leather industry. A report under the 'Python Conservation Partnership' programme of research. By D. Natusch and J. Lyons, 2014, $56 \mathrm{pp}$.

51. Best Practice Guidelines on Gibbon Rehabilitation, Reintroduction and Translocation. By B. Rawson et al., 2015.

52. Freshwater Key Biodiversity Areas in the Mediterranean Basin Hotspot: Informing species conservation and development planning in freshwater ecosystems. By W. Darwall, S. Carrizo, C. Numa, V. Barrios, J. Freyhof and K. Smith, 2014, 86 pp.

53. Amphibian Alliance for Zero Extinction Sites in Chiapas and Oaxaca. By J.F. Lamoreux, M.W. McKnight and R. Cabrera Hernandez, 2015, 344 pp.

54. An IUCN situation analysis of terrestrial and freshwater fauna in West and Central Africa. By D.P. Mallon, M. Hoffmann, M.J. Grainger, F. Hibert, N. van Vliet and P.J.K. McGowan, 2015, 172pp. [Also in French]

55. Seal Range State Policy and Management Review: A report prepared on behalf of the IUCN Sustainable Use and Livelihoods Specialist Group. By D.H.M Cummings, 2015, 108pp. 


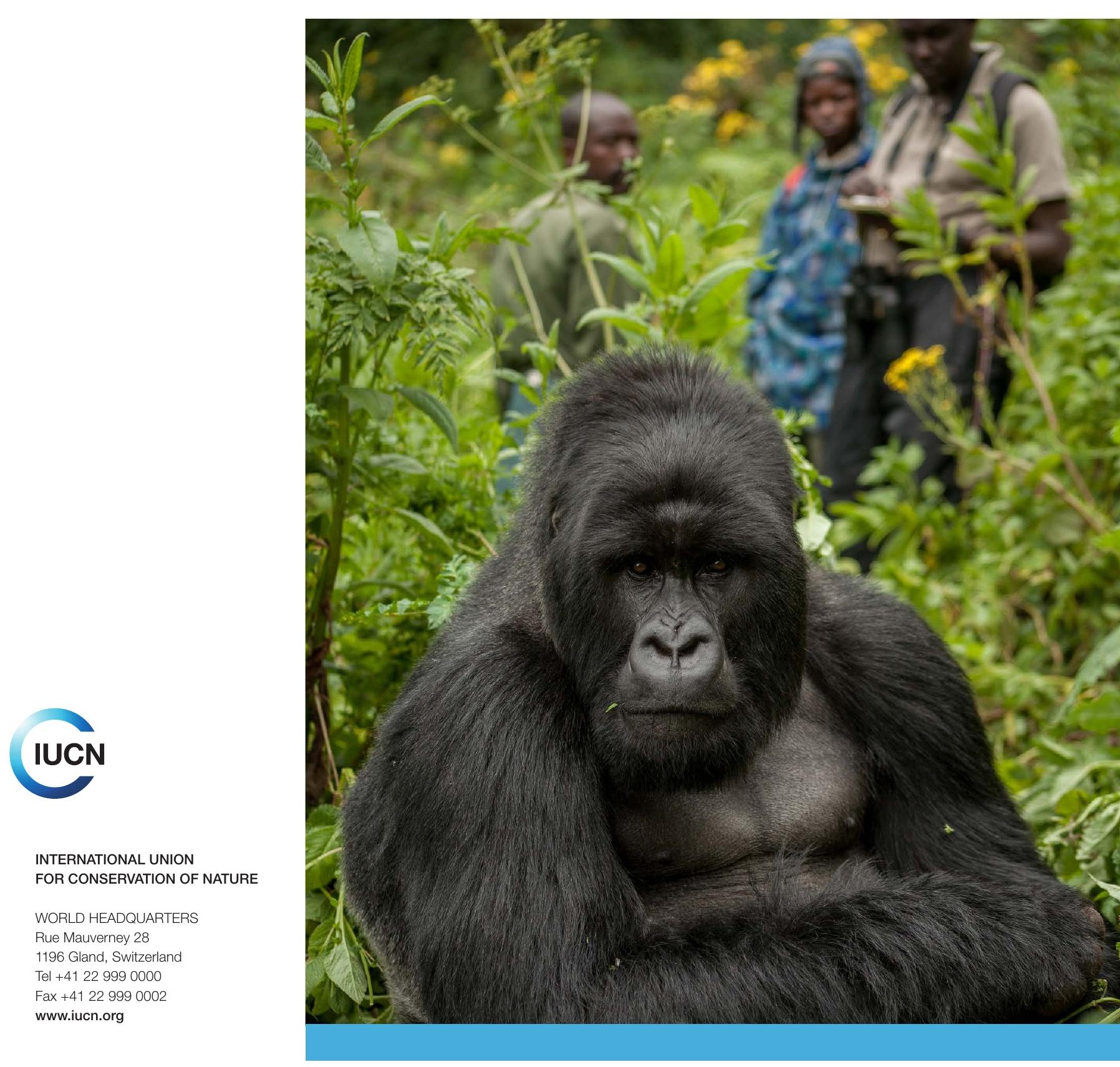

